\title{
A taxonomic revision of seed harvester ants of the Tetramorium solidum group (Hymenoptera: Formicidae) in southern Africa
}

\author{
Nokuthula MBANYANA ${ }^{1, *}$, Francisco HITA GARCIA ${ }^{2}$, \\ Hamish Gibson ROBERTSON ${ }^{3} \&$ Johannes Jacobus LE ROUX ${ }^{4}$ \\ 1,3 Iziko Museums of South Africa, P.O. Box 61, Cape Town, 8000 South Africa. \\ ${ }^{2}$ Okinawa Institute of Science and Technology Graduate University, \\ 1919-1 Tancha, Onna-son, Okinawa, Japan. \\ ${ }^{4}$ Department of Botany and Zoology, Stellenbosch University, Private Bag X1, \\ Matieland, 7602, South Africa. \\ *Corresponding author: nmbanyana@iziko.org.za \\ 2Email: fhitagarcia@gmail.com \\ ${ }^{3}$ Email: hrobertson@iziko.org.za \\ ${ }^{4}$ Email: jleroux@sun.ac.za \\ ${ }^{1}$ urn:lsid:zoobank.org:author:157A51ED-7C85-4CA3-84E4-B7BD1E2A7E8F \\ ${ }^{2}$ urn:1sid:zoobank.org:author:B7ADF56F-935D-4BD8-ADB3-50E96F8BB463 \\ ${ }^{3}$ urn:1sid:zoobank.org:author:972FAB6C-C5FA-45EA-9A17-9F156845BE4F \\ ${ }^{4}$ urn:lsid:zoobank.org:author:2995D443-01FA-4F65-BFEE-ECA07B73504A
}

\begin{abstract}
Ants of the Tetramorium solidum group occur in Africa, with the vast majority of species endemic to the arid regions of southern Africa. The first revision of the genus was published more than 30 years ago and ant surveys have since considerably expanded the number of specimens available for study. The revision of this group reveals five new species, expanding the total number to 19 . Almost all the species in this group occur in the southern parts of the Afrotropical region, with the exception of T. setuliferum Emery, 1895 and T. rothschildi (Forel, 1907). These two species have broad distributions within African grasslands and savannas, with T. setuliferum occurring in southern Africa and T. rothschildi in East Africa and the Sahel. Five new species are described in this revision: T. aisha sp. nov., T. brigitteae sp. nov., T. duncani sp. nov., T. lerouxi sp. nov. and T. margueriteae sp. nov. An illustrated key is presented and descriptions of new species are provided, supported by montage images and distribution maps.
\end{abstract}

Keywords. Ant taxonomy, arid regions, identification key, new species, systematics.

Mbanyana N., Hita Garcia F., Robertson H.G. \& Le Roux J.J. 2018. A taxonomic revision of seed harvester ants of the Tetramorium solidum group (Hymenoptera: Formicidae) in southern Africa. European Journal of Taxonomy 454: 1-59. https://doi.org/10.5852/ejt.2018.454 


\section{Introduction}

The genus Tetramorium Mayr, 1855 is one of the most diverse and species-rich ant genera, with approximately 580 described species (Hita Garcia \& Fisher 2015; Bolton 2017). It is distributed throughout most zoogeographical regions of the world but its highest diversity lies in the Afrotropical region, with about 250 described species (Bolton 1976, 1980, 1985; Hita Garcia et al. 2010a, 2010b, 2010c; Hita Garcia \& Fisher 2013). Members of the Tetramorium solidum group are ground-nesting, seed-harvesting ants, mainly restricted to dry semi-desert areas of southern Africa. Two species in the group have a wider distribution and are found further north in Africa. Bolton (1980) revised the group and listed 14 species. Other than this revision, and the recording of particular species in various ant surveys (e.g., Robertson 2000; Parr et al. 2002; Netshiliphala et al. 2005), very little has been published on the Tetramorium solidum group, despite the group's apparent ecological importance as seed harvesters in semi-arid habitats in southern Africa. In the 38 years since the revision of this group by Bolton (1980), ant surveys have considerably expanded the material available, which now provides an opportunity for a fresh perspective on this group.

In this paper we provide an updated taxonomic revision of the Tetramorium solidum group, including the description of five new species.

\section{Abbreviations of depositories}

The material upon which this study is based is located and/or was examined at the following institutions:

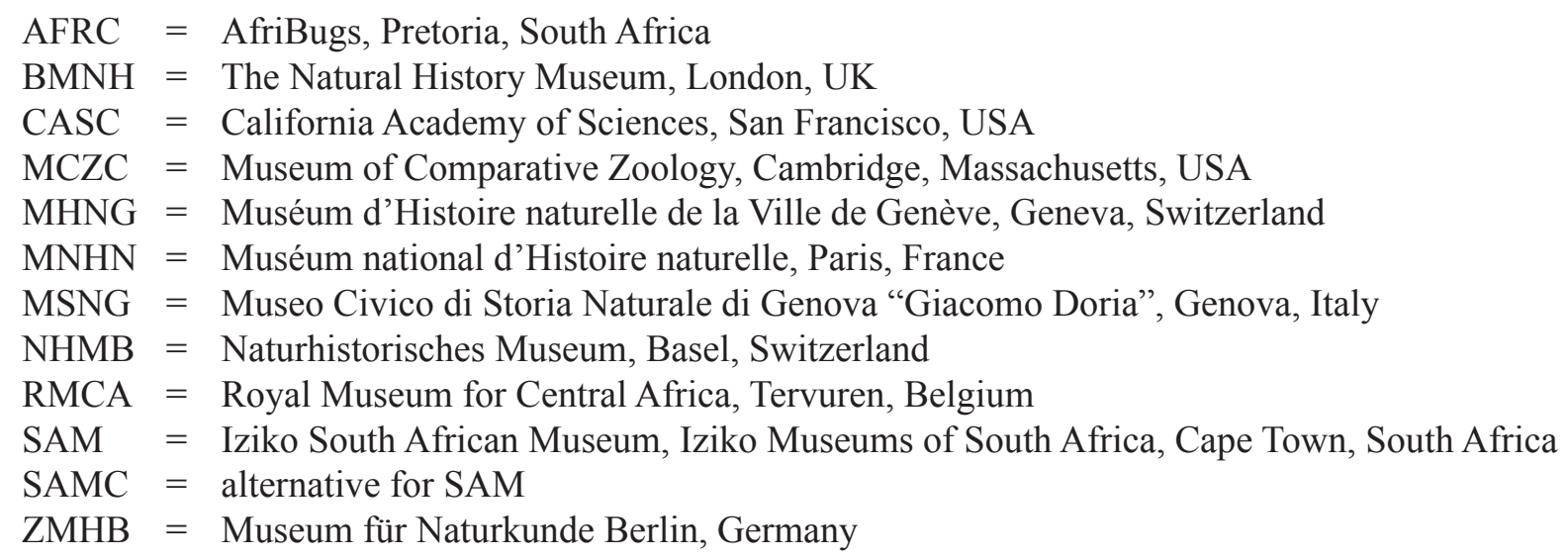

\section{Material and methods}

\section{Sample collection}

Specimens in the entomology collection at the Iziko South African Museum, Cape Town, were included in this study, along with further material loaned from the Natural History Museum in London, the California Academy of Sciences, Stellenbosch University and the consulting company AfriBugs (http://www.afribugs.com). Material was supplemented by specimens collected on field trips to the Northern Cape and Western Cape Provinces of South Africa, as well as Namibia. Ants were collected by hand, including digging up nests. Sampled ants were preserved in ethanol (96\%), with representatives mounted and labelled for further study.

To visualize species richness and distribution, maps were produced for all the species in the T. solidum group by overlaying known point locality records onto ecoregional maps of southern Africa using QGIS desktop 2.8.1-Wien. All available occurrence records for species of the T. solidum group were extracted from the ant database of the Iziko Museums of South Africa. All records contained information on locality and year of collection, with some records having information on habitat. 


\section{Morphological examination}

Raw images of most species were taken using an EntoVision multiple-focus imaging system in combination with the Leica Application Suite software (ver. 3.8), or with a Leica DFC450 and Leica Application Suite (ver. 4.1). Some species were not available for imaging, and in these cases photos were taken from AntWeb (https://www.antweb.org). AntWeb photos are marked as such in the figure captions. Morphological characters of adult workers were examined and measured using a Leica MZ16A stereo microscope, and all the measurements were taken with an ocular micrometer. The terminology used in this paper is based mainly on the morphological terminology of Bolton (1980). Measurements and indices used in this paper follow Hita Garcia \& Fisher (2015). All measurements and indices are presented as minimum and maximum, and are expressed in millimetres, with arithmetic means in parentheses. Abbreviations of the measurements taken and ratios based on them are as follows (Fig. 1):

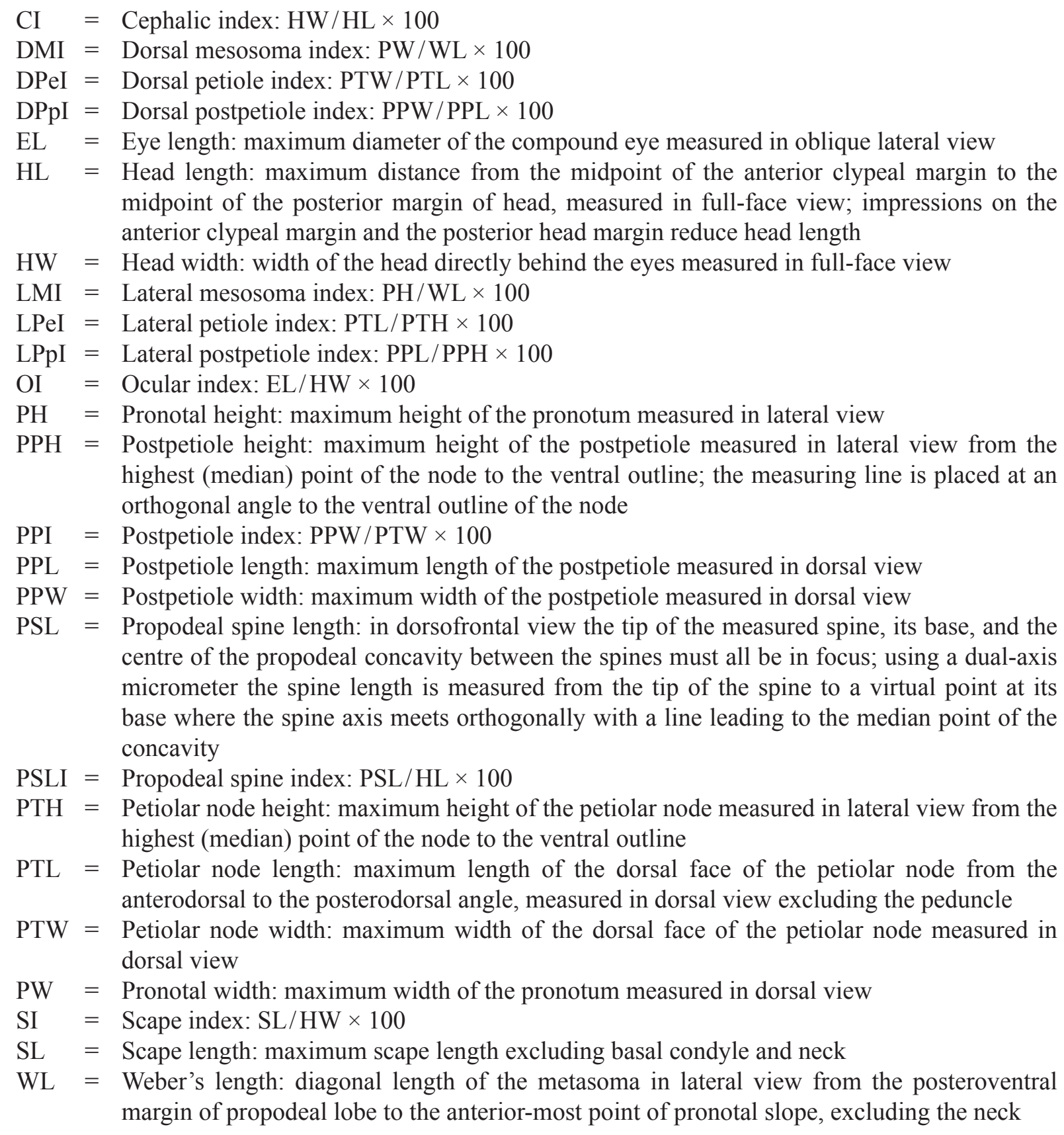
midpoint of the posterior margin of head, measured in full-face view; impressions on the anterior clypeal margin and the posterior head margin reduce head length

$\mathrm{HW}=$ Head width: width of the head directly behind the eyes measured in full-face view

LMI $=$ Lateral mesosoma index: $\mathrm{PH} / \mathrm{WL} \times 100$

LPeI $=$ Lateral petiole index: PTL $/ \mathrm{PTH} \times 100$

LPpI $=$ Lateral postpetiole index: PPL $/ \mathrm{PPH} \times 100$

$\mathrm{OI}=$ Ocular index: $\mathrm{EL} / \mathrm{HW} \times 100$

$\mathrm{PH}=$ Pronotal height: maximum height of the pronotum measured in lateral view

$\mathrm{PPH}=$ Postpetiole height: maximum height of the postpetiole measured in lateral view from the highest (median) point of the node to the ventral outline; the measuring line is placed at an orthogonal angle to the ventral outline of the node

PPI = Postpetiole index: PPW $/ \mathrm{PTW} \times 100$

PPL = Postpetiole length: maximum length of the postpetiole measured in dorsal view

PPW $=$ Postpetiole width: maximum width of the postpetiole measured in dorsal view

PSL = Propodeal spine length: in dorsofrontal view the tip of the measured spine, its base, and the centre of the propodeal concavity between the spines must all be in focus; using a dual-axis micrometer the spine length is measured from the tip of the spine to a virtual point at its base where the spine axis meets orthogonally with a line leading to the median point of the concavity

PSLI $=$ Propodeal spine index: PSL $/ \mathrm{HL} \times 100$

PTH $=$ Petiolar node height: maximum height of the petiolar node measured in lateral view from the highest (median) point of the node to the ventral outline

PTL = Petiolar node length: maximum length of the dorsal face of the petiolar node from the anterodorsal to the posterodorsal angle, measured in dorsal view excluding the peduncle

PTW $=$ Petiolar node width: maximum width of the dorsal face of the petiolar node measured in dorsal view

$\mathrm{PW}=$ Pronotal width: maximum width of the pronotum measured in dorsal view

SI = Scape index: SL $/ \mathrm{HW} \times 100$

$\mathrm{SL}=$ Scape length: maximum scape length excluding basal condyle and neck

$\mathrm{WL}=$ Weber's length: diagonal length of the metasoma in lateral view from the posteroventral margin of propodeal lobe to the anterior-most point of pronotal slope, excluding the neck 


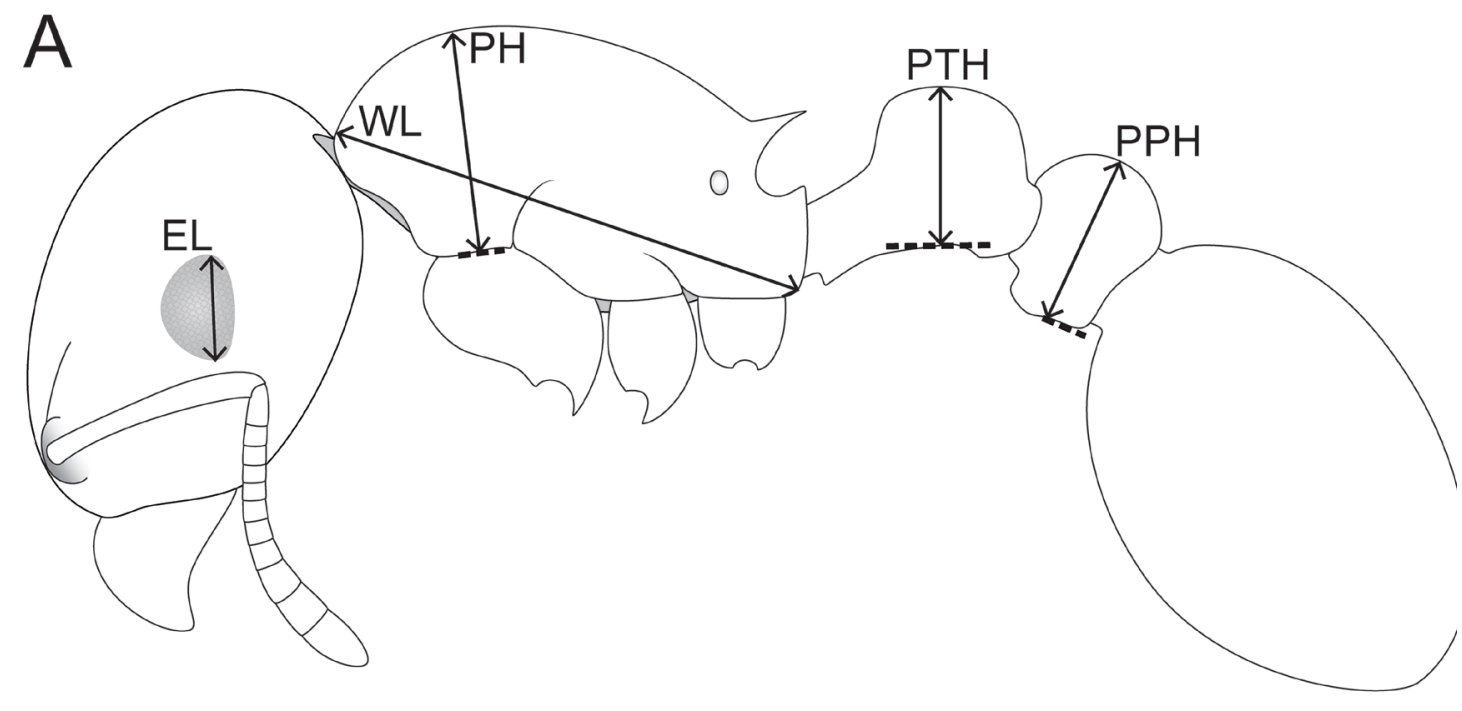

B

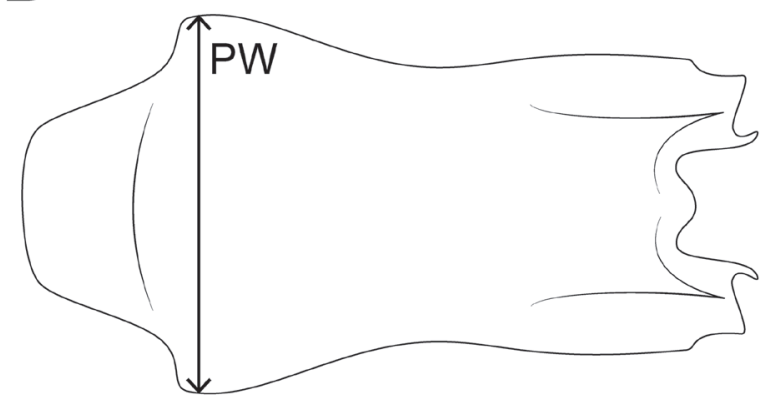

C
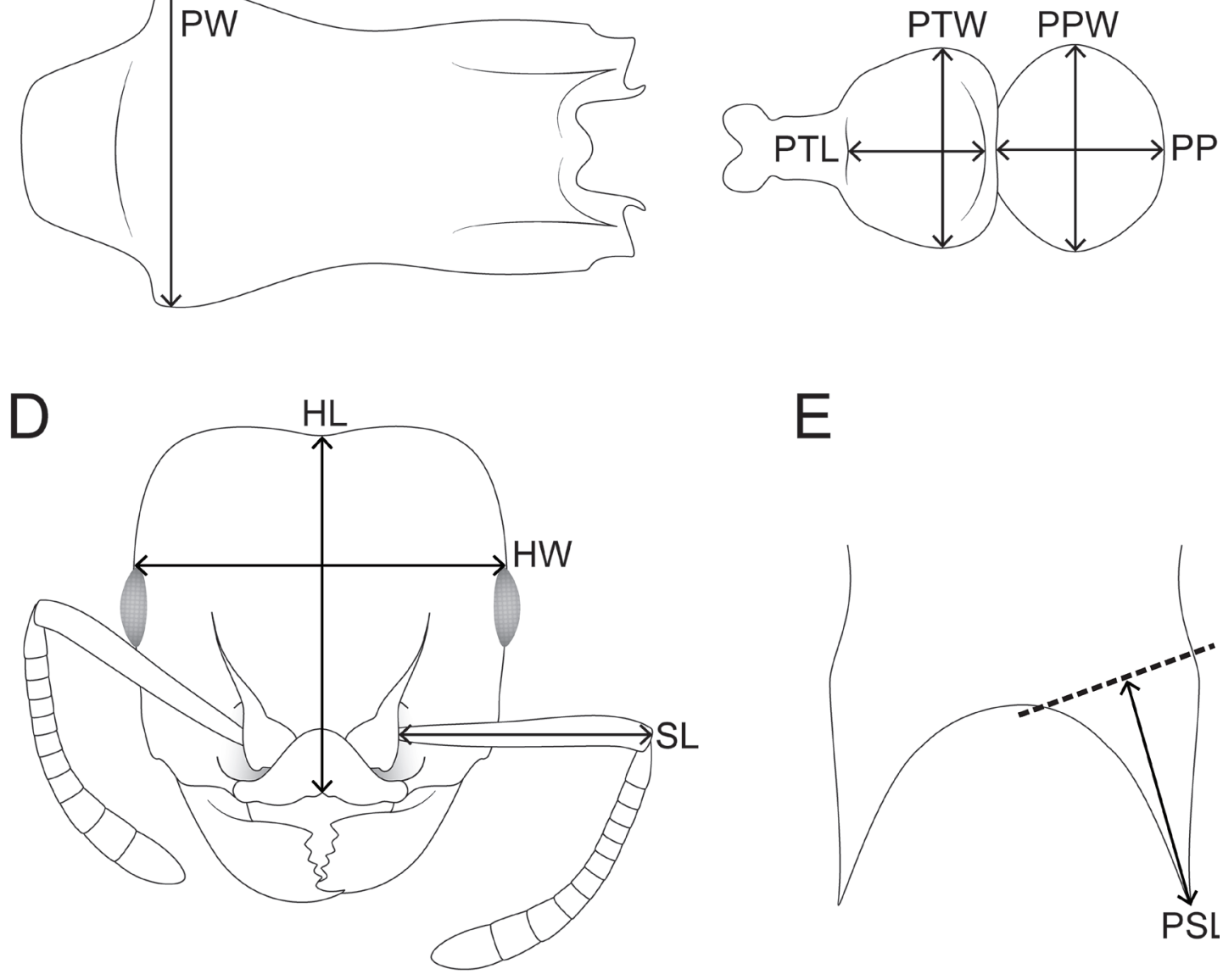

$E$

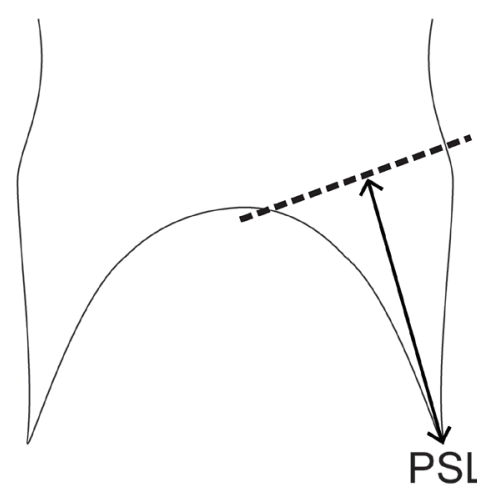

Fig. 1. Schematic line drawings of a $T$. solidum group species illustrating the used measurements. A. Body in profile with measuring lines for EL, WL, PH, PTH and PPH. B. Mesosoma in dorsal view with measuring line for PW. C. Petiole and postpetiole in dorsal view with measuring lines for PTL, PTW, PPL and PPW. D. Head in full-face view with measuring lines for HL, HW and SL. E. Dorsocaudal view of the propodeum with measuring line for PSL. 


\section{Results}

Order Hymenoptera Linnaeus, 1758

Family Formicidae Latreille, 1809

Subfamily Myrmicinae Lepeletier de Saint-Fargeau, 1835

Tribe Crematogastrini Forel, 1893

Genus Tetramorium Mayr, 1855

\section{Diagnosis of T. solidum species-group workers}

The following diagnosis, which is based on Bolton (1980), distinguishes the group from all other groups in the Afrotropical region: relatively large Tetramorium (HW 0.875-1.279 mm, WL 0.915-1.498 mm) with very well-developed, massively constructed heads (HW>0.80 mm and in most cases exceeding $1.00 \mathrm{~mm}$ ) equipped with strong mandibles; 12-segmented antennae; anterior clypeal margin with deep and wide median indentation, sometimes occupying half of the anterior clypeal margin, except for T. barbigerum Bolton, 1980, in which it is more shallowly impressed; large eyes (OI 24-26); frontal carinae absent or very short, if present ending before anterior eye level; frontal scrobes absent; ventral face of head (usually) with J-shaped ammocheate hairs; base of first gastral tergite always sculptured, even if weakly so.

\section{Overview of species of Tetramorium solidum group}

The species of the Tetramorium solidum group can be distinguished from other groups of Tetramorium by the presence of a median notch or impression on the anterior clypeal margin, which is often broad and deeply indented, combined with the presence of ammocheate hairs on the ventral side of the head (Bolton 1980). Bolton $(1980,1985)$ grouped species of the T. solidum group into three complexes based on the form of their pilosity. The first complex comprises T. dichroum Santschi, 1932, T. peringueyi Arnold, 1926 and T. rothschildi (Forel, 1907). These three species are characterized by the presence of abundant hairs on the dorsal surfaces of the head and body; these hairs are branched in T. rothschildi and simple in the other two species. The second complex includes T. clunum Forel, 1913, T. galoasanum Santschi, 1910 and T. setuliferum Emery, 1895; they all lack erect hairs on the dorsal surface of the antennae, mesosoma, petiole, postpetiole and first gastral tergite. They have a bizarre pilosity, which consists of short, broad, blunted, flattened and strongly appressed glittering silvery hairs. The third complex consists of T. barbigerum, T. glabratum Stitz, 1923, T. grandinode Santschi, 1913, T. jordani Santschi, 1937, T. pogonion Bolton, 1980, T. rufescens Stitz, 1923, T. signatum Emery, 1895 and T. solidum Emery, 1886, in which the body is hairless, or nearly so. Only T. solidum has a few hairs on the mesosoma (Bolton 1980).

\section{Synopsis of species of the Afrotropical region}

Tetramorium aisha Mbanyana, Robertson \& Hita Garcia sp. nov.

Tetramorium barbigerum Bolton, 1980

Tetramorium brigitteae Mbanyana, Robertson \& Hita Garcia sp. nov.

Tetramorium clunum Forel, 1913

Tetramorium dichroum Santschi, 1932

Tetramorium duncani Mbanyana, Robertson \& Hita Garcia sp. nov.

Tetramorium galoasanum Santschi, 1910

Tetramorium glabratum Stitz, 1923

= Tetramorium solidum st. glabratum Stitz, 1923

= Tetramorium solidum race glabratum var. aciculatum Stitz, 1923 [name unavailable]

= Tetramorium rutilum Prins, 1973

Tetramorium grandinode Santschi, 1913

= Tetramorium grandinode var. hopensis Forel, 1914 
Tetramorium jordani Santschi, 1937

= Tetramorium aspinatum Prins, 1973

Tetramorium lerouxi Mbanyana, Robertson \& Hita Garcia sp. nov.

Tetramorium margueriteae Mbanyana, Robertson \& Hita Garcia sp. nov.

Tetramorium peringueyi Arnold, 1926

Tetramorium pogonion Bolton, 1980

Tetramorium rothschildi (Forel, 1907)

Tetramorium rufescens Stitz, 1923

= Tetramorium solidum st. rufescens Stitz, 1923

Tetramorium setuliferum Emery, 1895

= Tetramorium squamiferum Forel, 1894 [name unavailable]

= Tetramorium setuliferum var. cucalense Santschi, 1910

= Tetramorium setuliferum var. triptolemus Arnold, 1917

Tetramorium signatum Emery, 1895

= Tetramorium solidum var. signatum Emery, 1895

= Tetramorium solidum subsp. lugubre Forel, 1910

= Tetramorium solidum var. grootensis Forel, 1913

= Tetramorium solidum var. tuckeri Arnold, 1926

Tetramorium solidum Emery, 1886

\section{Identification key to species in the Tetramorium solidum group (workers)}

1. Body with branched pilosity (Fig. 2C)

T. rothschildi (Forel, 1907)

- Body either lacking pilosity or with simple pilosity (Fig. 2A-B, D-I)

2. Dorsum of mesosoma in profile without any erect hairs, with appressed pubescence only (Fig. 2D-H)

- Dorsum of mesosoma in profile with erect hairs (Fig. 2A-B, I)

3. Body with short, broad, blunt, much flattened and strongly appressed glittering silvery hairs (Fig. 2D-F)

- Body without such hairs, only with sparse simple appressed pubescence (Fig. 2G-H) ..............6

4. Appressed pubescence long, dense and strap-like, hairs often overhanging one another (Fig. 2E)

T. galoasanum Santschi, 1910

- Appressed pubescence sparse and spaced out, not strap-like and not overlapping (Fig. 2D-E) ...5

5. The base of the first gastral tergite in profile forming a thick, laterally projecting downcurved flange, which obscures the tergosternal suture basally and base of the sternite; reddishbrown or red species (Fig. 3A)

T. setuliferum Emery, 1895

- The base of the first gasteral tergite in profile not projecting as above, the tergosternal suture and base of the sternite clearly visible; blackish brown to black species (Fig. 3B)

T. clunum Forel, 1913

6. In dorsal view both waist segments much broader than long and transverse, especially postpetiole extremely broadened with very well developed alar extensions making it approximately as broad as pronotum (Fig. 3C)

T. grandinode Santschi, 1913

- Waist segments, especially the postpetiole never shaped as above; if postpetiole with small alar extensions, then petiole not broadened (Fig. 3D-F)

7. Propodeum unarmed, lacking propodeal spines (Fig. 3G) T. jordani Santschi, 1937

- Propodeum armed with a pair of spines (Fig. 3H-I) .8 
8. Petiole in dorsal view broadened with lateral extensions on the sides (Fig. 3D)

T. lerouxi Mbanyana, Robertson \& Hita Garcia sp. nov.

- Petiole in dorsal view without any lateral extensions as above (Fig. 3E-F)

9. In full-face view head narrower in front of eyes than behind eyes (Fig. 3J)

T. barbigerum Bolton, 1980

- In full-face view head broader in front of eyes than behind the eyes, or same width (Fig. 3K-M) ...10

10. In profile posterodorsal corner of petiolar node sharply angled and slightly projecting posteriorly (Fig. $3 \mathrm{~N})$ T. duncani Mbanyana, Robertson \& Hita Garcia sp. nov.

- In profile posterodorsal corner of petiolar node rounded or rectangular but not sharply angled as above (Fig. 3O-P)

11. Head broader in front of eyes than behind eyes (Fig. 3K)

T. pogonion Bolton, 1980

- Head same width in front of eyes as behind eyes (Fig. 3L-M)

.12

12. Dorsum of mesosoma completely longitudinally or irregularly rugulose/rugose (Fig. 4A)

T. signatum Emery, 1895

- Dorsum of mesosoma either predominantly shiny with only superficial punctate sculpture, or densely reticulate punctate, often with few faint longitudinal costulae, median area of mesosoma usually very weakly sculptured (Fig. 4B)
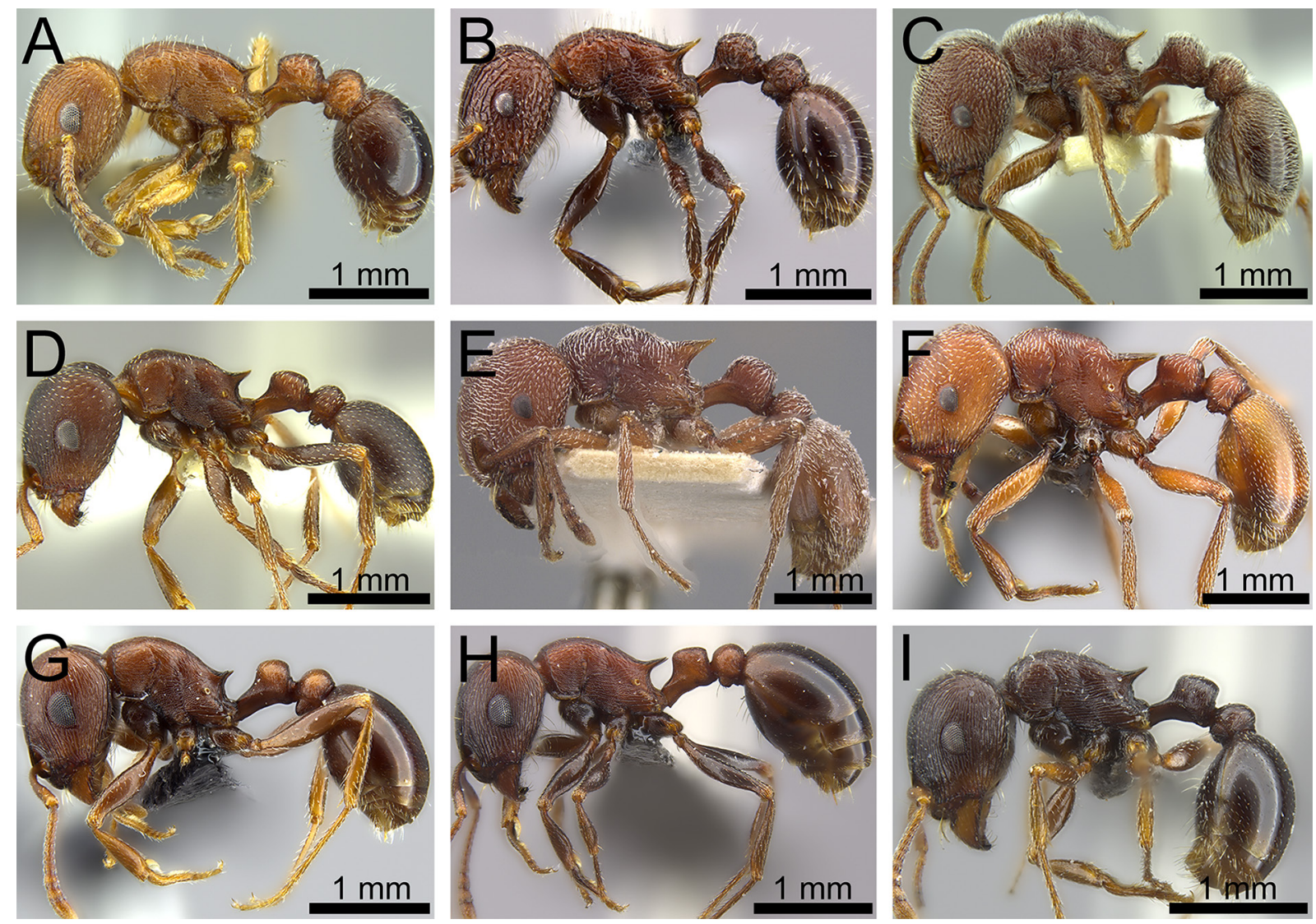

Fig. 2. Body in profile showing pilosity and pubescence. A. T. dichroum Santschi, 1932 (CASENT0746320). B. T. peringueyi Arnold, 1926 (CASENT0250873). C. T. rothschildi (Forel, 1907) (CASENT0764434). D. T. clunum Forel, 1913 (CASENT0764600). E. T. galoanasum Santschi, 1910 (CASENT0915015 - Antweb, William Ericson). F. T. setuliferum Emery, 1895 (MCZ_ENT00512567). G. T. glabratum Stitz, 1923 (SAM-HYM-C024395). H. T. rufescens Stitz, 1923 (CASENT0250852). I. T. solidum Emery, 1886 (CASENT0250960). 

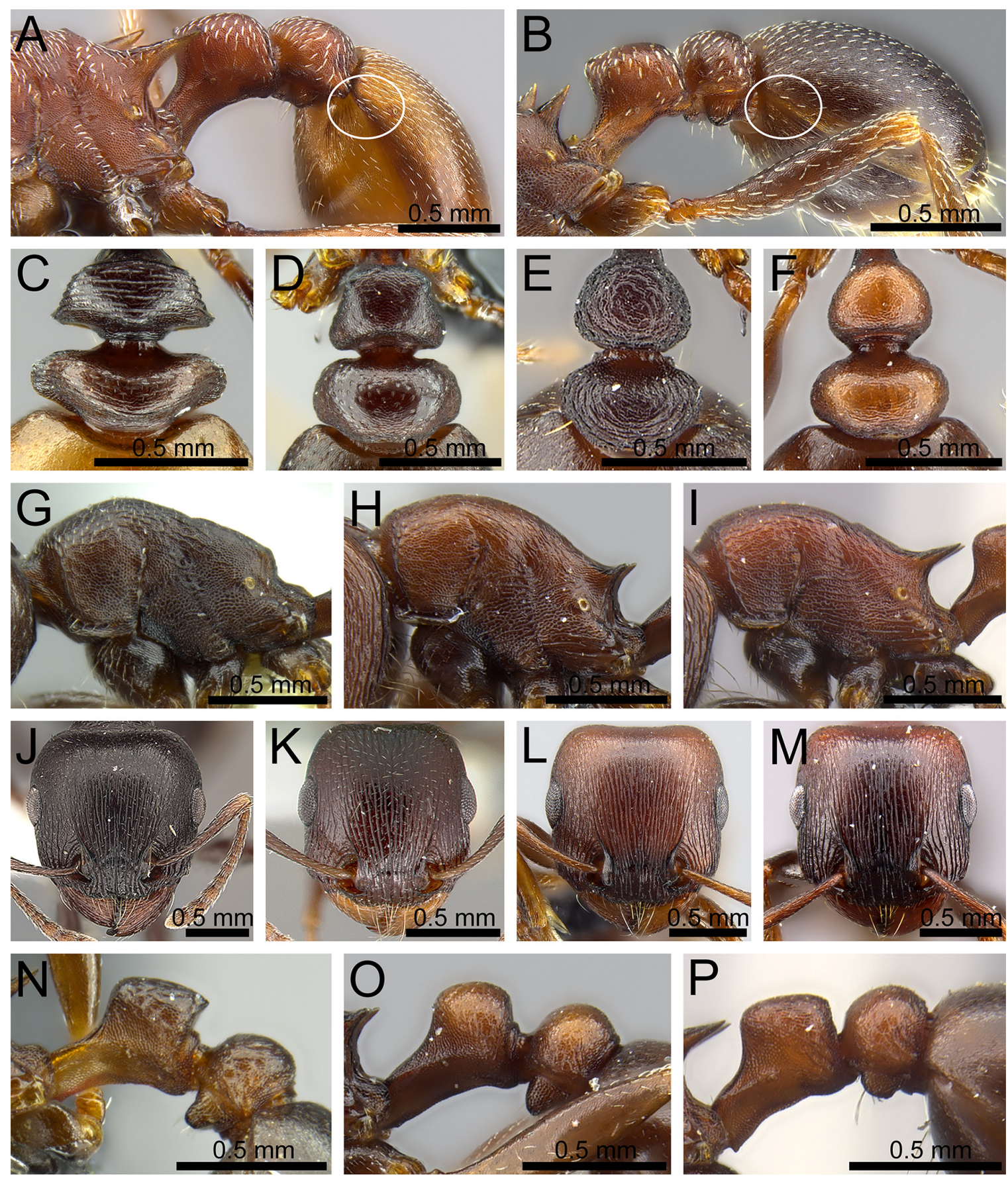

Fig. 3. A-B. Waist segments and gaster oblique lateral view. A. T. setuliferum Emery, 1895 (MCZ ENT00512567). B. T. clunum Forel, 1913 (CASENT0764600). C-F. Waist segments in dorsal view. C. T. grandinode Santschi, 1913 (CASENT0764655). D. T. lerouxi Mbanyana, Robertson \& Hita Garcia sp. nov. (SAM-HYM-C023329). E. T. signatum Emery, 1895 (SAM-HYM-C020573). F. T. glabratum Stitz, 1923 (SAM-HYM-C024395). G-I. Mesosoma in profile. G. T. jordani Santschi, 1937 (CASENT0248475). H. T. glabratum (SAM-HYM-C024395). I. T. rufescens Stitz, 1923 (CASENT0250852). J-M. Head in full-face view. J. T. barbigerum Bolton, 1980 (CASENT0901181). K. T. pogonion Bolton, 1980 (CASTYPE13390 - Antweb, photographer unknown). L. T. glabratum (SAM-HYM-C024395). M. T. rufescens (CASENT0250852). N-P. Waist segments in profile. N. T. duncani Mbanyana, Robertson \& Hita Garcia sp. nov. (SAM-HYM-C027003). O. T. glabratum (SAM-HYM-C024395). P. T. rufescens (CASENT0250852). 
13. Propodeal spines short, broad and acute apically (PSLI 4-8) (Fig. 3H) ...T. glabratum Stitz, 1923 - Propodeal spines long and narrow (PSLI 16-23) (Fig. 3I) ........................ T. rufescens Stitz, 1923

14. Abundant erect hairs on all dorsal surfaces of head and body (Fig. 2D-E) .......................15

- Only one to four pairs of hairs present on dorsum of mesosoma (Fig. 2L) ................................18

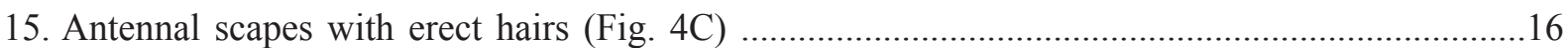

- Antennal scapes without erect hairs, only with flattened pubescence (Fig. 4D) ........................17
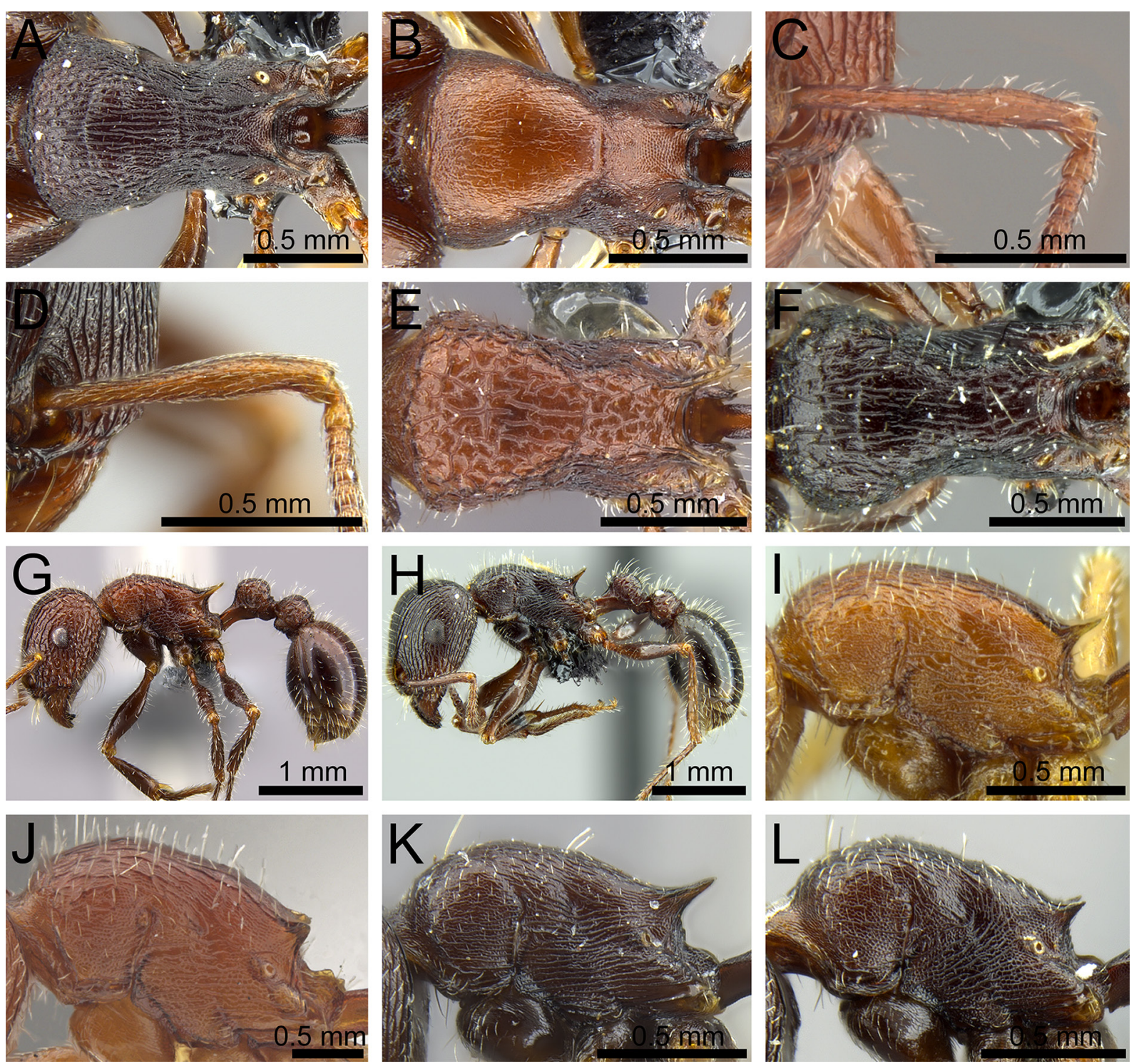

Fig. 4. A-B. Mesosoma in dorsal view. A. T. signatum Emery, 1895 (SAM-HYM-C020573). B. T. glabratum Stitz, 1923 (SAM-HYM-C024395). C-D. Antennal scape in frontal view. C. T. aisha Mbanyana, Robertson \& Hita Garcia sp. nov. (CASENT0250969). D. T. peringueyi Arnold, 1926 (SAM-HYM-C026796). E-F. Mesosoma in dorsal view. E. T. peringueyi (CASENT0250873). F. T. margueriteae Mbanyana, Robertson \& Hita Garcia sp. nov. (SAM-NC07-012). G-H. Body in profile. G. T. peringueyi (CASENT0250873). H. T. margueriteae sp. nov. (SAM-HYM-C019839). I-L. Mesosoma in profile. I. T. dichroum Santschi, 1932 (CASENT0746320). J. T. brigitteae Mbanyana, Robertson \& Hita Garcia sp. nov. (SAM-HYM-C027040). K. T. solidum Emery, 1886(CASENT0250960). L. T. aisha sp. nov. (CASENT0250969). 
16. Dorsal surface of mesosoma with strongly developed irregular reticulate sculpture; colour orange (Fig. 4E, G) . T. peringueyi Arnold, 1926

- Dorsal surface of mesosoma with short longitudinal rugulae; ground sculpture mainly smooth and shiny with peripheral patches of fine, superficial reticulations; colour uniformly black (Fig. 4F, H) T. margueriteae Mbanyana, Robertson \& Hita Garcia sp. nov.

17. Propodeum armed with acute spines (PSLI 10-16); colour light brown, with gaster a little bit darker compared to mesosoma (Fig. 4I)

T. dichroum Santschi, 1932

- Propodeum with short propodeal teeth (PSLI 6); colour reddish brown, with gaster black (Fig. 4J) T. brigitteae Mbanyana, Robertson \& Hita Garcia sp. nov.

18. Propodeum with elongate and acute spines (PSLI 17-21) (Fig. 4K) ....T. solidum Emery, 1886

- Propodeum with short triangular teeth (PSLI 5-9) (Fig. 4L)

..T. aisha Mbanyana, Robertson \& Hita Garcia sp. nov.

\section{Review of Species}

In this study, we provide species descriptions of new species only. The descriptions for the remainder of the species are given in Bolton (1980). Where possible, vegetation habitat of a species is listed under the Remarks section. Biomes are in accordance with Mucina \& Rutherford (2006) and include Fynbos, Succulent Karoo, Desert, Nama Karoo, Grassland and Savanna. The first letters of words that refer to specific vegetation types that are listed in Mucina \& Rutherford (2006) are capitalised.

Tetramorium aisha Mbanyana, Robertson \& Hita Garcia sp. nov. urn:Isid:zoobank.org:act:8F4D69D1-F181-4B73-A11F-6F7476793CD6

Figs 4D, L, 5, 24

\section{Diagnosis}

Morphologically, T. aisha sp. nov. is similar to T. solidum in that these are the only species in the group with sparse simple erect hairs that are restricted to the mesosoma and petiole only. They can be separated on the basis of the length of the propodeal spines: in T. aisha sp. nov., the propodeum is only armed with very short propodeal teeth (PSLI 5-9) (Fig. 4L), which are shorter than their basal width, whereas in T. solidum the propodeum is armed with elongate and acute spines (PSL 0.157-0.197) (Fig. 4K).

\section{Etymology}

Named after Aisha Mayekiso, one of the collectors, who is a Collections Manager (Entomology) in the Natural History Collections Department of the Iziko Museums of South Africa.

\section{Material examined}

Holotype

SOUTH AFRICA: worker, Western Cape, Abrahamskraal, 32.92560 S, $22.01319^{\circ}$ E, $516 \mathrm{~m}$ a.s.1., flood plain of dry river bed with Salsola aphylla and Acacia karoo, in deep finely grained soils, 15 Apr. 2008, N. Mbanyana, A. Mayekiso and H.G. Robertson leg. (SAM-HYM-C020292).

\section{Paratypes}

SOUTH AFRICA: 12 pinned workers, same collection data as for holotype (SAM-HYM-C020288 to SAM-HYM-C020292, SAM-HYM-C020316, SAM-HYM-C020329).

\section{Other material}

SOUTH AFRICA (29 pinned specimens): Northern Cape: Melton Wold, $31.46741^{\circ} \mathrm{S}, 22.72155^{\circ} \mathrm{E}$, 1333 m a.s.l., 7 Jan. 2009, N. Mbanyana and H.G. Robertson leg. (SAM-HYM-C023306, SAM- 

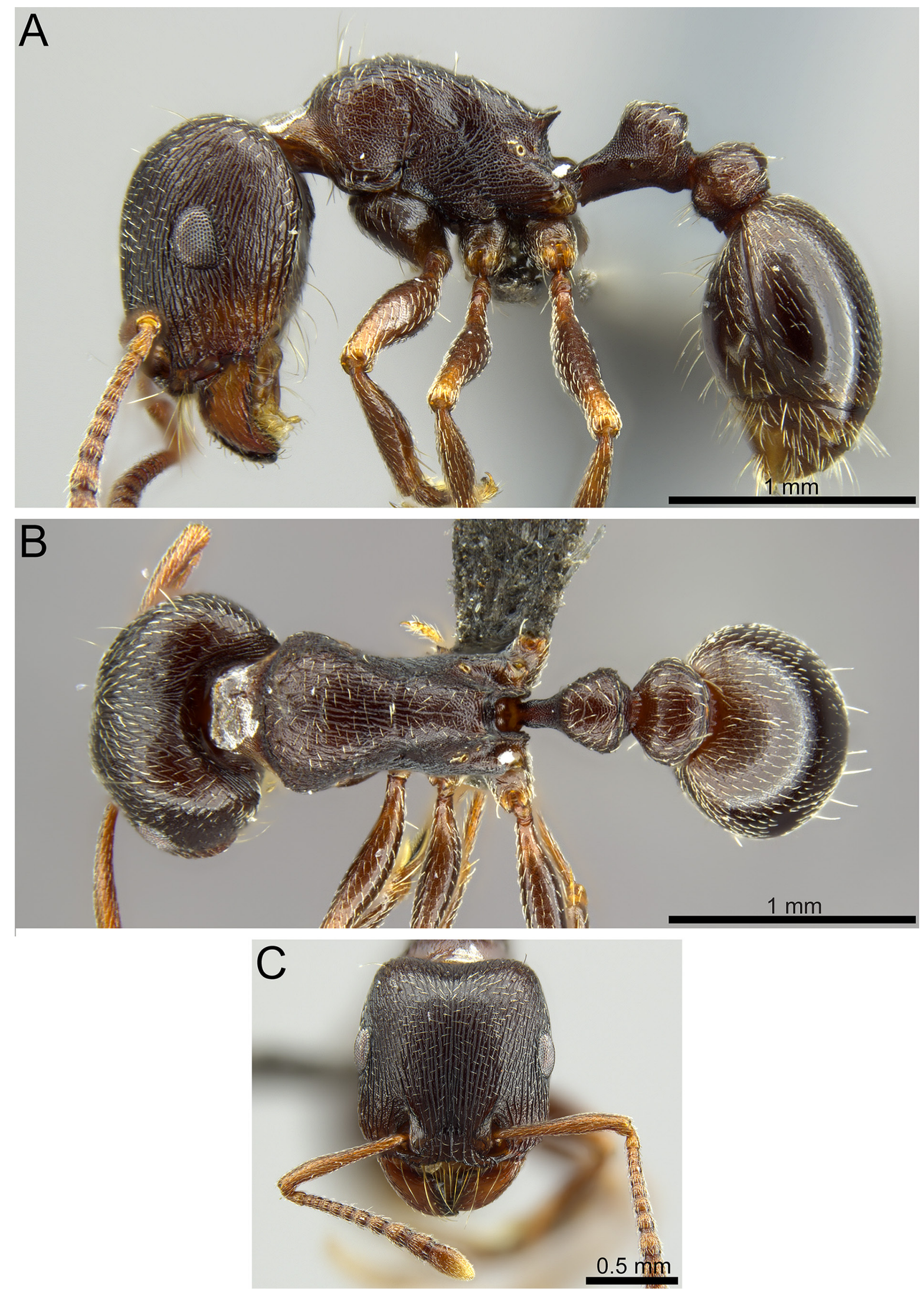

Fig. 5. Tetramorium aisha Mbanyana, Robertson \& Hita Garcia sp. nov. (CASENT0250969). A. Body in profile. B. Body in dorsal view. C. Head in full-face view. 
HYM-C023313); Sakrivier, 23 Apr. 1963, A.J. Prins leg. (SAM-HYM-C019290); Onder-downs, 24 Apr. 1963, A.J. Prins leg. (SAM-HYM-C019306); Kortkop farm near Strydenburg, 3009' S, 23ํ4' E, pitfall trap, Karoo vegetation, 17 Jun. 1995, B. Chambers leg. (SAM-HYM-C008783); Hopetown Municipal Farm, 4 km E of Hopetown, 15 Feb. 1997, B. Chambers leg. (SAM-HYM-C010847); Prieska, 2 mi. from Prieska to Canarvon, 23 Oct. 1963, A.J. Prins leg. (SAM-HYM-C015044). - Western Cape: 36

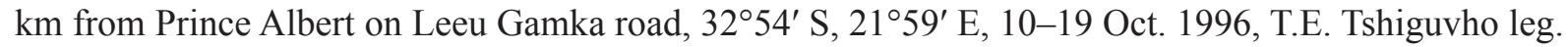

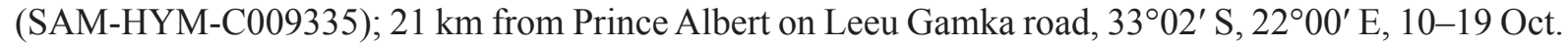
1996, T.E. Tshiguvho leg. (SAM-HYM-C009336).

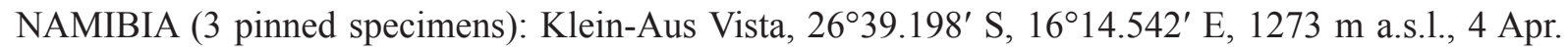
2011, in rocky sandy soil in the middle of dry riverbed, nest entrance with crater of soil around, N. Mbanyana and H.G. Robertson leg. (SAM-HYM-C026799); Erongo, Swakopmund, Central Namib Desert 2010 site $20,22.92214^{\circ} \mathrm{S}, 15.20903^{\circ} \mathrm{E}, 572 \mathrm{~m}$ a.s.l., hand collected, 26 Oct. 2010, P. Hawkes, J. Fisher, J. Irish and R. Scholtz leg. (AFRC: CASENT0250969).

Measurements (workers $\mathrm{N}=13$ )

HL 0.993-1.082(1.037); HW 1.023-1.082 (1.060) SL 0.718-0.787 (0.764); EL 0.236-0.275 (0.262); PH 0.393-0.580 (0.474); PW 0.639-0.738 (0.673); WL 1.013-1.208 (1.102); PSL 0.049-0.089 (0.070); PTH 0.305-0.364 (0.335); PTL 0.246-0.328 (0.277); PTW 0.305-0.364 (0.338); PPH 0.375-0.384 (0.356); PPL 0.256-0.344 (0.284); PPW 0.393-0.482 (0.436); OI 22-26 (25); CI 100-108 (102); SI 68-74 (72); DMI 56-68 (61); LMI 33-53 (43); PSLI 5-9 (7); PeNI 47-52 (50); LPeI 75-93 (83) DPeI 108-132 (122); PpNI 61-70 (65); LPpI 64-100 (80); DPpI 131-180 (154); PPI 126-133 (129).

\section{Description}

\section{Holotype (worker)}

Mandibles with fine longitudinal striations. Anterior clypeal margin with extensive, semicircular indentation. Frontal carinae extending back from frontal lobes as fine ridges ending approximately at level of anterior eye margin. Propodeum armed with pair of short triangular teeth (PSLI 5-9). Metapleural lobes low and rounded. Peduncle with prominent keel-shaped subpetiolar process. Petiolar node in profile nodiform, with posterior face slightly more steeply angled than anterior face; anterior face also rounding into dorsum but with slightly angled corners as seen in dorsal view. Postpetiolar node low and rounded. Dorsal surfaces of head and mesosoma with finely reticulate ground sculpture overlain by longitudinal striations. Petiolar and postpetiolar nodes with fine reticulate sculpture overlain by irregular transverse striations. First gastral tergite with fine, superficial reticulate pattern. Numerous long hairs on clypeus. Ventral surface of head with prominent psammophore. Erect hairs distributed as follows elsewhere: dorsum of head with four pairs; dorsum of mesosoma with three pairs (two on humeri and one on mesonotum); one pair on petiolar node; and numerous hairs on first gastral sternite. Colour uniformly black.

Paratypes and other material examined similar to holotype, except for following differences: three to five pairs of long erect hairs on dorsum of mesosoma, arranged as follows; two to four pairs along anterior margin of pronotum and one pair on the mesonotum.

\section{Distribution}

Known from South Africa (Western Cape and Northern Cape) and Namibia, where it occurs in Nama Karoo, Montane Fynbos, Renosterveld, Kalahari Xeric Savanna and Namib Desert. 
Tetramorium barbigerum Bolton, 1980

Figs 3J, 6

Tetramorium barbigerum Bolton, 1980: 243.

\section{Diagnosis}

Tetramorium barbigerum is easily distinguished from all species of the T. solidum group by its head shape, which is narrower in front of the eyes than behind (Fig. 3J). Morphologically, this species is similar to $T$. jordani and $T$. signatum in that they are all black in colour and lack erect hairs on the mesosoma, but the sculpture in T. signatum is much stronger developed compared to $T$. jordani and $T$. barbigerum. Tetramorium barbigerum and $T$. jordani have a feeble cephalic sculpture, fading out at the level of the eyes and replaced by a fine superficial punctation (Figs 6C, 14C). These two species can be easily distinguished from each other by the lack of propodeal spines/teeth in T. jordani (PSLI 1-2) (Fig. 3G) and the presence thereof in T. barbigerum (PSLI 7-8) (Fig. 6A).

\section{Material examined}

Holotype

NAMIBIA: worker, 10 mi. (16 km) W of Okombahe, 920 m a.s.1., 10 May 1958, R.E. Ross and R.E. Leech leg. (CASC: CASTYPE13386).

\section{Paratypes}

NAMIBIA: 17 pinned workers, same data as holotype (CASC: CASENT0270787 to CASENT0270792); 3 pinned workers, same data as holotype (BMNH).

Measurements (workers $\mathrm{N}=6$ )

HL 1.214-1.266(1.244); HW 1.201-1.240 (1.223) SL 0.827-0.891 (0.857); EL 0.297-0.323 (0.308); PH 0.570-0.590 (0.583); PW 0.747-0.806 (0.775); WL 1.227-1.356 (1.294); PSL 0.089-0.098 (0.093); PTH 0.354-0.374 (0.363); PTL 0.354-0.384 (0.370); PTW 0.364-0.384 (0.375); PPH 0.517-0.568 (0.536); PPL 0.295-0.403 (0.362); PPW 0.443-0.472 (0.462); OI 24-26 (25); CI 95-101 (98); SI 67-72 (70); DMI 56-62 (60); LMI 42-49 (45); PSLI 7-8 (8); PeNI 46-50 (48); LPeI 95-108 (102) DPeI 108-132 (101); PpNI 58-62 (60); LPpI 57-76 (68); DPpI 117-153 (129); PPI 118-127 (123).

\section{Distribution}

Only known from the type locality, Okombahe in Namibia.

Tetramorium brigitteae Mbanyana, Robertson \& Hita Garcia sp. nov. urn:1sid:zoobank.org:act:CC0CCBD7-3D23-4177-A1B8-36AC5B02A7DF

Figs 4J, 7, 24

\section{Diagnosis}

Tetramorium brigitteae sp. nov. is morphologically similar to $T$. peringueyi, $T$. dichroum and T. margueriteae sp. nov. These are the only species in the solidum group with abundant erect simple hairs covering the entire body. Tetramorium brigitteae sp. nov can be easily separated from $T$. peringueyi by the following characters: in T. brigitteae sp. nov., dorsum of mesosoma with longitudinal striations and superficial ground sculpture in between (Fig. 7B), whereas in T. peringueyi, the dorsal surface of the mesosoma with strongly developed irregular reticulate sculpture (Fig. 4E); propodeum armed with a pair of short propodeal teeth (PSLI6) in T. brigitteae sp. nov., whereas in T.peringueyi the propodeum is armed with elongate spines (PSLI 22). Antennae with sub-erect pubescence in T. brigitteae sp. nov., with erect hairs in T. peringueyi. Tetramorium brigittae sp. nov. can also be easily separated from T. margueriteae sp. nov. 

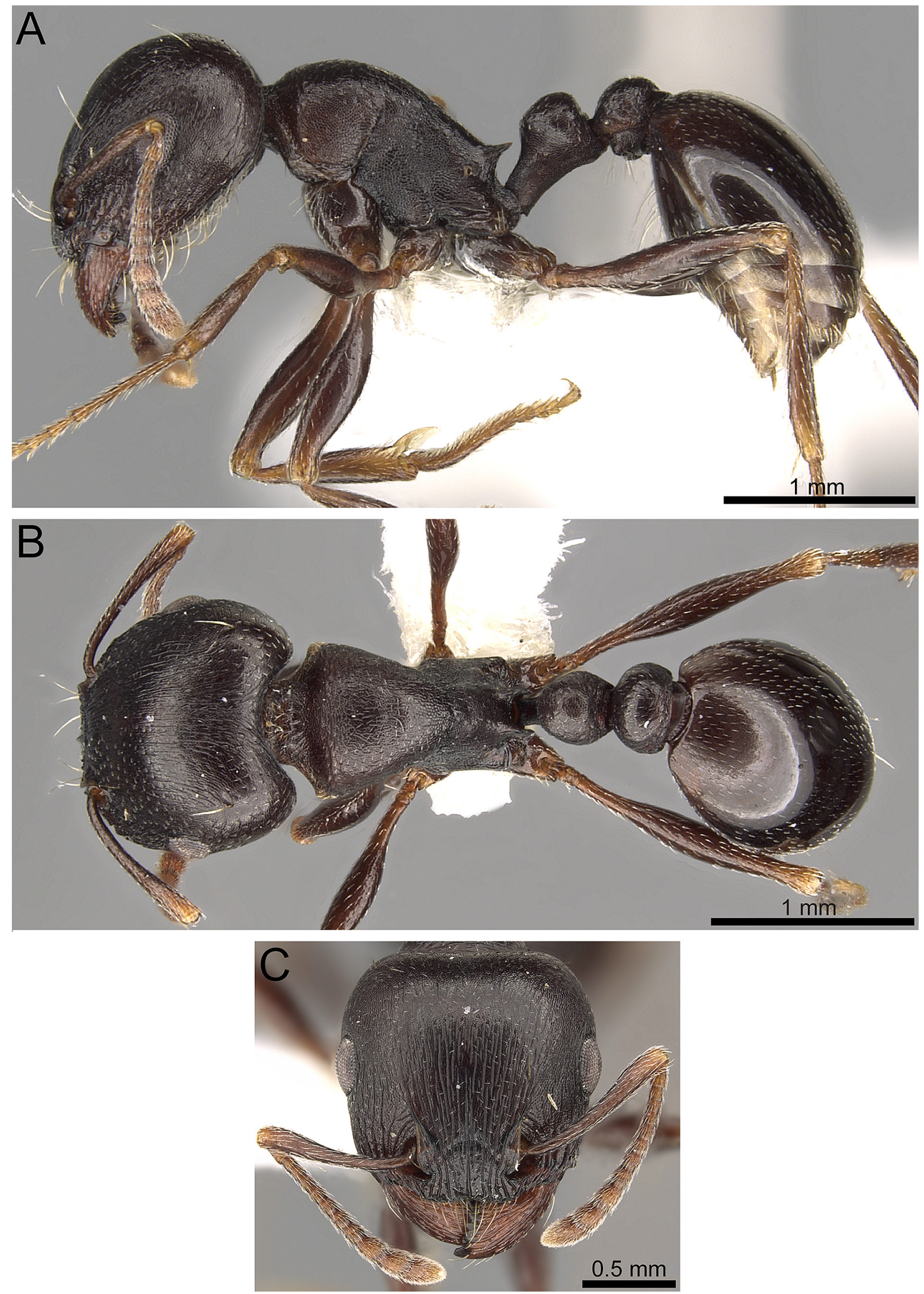

Fig. 6. Tetramorium barbigerum Bolton, 1980 (CASTYPE13386 - Antweb, photographer unknown). A. Body in profile. B. Body in dorsal view. C. Head in full-face view. 

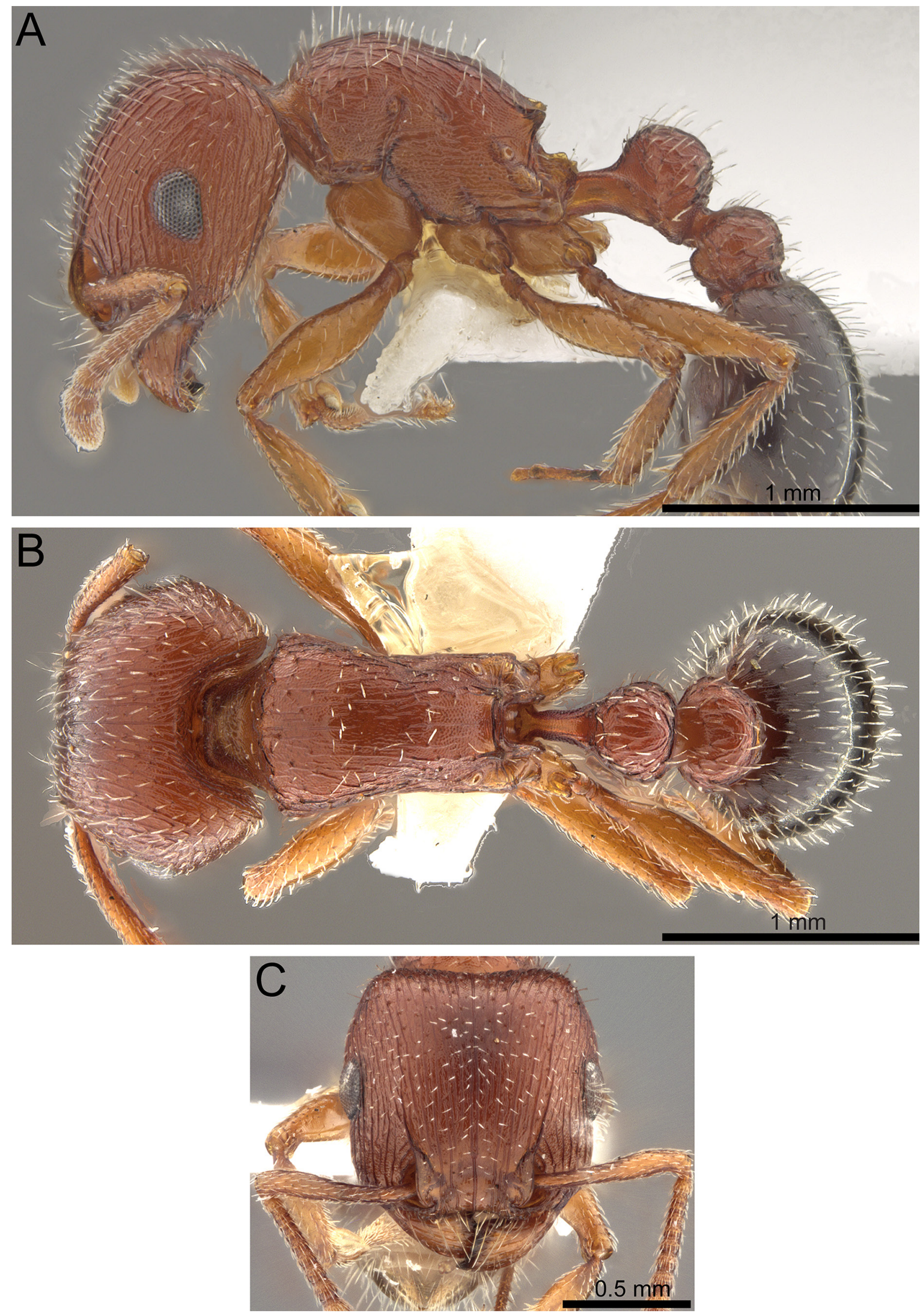

Fig. 7. Tetramorium brigitteae Mbanyana, Robertson \& Hita Garcia sp. nov. (SAM-HYM-C027040). A. Body in profile. B. Body in dorsal view. C. Head in full-face view. 
on the basis of colour and spine length, and also by the fact that $T$. margueriteae sp. nov. has erect hairs on the antennae, whereas T. brigitteae sp. nov. has sub-erect pubescence on the antennae. Tetramorium brigitteae sp. nov. and T. dichroum both have sub-erect hairs on the antennae, and in both species the dorsum of the mesosoma has longitudinal striations and a superficial ground sculpture in between. These two species can be separated on the basis of spine length and colour. In T. brigitteae sp. nov., propodeum armed with short propodeal teeth (PSLI 6) (Fig. 4J), whereas in $T$. dichroum propodeum armed with acute spines (PSLI 14) (Fig. 4I). Tetramorium brigitteae sp. nov. is reddish brown, with gaster black, whereas $T$. dichroum is light brown in colour, with gaster a little darker compared to the mesosoma. The lateral sides of the mesosoma have strong reticulate-punctate sculpture in T. brigitteae sp. nov., whereas in $T$. dichroum the sides of the mesosoma have lateral striations with a superficial reticulate sculpture in between.

\section{Etymology}

Named after Dr Brigitte Braschler who collected the holotype and who has made a significant contribution to our knowledge of southern African arid ants through field work conducted as part of the DST/NRF Centre of Excellence for Invasion Biology's Imbovane project.

\section{Material examined}

\section{Holotype}

SOUTH AFRICA: Northern Cape: worker, near Augrabies Falls National Park, on R359 past turnoff for Augrabies National Park, 28.623 S, 20.328 ${ }^{\circ}$ E, 639 m a.s.1., 13 Dec. 2011, Brigitte Braschler (SAMHYM-C027040).

\section{Measurements (worker $\mathrm{N}=1$ )}

HL 0.982; HW 1.059; SL 0.736; EL 0.284; PH 0.374; PW 0.672; WL 1.098; PSL 0.054; PTH 0.364; PTL 0.349; PTW 0.375; PPH 0.452; PPL 0.362; PPW 0.426; OI 27; CI 108; SI 70; DMI 61; LMI 34; PSLI 6; PeNI 56; LPeI 96; DPeI 107; PpNI 63; LPpI 80; DPpI 118; PPI 114.

\section{Description}

Holotype (worker)

Mandibles with fine longitudinal striations. Anterior clypeal margin with extensive and deep indentation. Frontal carinae extending back to posterior margins of eyes. Eyes with 16 ommatidia in longest row. Propodeum armed with pair of short propodeal teeth (PSLI 6), teeth longer than basal width. Metapleural lobes low and rounded. Peduncle with prominent keel-shaped subpetiolar process. Petiolar node in profile nodiform, with posterior face slightly more steeply angled than anterior face; anterior face rounding into dorsum but with slightly angled corners as seen in dorsal view. Postpetiolar node low and rounded. Peduncle lacking subpetiolar process. Dorsal surfaces of head and mesosoma with longitudinal striations, spaces between them with superficial ground sculpture. Petiolar and postpetiolar nodes with fine reticulate sculpture overlain by few irregular transverse striations. Gastral tergite with longitudinal short striations basally and remaining part with fine reticulate pattern. All dorsal surfaces of body with abundant, short to moderately long, erect pilosity. Antennae with sub-erect pubescence. Tibia of middle and hind legs with numerous short, stout, erect hairs. Ventral surface of head with strongly developed psammophore. Head and mesosoma light brown in colour and gaster black.

\section{Distribution}

Known from one specimen which was collected from the Nama Karoo region in the Northern Cape in South Africa. 
Tetramorium clunum Forel, 1913

Figs 2D, 3B, 8, 24

Tetramorium setuliferum st. cluna Forel, 1913: 218.

\section{Diagnosis}

In the T. solidum group there are only three species with short, broad, flattened and strongly appressed glittering silvery hairs covering the body (Fig. 2D-F), namely, T. setuliferum, T. clunum and T. galoasanum. Tetramorium galoasanum is distinguished from the other two species by its long, dense, overlapping strap-like hairs, whereas in the other two species these hairs are sparse and spaced out. Tetramorium clunum is separated from $T$. setuliferum by the following characters: (1) first gastral tergite does not overhang the tergosternal suture in profile (Fig. 3B); (2) first gastral tergite is sculptured throughout whereas in T. setuliferum only the base is sculptured; (3) dorsum of head behind clypeus with at least one pair of erect hairs, whereas $T$. setuliferum lacks elongate erect hairs on the dorsum of head; and (4) tergum of postpetiole without lateral alar prominences, whereas these are present in T. setuliferum.

\section{Material examined}

Syntypes

SOUTH AFRICA: workers, Eastern Cape, Willowmore, Dec. 1912, H. Brauns leg. (BMNH: CASENT0901182; MHNG: CASENT0909155).

\section{Other material}

SOUTH AFRICA (26 pinned specimens): Eastern Cape: Fish River Valley, Jun. 1965 (SAMHYM-C004009); Willomore, Sep. 1919, H. Brauns leg. (SAM-HYM-C004010); Willowmore, $33^{\circ} \mathrm{S}, 22^{\circ} \mathrm{E}, 500 \mathrm{~m}$ a.s.1., nest in sandy soil, 1 Dec. 1976, C.F. Jacot-Guillarmod leg. (CASC: CASENT0217964; BMNH: CASENT0764600 to CASENT0764602). - Western Cape: Oudtshoorn, Grootkop Nature Reserve, 33.577917 ${ }^{\circ}$ S, $22.217028^{\circ}$ E, 373 m a.s.l., 10 Mar. 2006, Succulent Karoo, pitfall trap, B. Braschler leg. (SAM-HYM-C024965); Josephskraal, 33.04182 ${ }^{\circ} \mathrm{S}, 20.72157^{\circ} \mathrm{E}, 896 \mathrm{~m}$ a.s.1., Koedoesberge-Moordenaars Karoo, deep soil on elevated flood plain, 16 Apr. 2008, N. Mbanyana and H.G. Robertson leg. (SAM-HYM-C020467); Nature's Valley, 3358'38" S, 2333'39" E, 10 m a.s.1., 8 Dec. 1967, A.J. Prins leg. (SAM-HYM-C015136). - Northern Cape: Melton Wold, 31.46189 S, $22.72417^{\circ}$ E, 1331 m a.s.1., 9 Jan. 2009, N. Mbanyana and H.G. Robertson leg. (SAM-HYM-C023304).

\section{Measurements (worker $\mathrm{N}=11$ )}

HL 0.885-1.062 (0.958); HW 0.919-1.090 (0.991); SL 0.688-0.757 (0.723); EL 0.207-0.266 (0.239); PH 0.482-0.570 (0.544); PW 0.570-0.669 (0.609); WL 0.922-1.023 (0.963); PSL 0.157-0.177 (0.168); PTH 0.285-0.344 (0.307); PTL 0.295-0.340 (0.315); PTW 0.305-0.381 (0.325); PPH 0.413-0.530 (0.461); PPL 0.187-0.246 (0.207); PPW 0.374-0.472 (0.401); OI 22-27 (24); CI 101-105 (103); SI 69-76 (73); DMI 61-67 (63); LMI 51-62 (57); PSLI 15-19 (18); PeNI 49-57 (53); LPeI 97-113 (103) DPeI 92-112 (103); PpNI 63-71 (66); LPpI 40-58 (45); DPpI 152-218 (195); PPI 117-127 (124).

\section{Distribution}

Tetramorium clunum has been recorded from South Africa (Eastern Cape, Western Cape and Northern Cape) and Namibia, where it occurs in Nama Karoo, Succulent Karoo and Namib Desert.

This is a ground-nesting species. It has been recorded nesting in deep soils. Nothing is known about its feeding behaviour, but presumably this species feeds on seeds, as this is recorded for most other species of this group. This species has been collected in yellow pan traps, pitfall traps and by turning stones. 

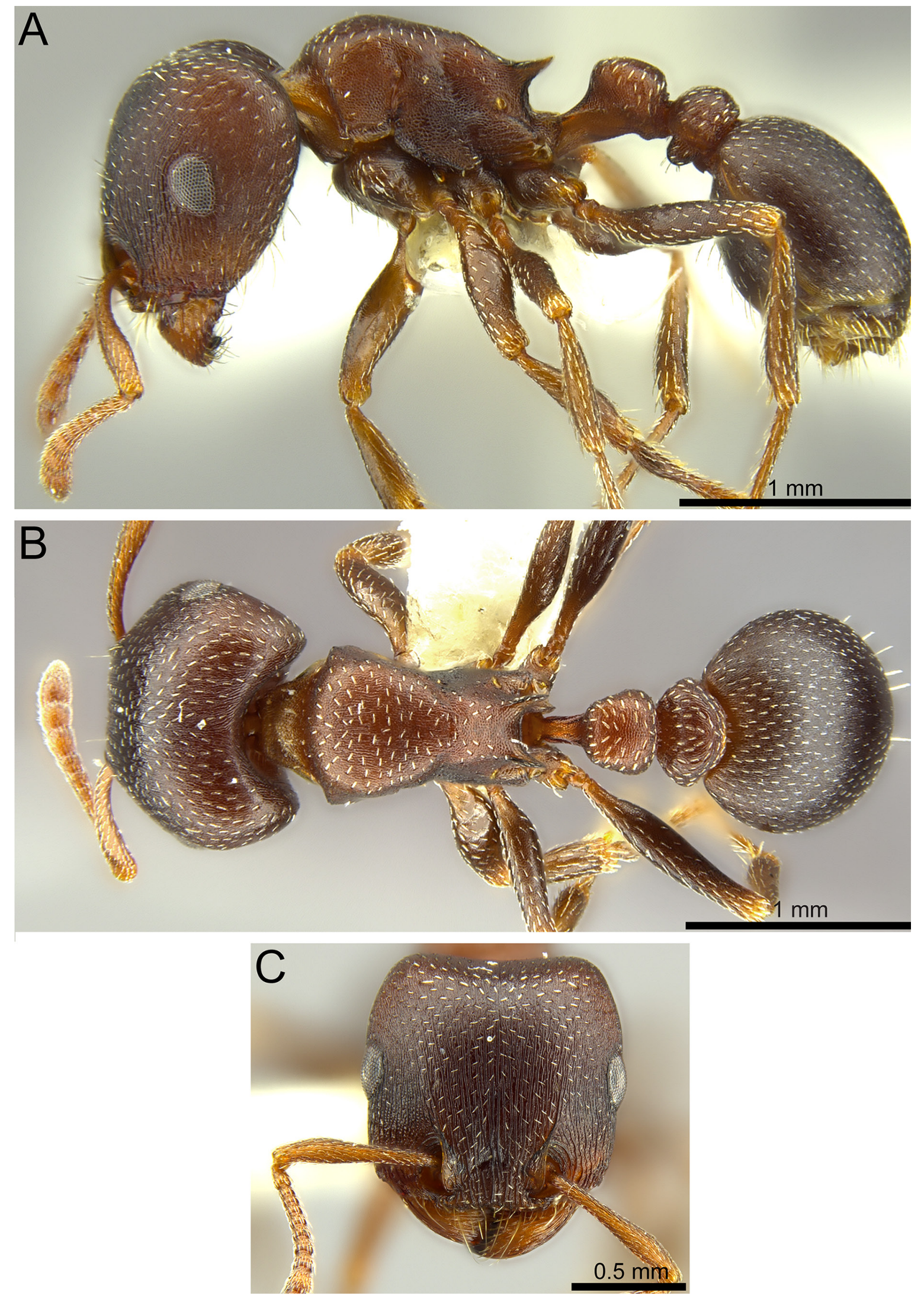

Fig. 8. Tetramorium clunum Forel, 1913 (CASENT0764600). A. Body in profile. B. Body in dorsal view. C. Head in full-face view. 
Tetramorium dichroum Santschi, 1932

Figs 2A, 4I, 9, 24

Tetramorium solidum st. dichroum Santschi, 1932: 388.

\section{Diagnosis}

In the Tetramorium solidum-group, there are five species with abundant hairs covering the dorsal surfaces of the whole body, namely, $T$. rothschildi, $T$. peringueyi, $T$. dichroum, T. margueriteae sp. nov. and T. brigitteae sp. nov. Tetramorium rothschildi is easily separated from other species by having branched hairs. Tetramorium dichroum can be easily distinguished from T. peringueyi and T. margueriteae sp. nov. by the absence of erect hairs on the antennal scapes. Tetramorium dichroum and T. brigitteae sp. nov. can be distinguished on the basis of the spine length: in $T$. dichroum spines are long and acute (PSLI 10-16) (Fig. 4I), whereas T. brigitteae sp. nov. has very short propodeal teeth (PSLI 6) (Fig. 4J).

\section{Material examined}

Syntypes

SOUTH AFRICA: 3 pinned workers, Northern Cape, Kimberley, 1924, Power leg. (NHMB: CASENT0915004; SAMC: SAM-ENT-0011758).

\section{Other material}

SOUTH AFRICA (40 pinned specimens): Orange Free State: Tussen Die Riviere, $30.295^{\circ} \mathrm{S}, 26.14^{\circ} \mathrm{E}$, 30 Mar.-1 Apr. 1987, H.G. Robertson leg. (SAM-HYM-C000310); Springfontein, Hillside Farm, $30^{\circ} 09^{\prime}$ S, $25^{\circ} 46^{\prime}$ E, 28 Sep. 1995, H. Adie leg. (SAM-HYM-HYM-C008451). - Northern Cape: Kortkop farm near Strydenburg, 3009' S, 2344' E, 17 Jun. 1995, ex pitfall trap, Karoo vegetation, B. Chambers leg. (SAM-HYM-C008779); Tankwa Karoo National Park, 32.17430 S, $19.97382^{\circ}$ E, $602 \mathrm{~m}$ a.s.l., 7 Jan. 2009, N. Mbanyana and H.G. Robertson leg. (SAM-HYM-C023307); Melton Wold, 31.46189 ${ }^{\circ}$, $22.72417^{\circ}$ E, 1331 m a.s.1., 9 Jan. 2009, N. Mbanyana and H.G. Robertson leg. (SAM-HYM-C024387).

- Eastern Cape: Cookhouse, 26 Jul. 1944, Agricultural Research Institute - Pretoria leg. (SAMHYM-C011579); Oviston, dolerite koppie, 21 Nov. 1988, W.R.J. Dean leg. (SAM-HYM-C001484);

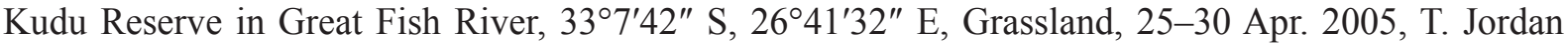
leg. (SAM-HYM-C018977). - Western Cape: Molenrivier, 3 Feb. 1959, A. Boonzaaier leg. (SAMHYM-C019203); Klein Pakhuis, 32.14398 ${ }^{\circ}$ S, 19.05645 E, 506 m a.s.l., 10 Sep. 2009, P. Hawkes and J. Fisher leg. (SAM-HYM-C024390); Cederberg Wilderness Area, Wupperthal, Hiking trail between Sneeukop Hut and Wupperthal site 3, 32.31096 S, 19.17055 E, 934 m a.s.1., 11 Oct. 2002, Fynbos, pitfall trap, A. Botes leg. (SAM-HYM-C024966).

ZAMBIA (4 pinned specimens): Northern Province, Luangwa National Park, $13.1667^{\circ} \mathrm{S}, 31.5^{\circ} \mathrm{E}$, $500 \mathrm{~m}$ a.s.1., hand collected, 1 Jan. 2005, R. van den Elzen leg. (BMNH: CASENT0746318 to CASENT0746321).

Measurements (worker $\mathrm{N}=11$ )

HL 0.934-1.023 (0.987); HW 0.944-1.072 (1.003); SL 0.659-0.747 (0.703); EL 0.216-0.246 (0.237); PH 0.393-0.521 (0.451); PW 0.590-0.669 (0.638); WL 0.924-1.121 (1.015); PSL 0.098-0.157 (0.136); PTH 0.315-0.364 (0.341); PTL 0.275-0.354 (0.325); PTW 0.315-0.374 (0.343); PPH 0.315-0.491 (0.438); PPL 0.246-0.285 (0.267); PPW 0.382-0.457 (0.415); OI 23-25 (24); CI 100-105 (102); SI 66-73 (70); DMI 59-70 (63); LMI 39-52 (45); PSLI 10-16 (14); PeNI 50-57 (54); LPeI 85-100 (95); DPeI 99-114 (106); PpNI 61-70 (65); LPpI 50-80 (62); DPpI 144-186 (156); PPI 115-128 (121). 

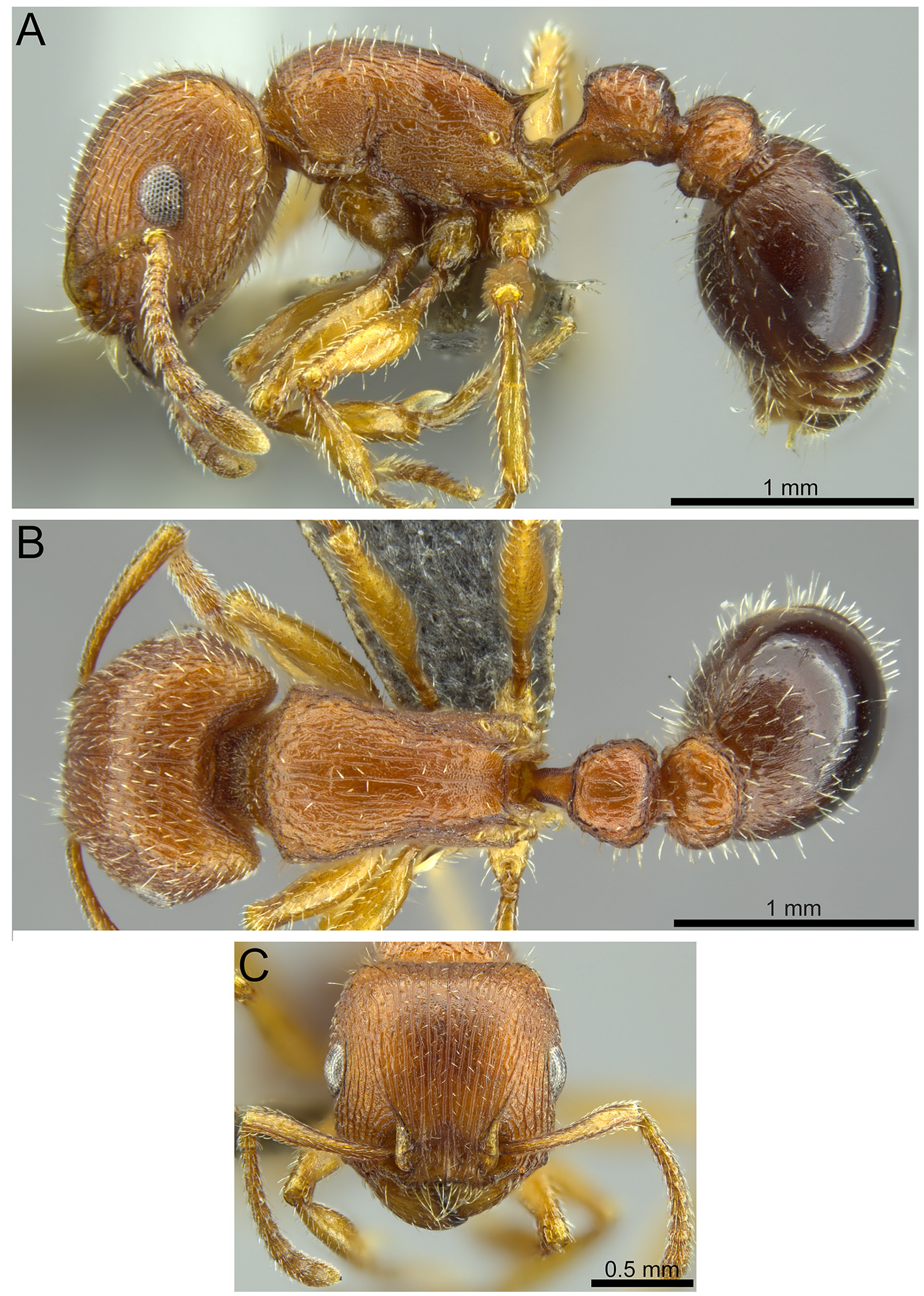

Fig. 9. Tetramorium dichroum Santschi, 1932 (CASENT0746320). A. Body in profile. B. Body in dorsal view. C. Head in full-face view. 


\section{Distribution}

Tetramorium dichroum has been recorded from South Africa (Eastern Cape Province, southern parts of the Free State, Northern Cape and Western Cape Provinces) and Zambia. This species occurs in Drakensberg Montane Grasslands, Kalahari Xeric Savanna, Montane Fynbos and Renosterveld, Nama Karoo, Succulent Karoo, Zambezian and Mopane Woodlands.

Tetramorium duncani Mbanyana, Robertson \& Hita Garcia sp. nov. urn:lsid:zoobank.org:act:6F687F00-D1C3-4DB9-8B3D-A588A1ED5A8F

Figs $3 \mathrm{~N}, 10,24$

\section{Diagnosis}

Morphologically, T. duncani sp. nov. is similar to T. pogonion, T. rufescens and T. signatum, but can be distinguished from these species by the acute angle between the dorsum of the petiole and the posterior face when viewed laterally (Fig. 3N).

\section{Etymology}

Named after Duncan Robertson, who assisted with field work, including photography of ants.

\section{Material examined}

\section{Holotype}

NAMIBIA: worker, Withuis, $11 \mathrm{~km} \mathrm{~N}$ of Grunau on B1, 27 $36.447^{\prime} \mathrm{S}, 18^{\circ} 23.920^{\prime} \mathrm{E}, 1243 \mathrm{~m}$ a.s.l., 3 Apr. 2011, N. Mbanyana and H.G. Robertson leg. (SAM-HYM-C027003).

Paratypes ( 9 pinned workers)

NAMIBIA: Withuis, $11 \mathrm{~km} \mathrm{~N}$ of Grunau on B1, 27 $7^{\circ} 36.447^{\prime} \mathrm{S}$ and $18^{\circ} 23.920^{\prime} \mathrm{E}, 1243 \mathrm{~m}$ a.s.l., 3 Apr. 2011, N. Mbanyana and H.G. Robertson leg. (SAM-HYM-C027003); Withuis, $11 \mathrm{~km} \mathrm{~N}$ of Grunau on B1, 27 $7^{\circ} 36.504^{\prime} \mathrm{S}$ and $18^{\circ} 23.823^{\prime} \mathrm{E}, 1241 \mathrm{~m}$ a.s.l., 2 Apr. 2011, N. Mbanyana and H.G. Robertson leg.

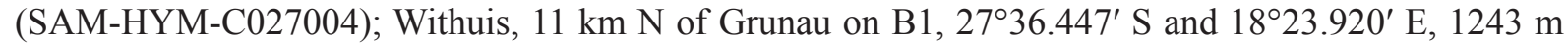
a.s.l., 3 Apr. 2011, N. Mbanyana and H.G. Robertson leg. (SAM-HYM-C027010); Kyffhauser, $24^{\circ} 28.708^{\prime} \mathrm{S}$ and $16^{\circ} 20.148^{\prime} \mathrm{E}, 1381 \mathrm{~m}$ a.s.1., 6 Apr. 2011, N. Mbanyana and H.G. Robertson leg.

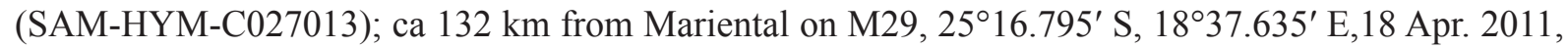
N. Mbanyana and H.G. Robertson leg. (SAM-HYM-C027001).

\section{Other material}

SOUTH AFRICA (2 pinned specimens): Northern Cape: Breekkierie dunes, 30 $07^{\prime} \mathrm{S}, 21^{\circ} 33^{\prime} \mathrm{E}$, 4 May 1985, M.A. Macpherson leg. (SAM-HYM-C001771); Kortkop farm near Strydenburg, $30^{\circ} 09^{\prime}$ S, $23^{\circ} 44^{\prime}$ E, 17 Jun. 1995, B. Chambers leg. (SAM-HYM-C008763).

\section{Measurements (worker $\mathrm{N}=5$ )}

HL 1.033-1.266 (1.132); HW 1.033-1.266 (1.116); SL 0.723-0.865 (0.798); EL 0.297-0.362 (0.320); PH 0.374-0.482 (0.452); PW 0.672-0.840 (0.716); WL 1.072-1.382 (1.168); PSL 0.148-0.187 (0.163); PTH 0.325-0.433 (0.358); PTL 0.297-0.336 (0.318); PTW 0.323-0.413 (0.364); PPH 0.465-0.607 (0.519); PPL 0.284-0.336 (0.310); PPW 0.413-0.555 (0.475); OI 27-31 (29); CI 97-100 (99); SI 68-75 (71); DMI 59-63 (61); LMI 35-44 (39); PSLI 12-17 (15); PeNI 48-54 (51); LPeI 78-96 (89); DPeI 104-123 (115); PpNI 62-69 (66); LPpI 54-68 (60); DPpI 139-168 (153); PPI 128-134 (130).

\section{Description}

Holotype (worker)

Mandibles with fine longitudinal striations. Anterior clypeal margin with conspicuous, semicircular indentation. Frontal carinae fading out before reaching back of posterior eye margin. Eyes with 16 

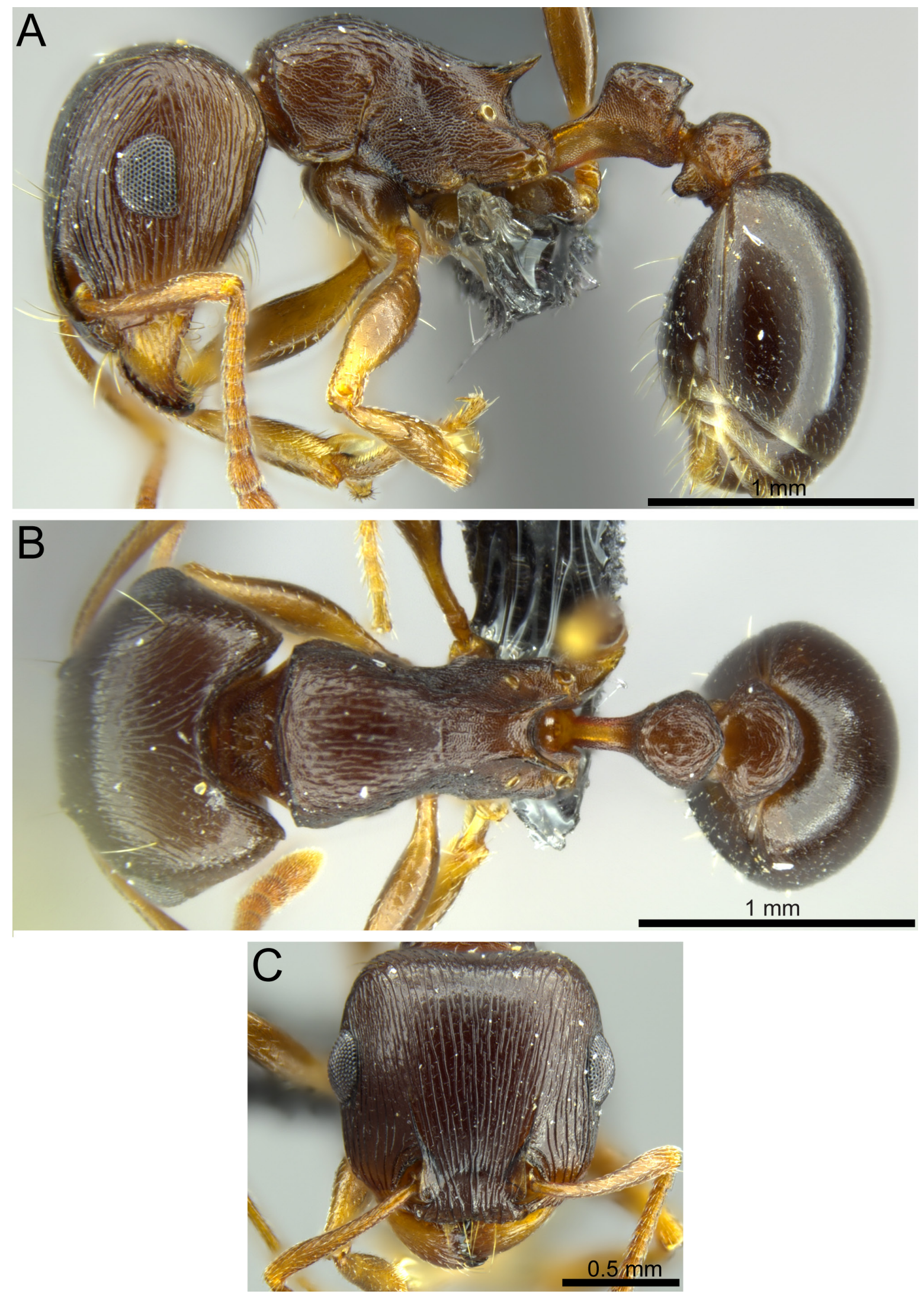

Fig. 10. Tetramorium duncani Mbanyana, Robertson \& Hita Garcia sp. nov. (SAM-HYM-C027003). A. Body in profile. B. Body in dorsal view. C. Head in full-face view. 
ommatidia in longest row. Propodeum armed with pair of long spines (PSLI 12-17). Metapleural lobes low, rounded. Peduncle lacking subpetiolar process. Petiolar node in profile nodiform, with anterior face rounding onto dorsum and dorsum forming acute angle with posterior face. Postpetiolar node low and rounded. Dorsal surfaces of head with longitudinal striations, spaces between them with superficial ground sculpture. Dorsum of mesosoma with short longitudinal striations, with shiny superficial ground sculpture in between them. Petiolar and postpetiolar nodes with fine reticulate sculpture overlain by few irregular striations. Gastral tergite with fine, superficial reticulate pattern. Dorsum of head with four long erect pairs of hairs. Ventral surface of head with strongly developed psammophore. Remaining dorsum of the body without any standing hairs. Colour blackish brown.

\section{Distribution}

Known from Namibia and South Africa (Northern Cape), where these specimens were collected from Namibian Savanna Woodlands and Kalahari Xeric Savanna. Specimens collected by hand (including in nets) and from pitfall traps.

Tetramorium galoasanum Santschi, 1910

Figs 2E, 11

Tetramorium setuliferum var. galaosana Santschi, 1910: 381.

\section{Diagnosis}

T. galoasanum, T. clunum and T. setuliferum are the only species in the Tetramorium solidum group with appressed silvery hairs covering the entire body (Fig. 2E). The appressed silvery hairs are denser in T. galoasanum than in the other two species.

\section{Material examined}

Syntypes

REPUBLIC OF CONGO: Brazzaville, M'Bounion, Mindouga, Comba-Ibre, Aug. 1908, Weiss leg. (NHMB: CASENT0915015; RMCA: RMCAENT000017787; MCZC (not examined); BMNH: CASENT0901178).

\section{Distribution}

Only known from Congo.

Tetramorium glabratum Stitz, 1923

Figs 2G, 3F, H, L, O, 4B, 12, 24

Tetramorium solidum st. glabratum Stitz, 1923: 162 (included in Bolton 1980: 246).

Tetramorium solidum race glabratum var. aciculatum Stitz, 1923: 162.

Tetramorium rutilum Prins, 1973: 14 (included in Bolton 1980: 246).

\section{Diagnosis}

Tetramorium glabratum is similar to T. rufescens. They both lack pilosity on the dorsum of the mesosoma and on the first gastral tergite and are both reddish coloured. Tetramorium glabratum can be distinguished from the latter by the short and broad propodeal spines (PSLI 4-8) (3H), which are long and narrow in T. rufescens (PSLI 16-23) (Fig. 3I).

\section{Unexamined type material}

NAMIBIA: holotype of Tetramorium solidum st. glabratum Stitz, 1923, worker: Karibib, 23-26 Apr. 1911, W. Michaelsen leg. (ZMHB: FOCOL2085); holotype of Tetramorium solidum race glabratum var. 

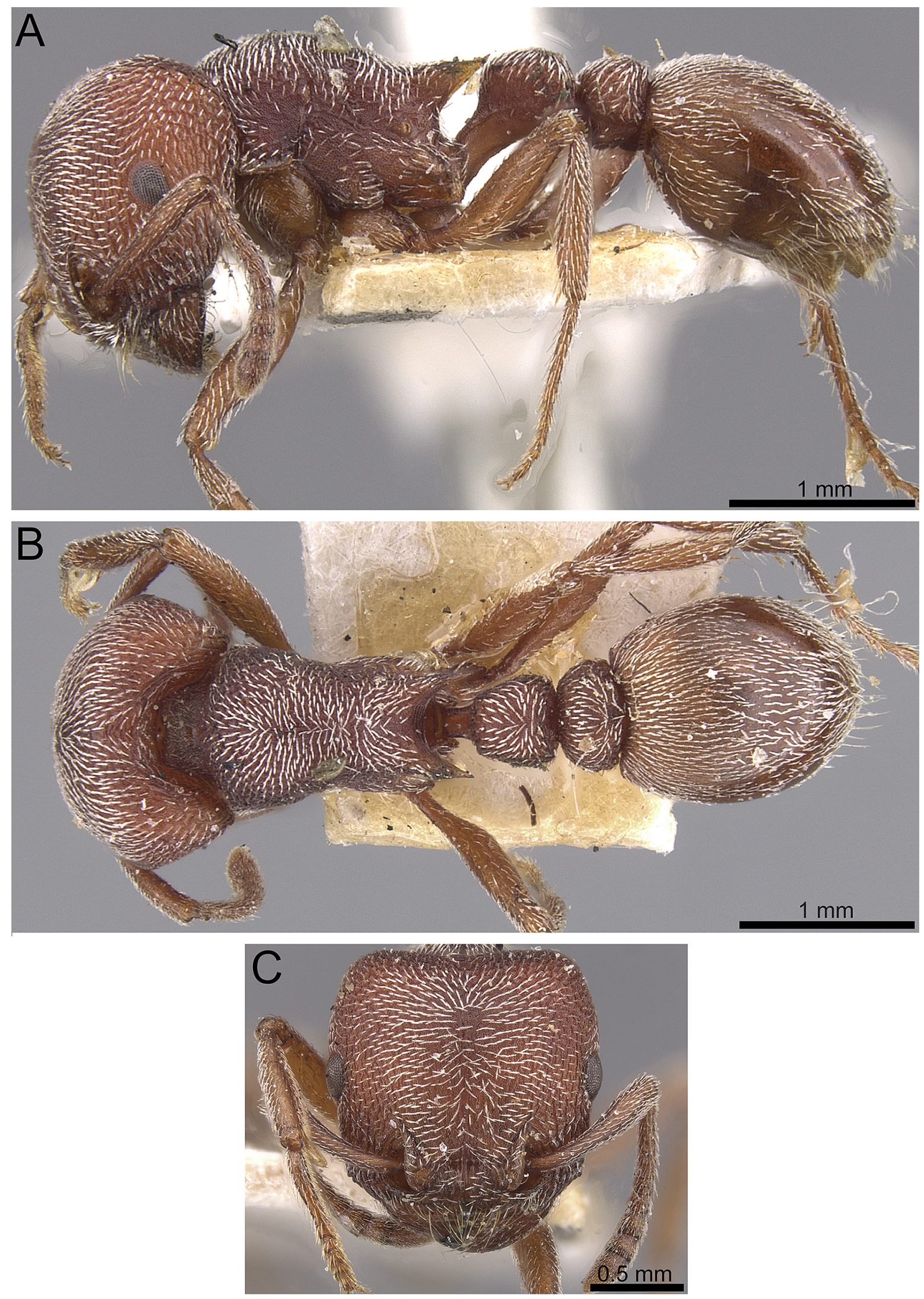

Fig. 11. Tetramorium galoasanum Santschi, 1910 (RMCAENT000017787 - Antweb, Will Ericson). A. Body in profile. B. Body in dorsal view. C. Head in full-face view. 

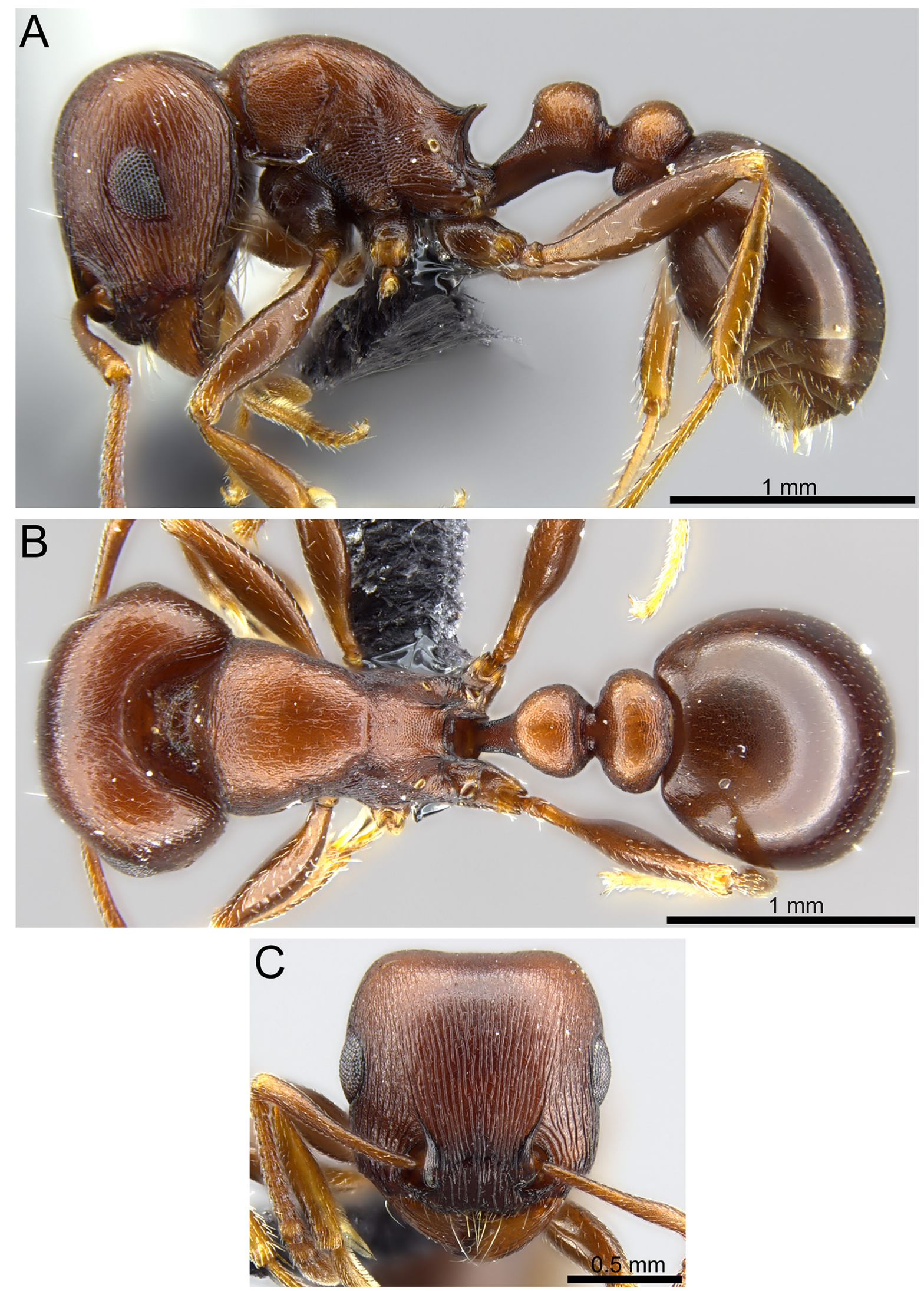

Fig. 12. Tetramorium glabratum Stitz, 1923 (SAM-HYM-C024395). A. Body in profile. B. Body in dorsal view. C. Head in full-face view. 
aciculatum Stitz, 1923: worker, Lüderitzbucht, 5-13 Jul. 1911, W. Michaelsen leg. (types not in ZMHB, presumably lost).

\section{Material examined}

Type material

SOUTH AFRICA: syntypes of Tetramorium rutilum Prins, 1973: 8 pinned workers, 1 pinned 9 , Western Cape, Van Rhynsdorp, 19 Apr. 1963, J.J. Cillie leg. (SAM-ENT-0011750).

\section{Other material}

SOUTH AFRICA (24 pinned specimens): Western Cape: Klawer, 19 Apr. 1963, A.J. Prins leg. (SAMHYM-C019335); Bitterfontein, 9 Oct. 1959, A.J. Prins leg. (SAM-HYM-C019341); Kleinsee, 29 S, $17^{\circ}$ E, 12 Jul. 1995, M. Jones leg. (SAM-HYM-C024395); BPB Gypsum, 31³3.6' S, $18^{\circ} 45.2^{\prime}$ E, 8 Nov. 2000, pitfall traps, A. Schmidt leg. (SAM-HYM-C023291). - Northern Cape: Okiep, 21 Apr. 1963, A.J. Prins leg. (SAM-HYM-C019337); Garies, 6 Oct. 1959, A.J. Prins leg. (SAM-HYM-C019338); Port Nolloth, 7 Oct. 1959, A.J. Prins leg. (SAM-HYM-C019339); Springfontein, 8 Oct. 1969, A.J. Prins leg. (SAM-HYM-C019340); Port Nolloth, 7 Oct. 1959, A.J. Prins leg. (SAM-HYM-C019174, SAMHYM-C019175); Port Nolloth, May 1986, A.J. Prins leg. (SAM-HYM-C019193).

NAMIBIA (5 pinned specimens): Diamond area, $28.3833^{\circ} \mathrm{S}, 16.31667^{\circ}$ E, 29 Sep. 1994, E. Marais leg.;

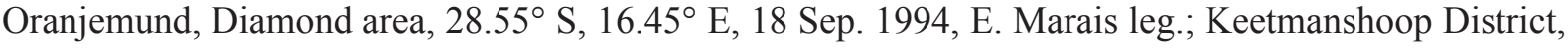
Khabus $146,26^{\circ} 18^{\prime} \mathrm{S}, 18^{\circ} 13^{\prime}$ E, on sandy plain next riverbed, 14 Apr.-30 Jun. 1988, N. and G. Olivier leg.

\section{Measurements (worker $\mathrm{N}=7$ )}

HL 1.042-1.141 (1.065); HW 1.031-1.092 (1.065) SL 0.757-0.836 (0.800); EL 0.295-0.315 (0.304); PH 0.462-0.531 (0.504); PW 0.667-0.738 (0.705); WL 1.033-1.239 (1.105); PSL 0.049-0.489 (0.060); PTH 0.344-0.374 (0.357); PTL 0.266-0.305 (0.290); PTW 0.315-0.384 (0.359); PPH 0.384-0.433 (0.410); PPL 0.246-0.275 (0.259); PPW 0.423-0.482 (0.452); OI 28-29 (29); CI 95-100 (97); SI 73-78 (75); DMI 57-71 (64); LMI 40-50 (46); PSLI 4-8 (5); PeNI 44-55 (51); LPeI 73-89 (81) DPeI 108-131 (124); PpNI 58-69 (64); LPpI 59-68 (63); DPpI 165-186 (174); PPI 120-141 (126).

\section{Distribution}

This species is known from South Africa and Namibia. It has been collected from the Nama Karoo, Succulent Karoo and Namib Desert.

\section{Remarks}

A detailed description of this species is given in Bolton 1980.

\section{Tetramorium grandinode Santschi, 1913}

Figs $3 \mathrm{C}, 13,24$

Tetramorium grandinode Santschi, 1913: 308 (included in Bolton 1980: 247).

Tetramorium grandinode var. hopensis Forel, 1914: 223 (included in Bolton 1980: 247).

\section{Diagnosis}

The remarkable lateral extensions of both petiolar and postpetiolar nodes (Fig. 3C) distinguish $T$. grandinode from all other species in the T. solidum group. This species has superficial similarities with $T$. duncani sp. nov. in that $T$. duncani sp. nov. also has a broader postpetiole, but to a much lesser extent (DPpI 104-123) compared to T. grandinode (DPpI 184-322). Moreover, T. grandinode has a 
much broader petiole node when viewed dorsally compared to $T$. duncani sp. nov. Additionally, these two species can be separated on the basis of the mesosoma sculpture: in $T$. grandinode, the dorsal surface has fine longitudinal rugulae and a glossy appearance in between, whereas in $T$. duncani sp. nov. it has a reticulate ground sculpture overlain by short fine longitudinal striations.

\section{Material examined}

\section{Type material}

SOUTH AFRICA: syntype of Tetramorium grandinode Santschi, 1913: worker, Western Cape, Cape Colony (NHMB: CASENT0915017); syntype of Tetramorium grandinode var. hopensis Forel, 1914, worker, Northern Cape, Orange River, Hope Town (MNHG: CASENT0909135).

\section{Other material}

SOUTH AFRICA(98 pinned specimens): Northern Cape: Goegap Nature Reserve, Jul. 1986, U. Kruger leg. (SAM-HYM-C013306); Tankwa Karoo National Park, 32.17430 S, 19.97382' E, 602 m a.s.l., 9 Jan. 2009, N. Mbanyana and H.G. Robertson leg. (SAM-HYM-C023302); Road between Karsten Farms and Goodhouse, Klein Pella, 29.02700 ${ }^{\circ}$ S, $18.99008^{\circ}$ E, $621 \mathrm{~m}$ a.s.l., Plein Gariep desert, deep soils without gravel, Euphorbia present, 16 Dec. 2007, N. Mbanyana and H.G. Robertson leg. (SAMHYM-C019900). - Western Cape: Prince Albert, Farm Argentina, 33.165444ㅇ S, $22.2595^{\circ}$ E, $745 \mathrm{~m}$ a.s.1., 3 Mar. 2007, Succulent Karoo, pitfall trap, Iimbovane Outreach Project, B. Braschler leg. (SAMHYM-C024969); Abrahamskraal, 32.93011 $\mathrm{S}, 22.00949^{\circ} \mathrm{E}, 522 \mathrm{~m}$ a.s.1., 12 Apr. 2008, rocky ridges, with sparsely distributed shrubs including Lycium, shallow soils, N. Mbanyana and H.G. Robertson leg. (SAM-HYM-C020349); Vêrgenoeg, 33.24421ํ S, 21.47939, 10 Apr. 2008, Koedoesberge-Moordenaars Karoo, N. Mbanyana and H.G. Robertson leg. (SAM-HYM-C020425); Vêrgenoeg, 33.24467 ${ }^{\circ}$ S, $21.47597^{\circ}$ E, 10 Apr. 2008, Koedoesberge-Moordenaars Karoo, east-facing rocky slope, N. Mbanyana and H.G. Robertson leg. (SAM-HYM-C020434); Josephskraal, 33.04287 $\mathrm{S}, 20.71934^{\circ} \mathrm{E}, 900 \mathrm{~m}$ a.s.1., 16 Apr. 2008, Koedoesberge-Moordenaars Karoo, Karoo plain slightly N-facing, N. Mbanyana and H.G. Robertson leg. (SAM-HYM-C020482).

NAMIBIA (42 pinned specimens): Navachab 67, Karibib District, SE 2715 Ba, Mar.-24 Apr. 1988, pitfall traps, S. Schubert leg.; Rotkop, Diamond Area 1, 26 $42^{\prime}$ S, $15^{\circ} 23^{\prime}$ E, 12-26 Nov. 1993, pitfall trap, E. Marais leg.; Klein Aus 10, Luderitz District, $26^{\circ} 38^{\prime}$ S, $16^{\circ} 10^{\prime}$ E, 12-26 Nov. 1993, pitfall trap, E. Marais leg.; Khabus 146, Keetmanshoop District, $26^{\circ} 18^{\prime} \mathrm{S}, 18^{\circ} 13^{\prime} \mathrm{E}$, sandy plain next to dry riverbed,

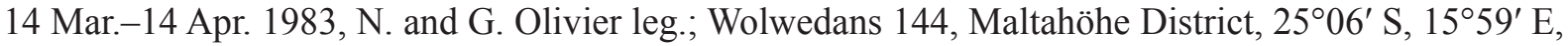

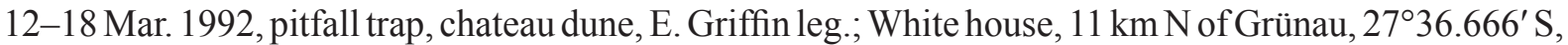
$18^{\circ} 23.726^{\prime} \mathrm{E}, 1241 \mathrm{~m}$ a.s.1., nest in rocky soil with crater of soil around the entrance, 2 Apr. 2011, N. Mbanyana and H.G. Robertson leg. (SAM-HYM-C026796); Klein-Aus Vista, 26 $6^{\circ} 39.143^{\prime}$ S, $16^{\circ} 14.546^{\prime} \mathrm{E}, 1316 \mathrm{~m}$ a.s.l., nest in rocky sandy soil, two entrances at opposite sides of grass tuft, $4 \mathrm{Apr}$. 2011 (SAM-HYM-C026794); 59 km from Mariental on M29, 2450.592' S, 18 17.173' E, 18 Apr. 2011, nest in rocky soil with rounded pebbles and red sandy soil, found under rock and excavated to a depth of $20 \mathrm{~cm}$ (SAM-HYM-C026793); Namib Desert, Ganab, G34, 25.1 ${ }^{\circ} \mathrm{S}, 15.66^{\circ} \mathrm{E}$, collected at the edge of sandy dry river bed, 18 May 1981, A.C. Marsh leg. ( BMNH: CASENT0764655); Luderitz, 1 Sep. 2003, A. Andersen leg. (BMNH: CASENT0248477).

\section{Measurements (worker $\mathrm{N}=26$ )}

HL 1.003-1.229 (1.122); HW 0.962-1.229 (1.095); SL 0.757-0.885 (0.816); EL 0.248-0.354 (0.301); PH 0.462-0.679 (0.528); PW 0.669-0.856 (0.743); WL 0.915-1.377 (1.189); PSL 0.197-0.275 (0.240); PTH 0.374-0.521 (0.431); PTL 0.246-0.344 (0.297); PTW 0.384-0.659 (0.523); PPH 0.384-0.570 (0.450); PPL 0.207-0.315 (0.255); PPW 0.482-0.875 (0.652); OI 27-29 (27); CI 95-102 (98); SI 68180 (75); DMI 59-79 (63); LMI 39-54 (44); PSLI 19-24 (21); PeNI 56-83 (70); LPeI 58-85 (70); DPeI 130-212 (177); PpNI 68-110 (87); LPpI 45-73 (57); DPpI 184-322 (257); PPI 118-134 (124). 

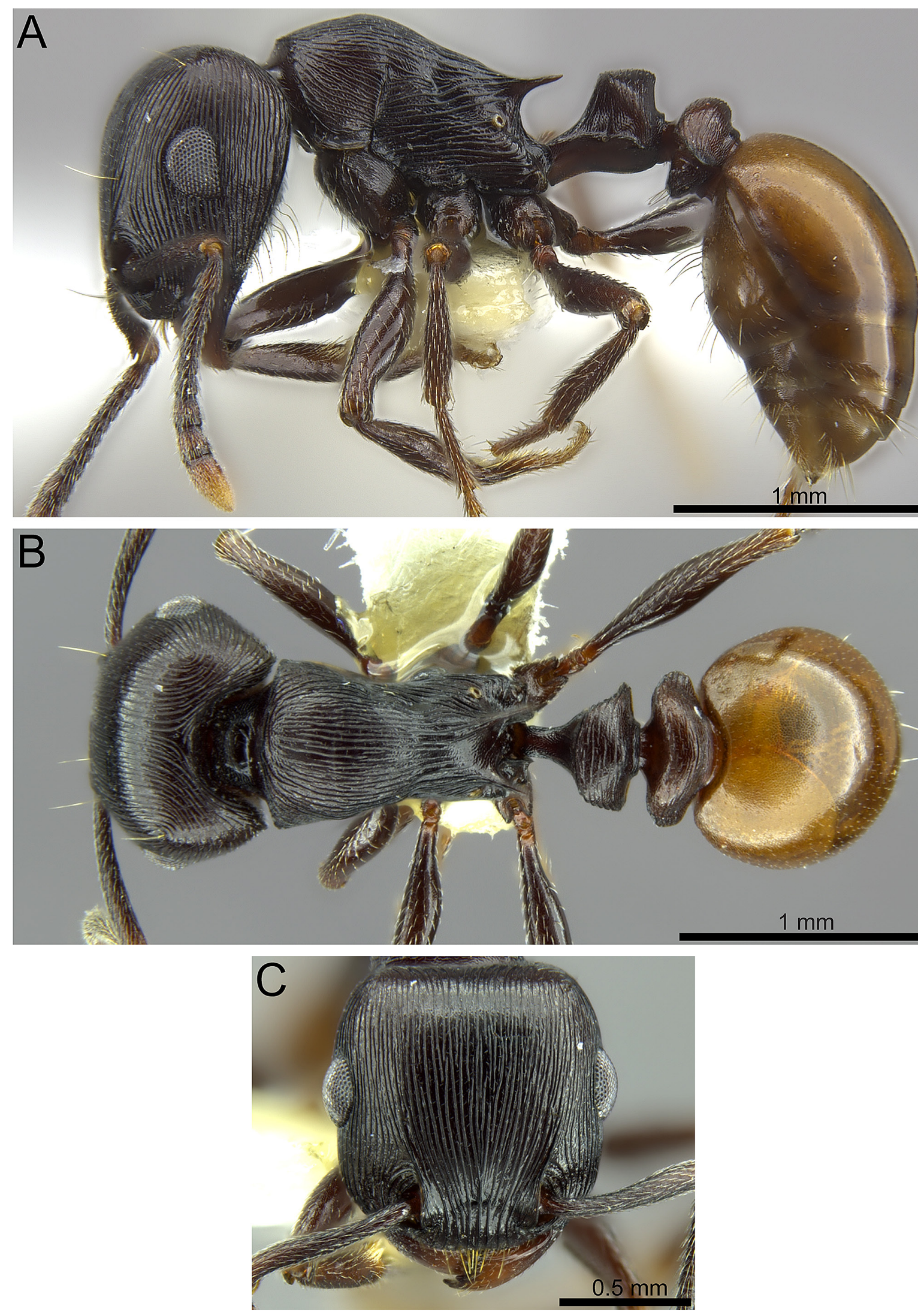

Fig. 13. Tetramorium grandinode Santschi, 1913 (CASENT0764655). A. Body in profile. B. Body in dorsal view. C. Head in full-face view. 


\section{Distribution}

Tetramorium grandinode is known to occur in South Africa (Northern Cape, Western Cape) and Namibia, where it has been collected in the Kalahari Xeric Savanna, Nama Karoo, Succulent Karoo, Namibian Savanna Woodlands and Namib Desert.

\section{Remarks}

This species has been recorded nesting in deep soil on a flood plain. Specimens of $T$. grandinode have been collected from pitfall traps, tuna baits, sugar baits and cookie bait.

\section{Tetramorium jordani Santschi, 1937}

Figs $3 \mathrm{G}, 14,24$

Tetramorium jordani Santschi, 1937: 62.

Tetramorium aspinatum Prins, 1973: 12 (included in Bolton 1980: 248).

\section{Diagnosis}

Tetramorium jordani is the only species in the Tetramorium solidum group with the combination of no propodeal spines (the propodeum is only angulated with PSLI 1-3) and a hairless body (Fig. 3G). The only other species without propodeal spines is T. brigitteae sp. nov., which has erect hairs covering the entire body.

\section{Material examined}

Type material

NAMIBIA: 2 syntypes of Tetramorium jordan Santschi, 1937: W of Maltahohe, 1500 m a.s.1., 12 Dec. 1933, K. Jordan leg. (BMNH: CASENT0901180; NHMB: CASENT0915021).

SOUTH AFRICA: syntypes of Tetramorium aspinatum Prins, 1973, 8 pinned workers, Northern Cape, Port Nolloth, 20 Apr. 1963, J.J. Cillie leg. (SAM-ENT0011753).

\section{Other material}

SOUTH AFRICA (112 pinned workers): Northern Cape: Rondabel 542 (Farm), 30 $50^{\prime} \mathrm{S}, 1^{\circ} 45^{\prime} \mathrm{E}$, 4 Sep. 1996, on vegetated red dunes, V.B. Whitehead leg. (SAM-HYM-C008958); Rietfontein bos, 23 Apr. 1963 (SAM-HYM-C019259); Calvinia, 24 Apr. 1963 (SAM-HYM-C019261); Springbok, 20 Apr. 1963, A.J. Prins leg. (SAM-HYM-C019260); Van Rhynsdorp, 5 May 1959, A.J. Prins leg. (SAM-HYM-C019262); Clanwilliam, 4 Jan. 1962, A.J. Prins leg. (SAM-HYM-C019265); Nardou Pass, 4 Jan. 1960, A.J. Prins leg. (SAM-HYM-C019266); Kamieskroon, 6 Oct. 1959, A.J. Prins leg.

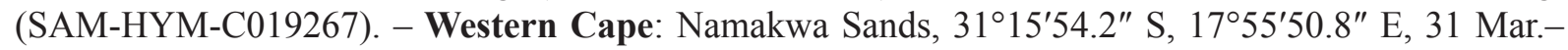
4 Apr. 2003, pitfall trap, minespoil, Strandveld, N. Netshilaphala leg. (SAM-HYM-C018132); West Coast Fossil Park (4 km $270^{\circ} \mathrm{W}$ of Langebaanweg), 32 $2^{\circ} 58.444^{\prime} \mathrm{S}, 18^{\circ} 06.731^{\prime} \mathrm{E}$, 4-11 Sep. 2002, pitfall trap, Sand Plain Fynbos dominated by Lebeckia, S. van Noort, D. Larsen and E. Bartnick leg. (SAMHYM-C018894); West Coast Fossil Park (5.5 km 290 ${ }^{\circ}$ E of Langebaanweg), 32 ${ }^{\circ} 57.51^{\prime} \mathrm{S}, 18^{\circ} 06.728^{\prime} \mathrm{E}$, 4-11 Sep. 2002, pitfall trap, rehabilitated mine dump, S. van Noort, D. Larsen and E. Bartnick leg. (SAMHYM-C018895); West Coast Fossil Park (3 km $280^{\circ} \mathrm{W}$ of Langebaanweg), $32^{\circ} 58.020^{\prime} \mathrm{S}, 1^{\circ} 07.285^{\prime} \mathrm{E}$, 4-11 Sep. 2002, pitfall trap, rehabilitated mine dump, S. van Noort, D. Larsen and E. Bartnick leg. (SAM-HYM-C0188900); foragers, 16 mi. from Clanwilliam near Calvinia, 5 Jan. 1962, J.J. Cillie leg. (SAM-HYM-C015544); Petersfield, Citrusdal, 6 Mar. 1969, A.J. Prins leg. (SAM-HYM-C018314); Clanwilliam, Farm Sawadee, $32.3388^{\circ}$ S, $18.987817^{\circ}$ E, $332 \mathrm{~m}$ a.s.1., Fynbos, pitfall trap, A. Botes leg. (SAM-HYM-C024971). 

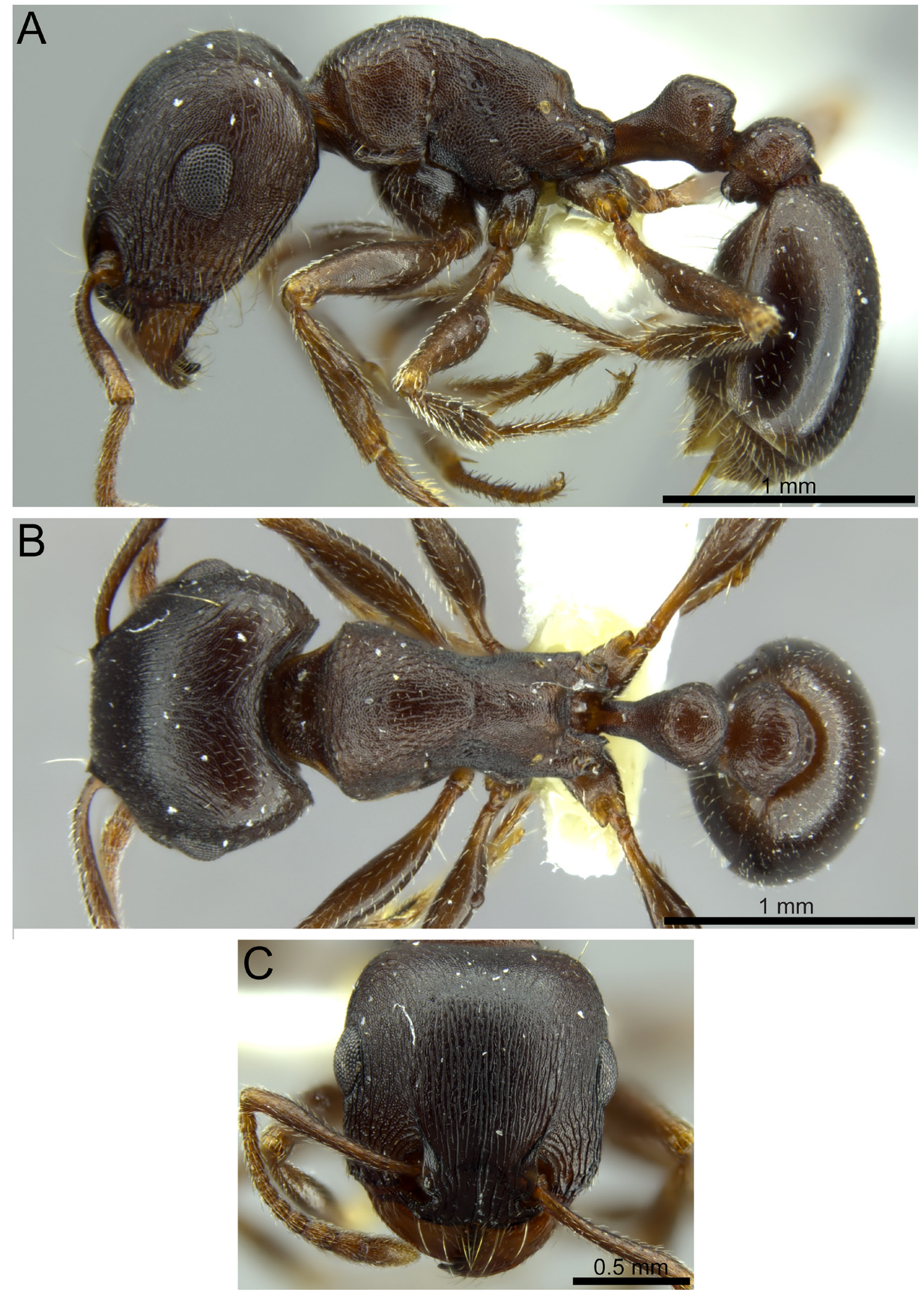

Fig. 14. Tetramorium jordani Santschi, 1937 (CASENT0248475). A. Body in profile. B. Body in dorsal view. C. Head in full-face view. 
NAMIBIA: Namib Naukluft National Park, Big Slip Face, 23.39 S, $15.20^{\circ}$ E, 11 Sep. 1987, collected from nest, H.G. Robertson leg. (SAM-HYM-C000509); Namib Naukluft Khomabes, 23.33 ${ }^{\circ}$ S, $14.59^{\circ}$ E, 11 Sep. 1987, collected from nest, H.G. Robertson leg. (SAM-HYM-C000498); Fish River Canyon, 1 Sep. 1998, A. Chapman leg. (BMNH: CASENT248475).

Measurements (worker $\mathrm{N}=13$ )

HL 0.974-1.135 (1.071); HW 0.915-1.121 (1.064); SL 0.777-0.846 (0.795); EL 0.256-0.295 (0.266); PH 0.364-0.492 (0.453); PW 0.593-0.734 (0.673); WL 1.072-1.170 (1.158); PSL 0.010-0.030 (0.017); PTH 0.305-0.364 (0.340); PTL 0.285-0.334 (0.306); PTW 0.305-0.388 (0.342); PPH 0.452-0.555 (0.490); PPL 0.256-0.319 (0.289); PPW 0.416-0.492 (0.460); OI 23-28 (25); CI 94-109 (99); SI 69-85 (75); DMI 47-65 (58); LMI 32-44 (39); PSLI 1-3 (2); PeNI 48-56 (51); LPeI 85-94 (90); DPeI 104123 (112); PpNI 62-75 (68); LPpI 55-63 (59); DPpI 136-177 (159); PPI 122-150 (135).

\section{Distribution}

This species has been recorded from arid regions of South Africa (Western Cape and Northern Cape) and Namibia in the following habitats: Succulent Karoo, Namib Desert, Lowland Fynbos and Renosterveld, Montane Fynbos and Renosterveld and Nama Karoo.

\section{Remarks}

Tetramorium jordani nests in sandy soils, with nests located either at the base of plants or with the entrance in the open, away from plants. The nest usually has a crater of soil around the entrance. In sand dunes of the Namib Desert, the tunnels inside the nest have crust-like walls to stop sand from falling in, and the entrance of one nest observed was funnel shaped due to the crust-like lining and the fact that the loose sand around the entrance was blown away by the wind. The species has been collected using yellow pan traps, pitfall traps and hand collecting. Tetramorium jordani feeds on seeds.

Tetramorium lerouxi Mbanyana, Robertson \& Hita Garcia sp. nov. urn:Isid:zoobank.org:act:A9FED9EF-D2F9-43FE-9A9B-20026D908BBF

Figs 3D, 15, 24

\section{Diagnosis}

Tetramorium lerouxi sp. nov. is distinguished from all other species of the T. solidum group by its unique petiolar node, which has posterior, lateral, rounded extentions; in posterior view, the dorsal margin is straight and angulate with respect to the lateral margin (Fig. 3D).

\section{Etymology}

Named after Dr Jaco Le Roux who supervised and helped with molecular genetic work on the T. solidum group, which helped to confirm the validity of this species.

\section{Material examined}

\section{Holotype}

SOUTH AFRICA: Northern Cape: worker, Melton Wold, 31.46741 ${ }^{\circ}$ S, $22.721550^{\circ}$ E, $1333 \mathrm{~m}$ a.s.l., 7 Jan. 2009, N. Mbanyana and H.G. Robertson leg. (SAM-HYM-C023330).

\section{Paratypes}

SOUTH AFRICA: 2 pinned workers, same collection data as for holotype (SAM-HYM-C023329).

\section{Other material}

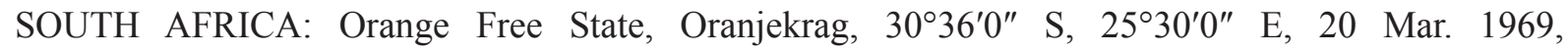
A.A. Boonzaaier leg. (AM-HYM-C015315). 

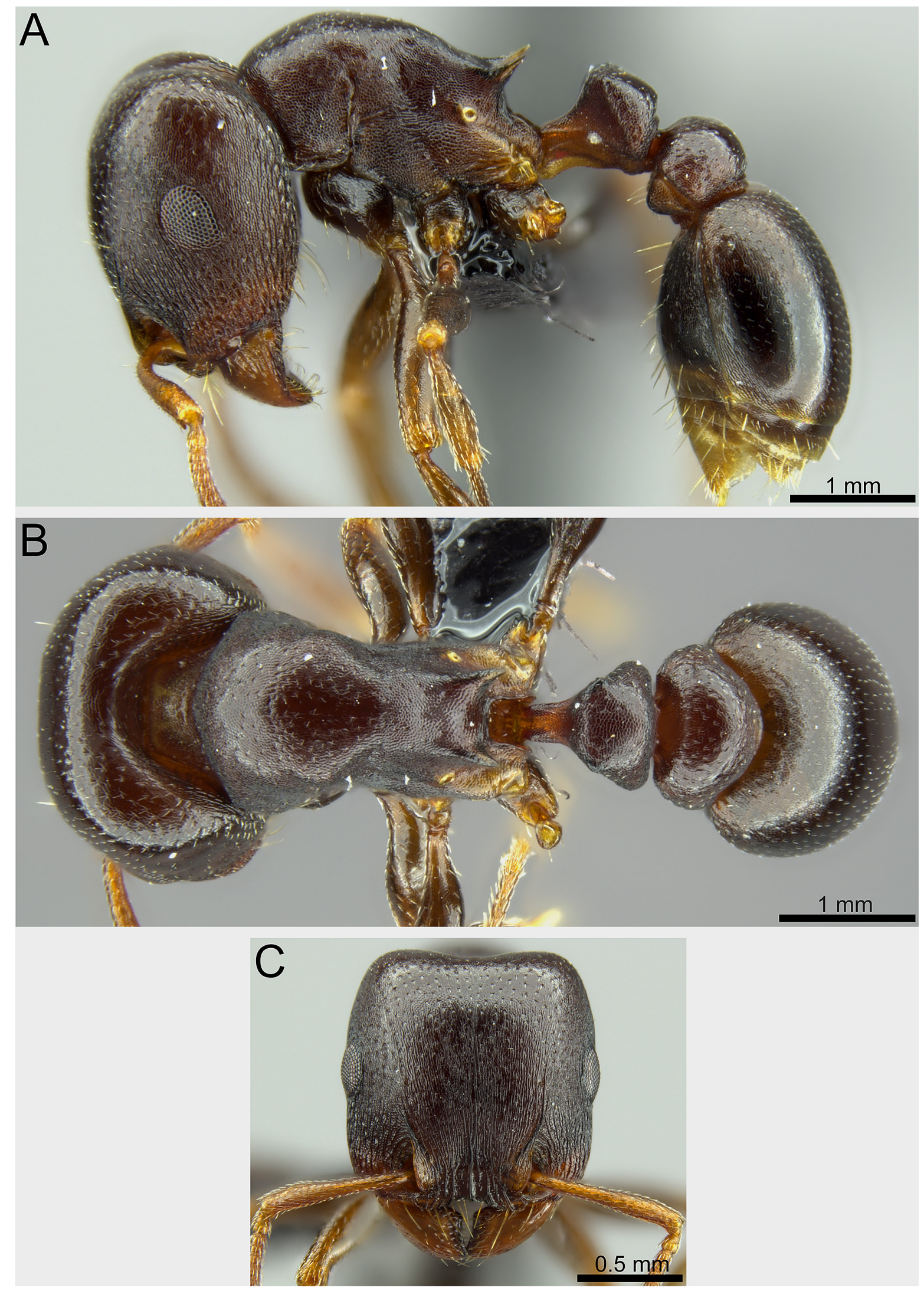

Fig. 15. Tetramorium lerouxi Mbanyana, Robertson \& Hita Garcia sp. nov. (SAM-HYM-C027003). A. Body in profile. B. Body in dorsal view. C. Head in full-face view. 
Measurements (worker $\mathrm{N}=2$ )

HL 1.080-1.151 (1.115); HW 1.151-1.210 (1.180); SL 0.767-0.738 (0.752); EL 0.275-0.285 (0.280); PH 0.570-0.580 (0.575); PW 0.713-0.767 (0.740); WL 1.180-1.190 (1.185); PSL 0.207-0.216 (0.211); PTH 0.452-0.462 (0.457); PTL 0.295-0.299 (0.297); PTW 0.446-0.482 (0.464); PPH 0.443-0.452 (0.447); PPL 0.334-0.354 (0.344); PPW 0.572-0.600 (0.586); OI 24 (24); CI 105-107 (106); SI 61-67 (64); DMI 60-65 (62); LMI 48-49 (49); PSLI 18-20 (19); PeNI 63 (63); LPeI 65 (65); DPeI 149-163 (156); PpNI 78-80 (79); LPpI 74-80 (77); DPpI 162-179 (171); PPI 124-128 (126).

\section{Description}

\section{Holotype (worker)}

Mandibles predominantly smooth with fine striations basally. Anterior clypeal margin with extensive and deep indentation. Frontal carinae absent. Eyes with 15 ommatidia in longest row. Propodeal spines long and acute (PSLI 18-20). Metapleural lobes low and rounded. Peduncle with broad keel-shaped subpetiolar process. Petiole in profile nodiform, with anterior face slightly more steeply angled with blunt corners. In dorsal view, petiolar node shaped almost rectangular broadening posteriorly with rounded corners and narrowing anteriorly with prominent blunt corners (Fig. 3D). Postpetiole low and rounded both in dorsal view and in profile. Dorsum of head with fine longitudinal striations. Spaces between striations with very fine reticulate ground sculpture. Dorsal surfaces of mesosoma and petiole with fine reticulate sculpture. Postpetiolar node predominantly smooth, with fine reticulate sculpture in places. Gastral tergite with fine reticulate sculpture. Numerous hairs on anterior clypeal margin. Dorsum of head with two pairs of erect hairs. Dorsum of mesosoma, nodes and first gastral tergite without any erect hairs, with only sparse white pubescence. Ventral surface of head with psammophore. Colour uniformly black.

\section{Distribution}

This species is only known from South Africa, where it has been collected in Melton Wold near Victoria West in the Northern Cape and from Oranjekrag in the Free State.

Tetramorium margueriteae Mbanyana, Robertson \& Hita Garcia sp. nov. urn:1sid:zoobank.org:act:6E9371F8-EEC3-4487-8333-BB6CCEE01932

Figs 4F, H, 16, 24

\section{Diagnosis}

Morphologically, T. margueriteae sp. nov. is similar to T. peringueyi, T. dichroum and T. brigitteae sp. nov. in that, these are the only species in the solidum group with erect simple hairs covering the entire body. This species can be separated from T. peringueyi on the basis of colour and the pattern of the sculpture on the mesosoma. Tetramorium margueriteae sp. nov. is black in colour, whereas T. peringueyi is orange to light brown. In T. peringueyi, the dorsal surface of the mesosoma has a strongly developed irregular reticulate sculpture (Fig. 4E), whereas in T. margueriteae sp. nov. the dorsum of the mesosoma has short longitudinal rugulae, and the ground sculpture is mainly smooth and shiny, with peripheral patches of fine, superficial reticulations (Fig. 4F). Tetramorium margueriteae sp. nov. is separated from both $T$. dichroum and T. brigitteae sp. nov. by the presence of erect hairs on the antennal scapes.

\section{Etymology}

Named after Marguerite Blignaut who helped with molecular lab work on the T. solidum group. 


\section{Material examined}

Holotype

SOUTH AFRICA: Northern Cape: worker, Klein Pella, road between Karsten Farms and Goodhouse, Kokerboom site, $29.06211^{\circ}$ S, $18.97985^{\circ}$ E, 832 m a.s.1., Gariep Rocky Desert with Kokerboom and Euphorbia, 16 Dec. 2007, N. Mbanyana and H.G. Robertson leg. (SAM-HYM-C019829).

\section{Paratypes}

SOUTH AFRICA: Northern Cape: 24 pinned workers, same collection data as for holotype (SAMHYM-C019827, SAM-HYM-C019836, SAM-HYM-C019838, SAM-HYM-C019839).

\section{Other material}

SOUTH AFRICA (37 pinned workers): Western Cape: Tierberg, near Prince Albert, $33^{\circ} 10^{\prime} \mathrm{S}, 22^{\circ} 16^{\prime} \mathrm{E}$, 14 Feb. 1995, H. Adie leg. (SAM-HYM-C008443); 6 km from Prince Albert on Leeu Gamka Road, $33^{\circ} 09^{\prime} \mathrm{S}, 22^{\circ} 02^{\prime} \mathrm{E}, 10-19$ Oct. 1996, T.E. Tshiguvho leg. (SAM-HYM-C009333); $27 \mathrm{~km}$ from Prince

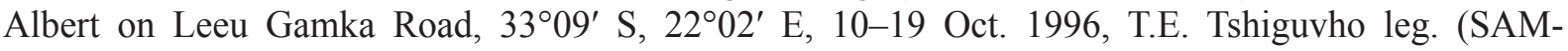
HYM-C009334). - Eastern Cape: Kudu Reserve at Great Fish River, 3307'42" S, 2641'32" E, 25-30 Apr. 2005, grassland, T. Jordan leg. (SAM-HYM-C018977). - Northern Cape: Kortkop farm, Strydenburg, $30^{\circ} 09^{\prime} \mathrm{S}, 23^{\circ} 44^{\prime}$ E, 17 Jun. 1995, pitfall traps, on Karoo vegetation, B. Chambers leg. (SAM-HYM-C008768); same collection data as for holotype (SAM-HYM-C019825); Klein Pella, road between Karsten Farms and Goodhouse, Kokerboom site, $29.035271^{\circ}$ S, $18.97662^{\circ}$ E, $678 \mathrm{~m}$ a.s.1., East Gariep with large Euphorbia, 16 Dec. 2007, N. Mbanyana and H.G. Robertson leg. (SAMHYM-C019831); Rietfontein oos, 23 Apr. 1963 (SAM-HYM-C019198).

\section{Measurements (worker $\mathrm{N}=6$ )}

HL 1.059-1.163 (1.107); HW 1.137-1.279 (1.199); SL 0.775-0.930 (0.840); EL 0.245-0.258 (0.256); PH 0.472-0.610 (0.528); PW 0.710-0.827 (0.764); WL 1.201-1.356 (1.281); PSL 0.167-0.207 (0.183); PTH 0.369-0.423 (0.392); PTL 0.388-0.413 (0.405); PTW 0.388-0.452 (0.415); PPH 0.439-0.594 (0.499); PPL 0.362-0.388 (0.377); PPW 0.478-0.530 (0.502); OI 20-23 (21); CI 107-110 (108); SI 66-74 (70); DMI 58-61 (60); LMI 39-45 (41); PSLI 14-19 (17); PeNI 52-56 (54); LPeI 98-109 (103); DPeI 100-106 (103); PpNI 62-68 (66); LPpI 65-82 (76); DPpI 127-141 (133); PPI 116-124 (121).

\section{Description}

\section{Holotype (worker)}

Mandibles with longitudinal striations. Anterior clypeal margin with extensive, semicircular indentation. Frontal carinae extending back from frontal lobes as fine ridges and ending at about level of anterior eye margin. Eyes with 16 ommatidia in longest row. Propodeum armed with pair of medium length propodeal spines, longer than basal width (PSLI 14-19). Metapleural lobes low with angled corner. Peduncle with prominent keel-shaped subpetiolar process. Petiolar node in profile nodiform, with posterior face slightly more steeply angled than anterior face; anterior face rounding onto dorsum but with slightly angled corners as seen in dorsal view. Postpetiolar node low and rounded. Dorsal surfaces of head with longitudinal striations, spaces between them with superficial reticulate ground sculpture. Dorsum of mesosoma with short longitudinal striations, with superficial ground sculpture in between them. Petiolar and postpetiolar nodes with fine reticulate sculpture overlain by irregular striations. Gastral tergite with fine, superficial reticulate pattern. All dorsal surfaces of head and body with abundant fine, erect, and short hairs. The tibia of middle and hind legs with numerous short, stout, erect hairs. Ventral surface of head with strongly developed psammophore. Colour uniformly black.

\section{Distribution}

Known from South Africa (Western Cape, Northern Cape and Eastern Cape), where it occurs in Nama Karoo and Drakensberg Montane Grasslands. 

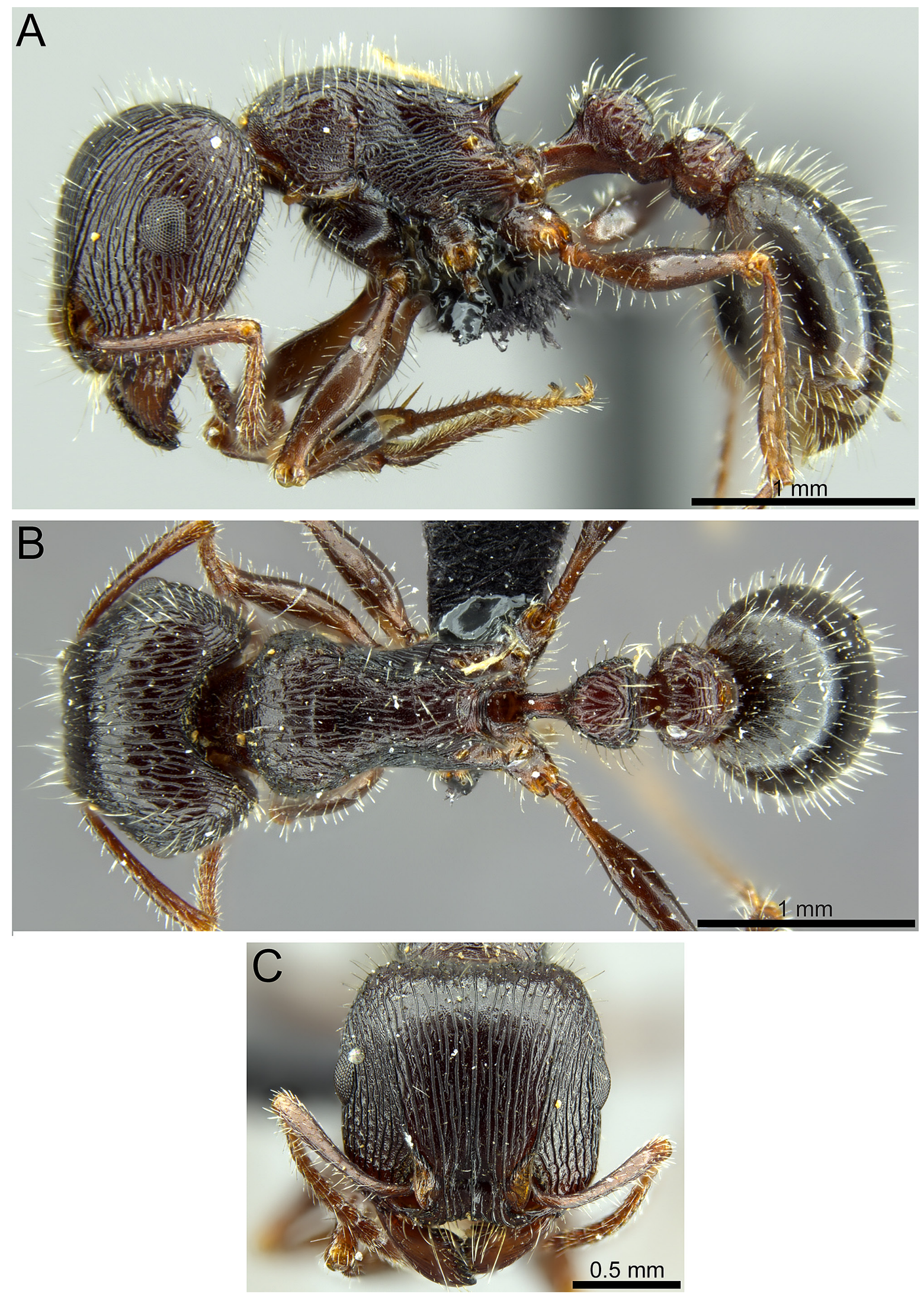

Fig. 16. Tetramorium margueriteae Mbanyana, Robertson \& Hita Garcia sp.nov. (SAM-HYM-C019839). A. Body in profile. B. Body in dorsal view. C. Head in full-face view. 
Tetramorium peringueyi Arnold, 1926

Figs 2B, 4C, E, G, 17, 24

Tetramorium peringueyi Arnold, 1926: 260.

\section{Diagnosis}

Tetramorium peringueyi is morphologically similar to $T$. dichroum, T. margueriteae sp. nov. and T. brigitteae sp. nov. They all have numerous simple, erect hairs covering the body. This species is separated from $T$. dichroum and $T$. brigitteae sp. nov. by the presence of erect hairs on the leading edges of the antennal scapes (Fig. 4C), whereas the other two species only have a sub-erect pubescence (Fig. 4D). Tetramorium peringueyi and T. margueriteae sp. nov. can be distinguished based the characters listed under T. margueriteae sp. nov.

\section{Material examined}

Syntypes

SOUTH AFRICA: 18 pinned workers, Northern Cape, Kimberley, 1916, Power leg. (SAMC: SAMENT-0011759, SAM-ENT-0011966; BMNH: CASENT0901179).

\section{Other material}

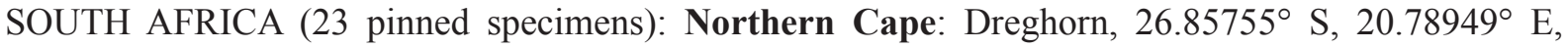
862 m a.s.1., 17 Dec. 2009, N. Mbanyana and H.G. Robertson leg. (SAM-HYM-C019820); Dreghorn, $26.857705^{\circ} \mathrm{S}, 20.78656^{\circ}$ E, $855 \mathrm{~m}$ a.s.1., 17 Dec. 2009, N. Mbanyana and H.G. Robertson leg. (SAMHYM-C019822); Mokala National Park, Lilydale Lodge, 29.06377 S, 24.47202 ${ }^{\circ}$ E, $602 \mathrm{~m}$ a.s.1., 12 Jan. 2009, N. Mbanyana and H.G. Robertson leg. (SAM-HYM-C023308); 10 mi. from Grikwastad to Prieska, 22 Oct. 1963, J.J. Cillie leg. (SAM-HYM-C015261), Postmasburg, Oryx Game Farm site 5, $28.44786^{\circ} \mathrm{S}, 22.13321^{\circ} \mathrm{E}, 1107 \mathrm{~m}$ a.s.l., 26 Mar. 2011, pitfall trap, mixed savannah in Gordonia Duneveld, OGF-5-2, D. Pietersen leg. (BMNH: CASENT0250873). - Eastern Cape: Mountain Zebra National Park, 32.14S, 25.28E, 27 Oct. 1985, H.G. Robertson leg. (SAM-HYM-C000057); Vosburg, Apr. 1954 (SAM-HYMC004121); Hopetown, 4 km E of Hopetown, Hopetown Municipal Farm, 15 Feb. 1997, B. Chambers leg. (SAM-HYM-C010850).

NAMIBIA (20 pinned specimens): SE of Windhoek, M'Bela Farm, on sand, C. Dickman leg. (SAMHYM-C006261); SE of Windhoek, Christine Farm, on sand, C. Dickman leg. (SAM-HYM-C006264); Klein-Aus Vista, $26^{\circ} 39.198^{\prime} \mathrm{S}, 16^{\circ} 14.542^{\prime} \mathrm{E}, 1273 \mathrm{~m}$ a.s.l., nesting in rocky sandy soil almost in the middle of a riverbed, 3 Apr. 2011, N. Mbanyana and H.G. Robertson leg. (SAM-HYM-C026797); KleinAus Vista, $26^{\circ} 39.198^{\prime} \mathrm{S}, 16^{\circ} 14.542^{\prime} \mathrm{E}, 1273 \mathrm{~m}$ a.s.l., nesting in river sand in the middle of a dry riverbed, nest with crater of soil around entrance, 3 Apr. 2011, N. Mbanyana and H.G. Robertson leg. (SAMHYM-C026796); 72 km from Kamanjab on C40, dry riverbed near Grootberg Village, 1946.997' S, $14^{\circ} 17.357^{\prime} \mathrm{E}, 1196 \mathrm{~m}$ a.s.1., nesting in soil, with crater of soil around entrance, 11 Apr. 2011, N. Mbanyana and H.G. Robertson leg. (SAM-HYM-C027109).

Measurements (worker $\mathrm{N}=17$ )

HL 0.993-1.170 (1.096); HW 1.040-1.2719 (1.138); SL 0.777-0.885 (0.827); EL 0.216-0.263 (0.238); PH 0.462-0.639 (0.532); PW 0.649-0.767 (0.724); WL 1.050-1.249 (1.175); PSL 0.197-0.285 (0.238); PTH 0.354-0.433 (0.386); PTL 0.320-0.393 (0.356); PTW 0.344-0.460 (0.403); PPH 0.344-0.472 (0.400); PPL 0.256-0.393 (0.340); PPW 0.415-0.587 (0.492); OI 19-23 (21); CI 99-109 (104); SI 69-75 (73); DMI 57-65 (62); LMI 38-56 (45); PSLI 17-26 (22); PeNI 51-60 (56); LPeI 83-108 (92); DPeI 102-122 (113); PpNI 63-77 (68); LPpI 68-103 (85); DPpI 131-156 (145); PPI 118-128 (122). 

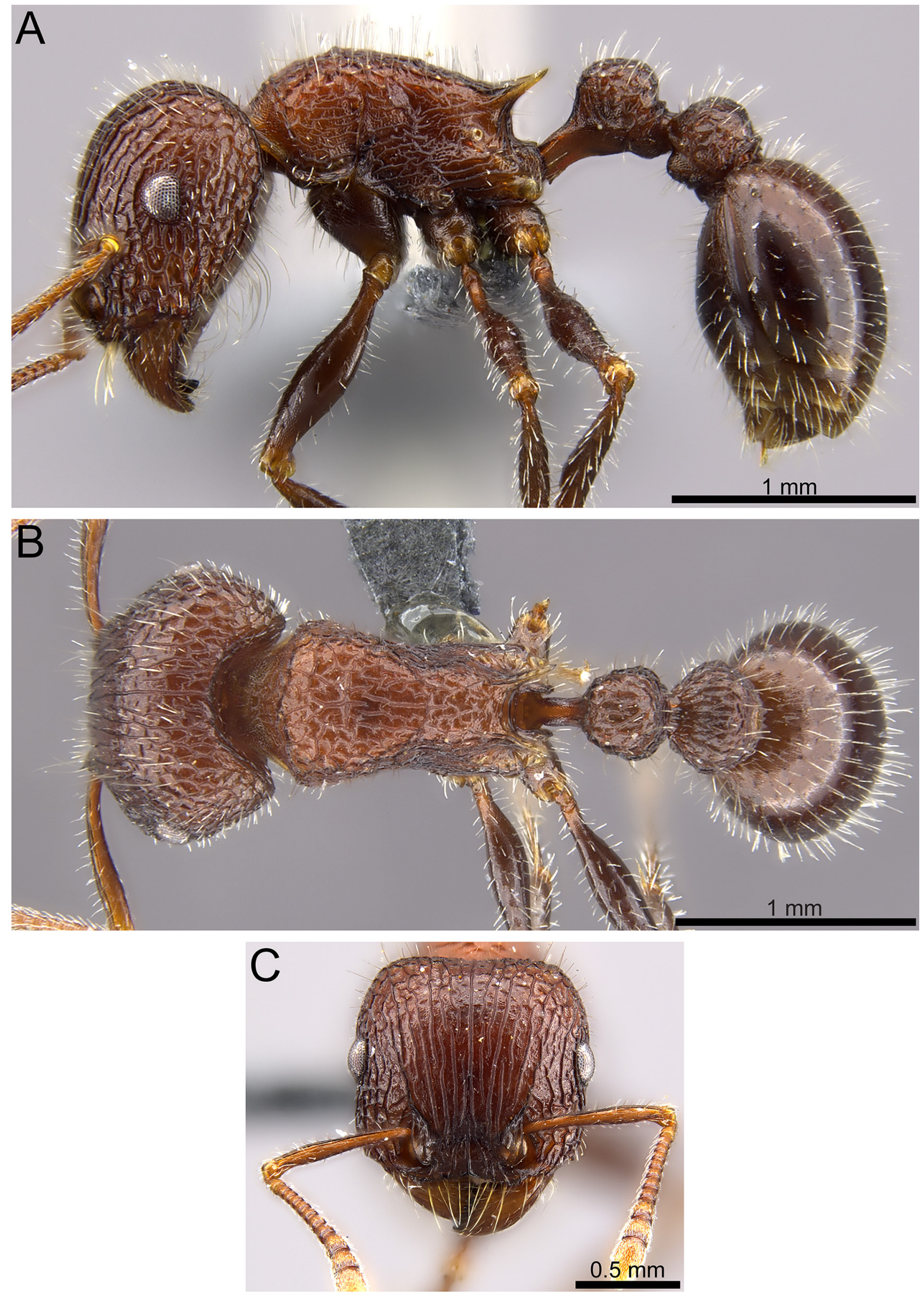

Fig. 17. Tetramorium peringueyi Arnold, 1926 (CASENT0250873). A. Body in profile. B. Body in dorsal view. C. Head in full-face view. 


\section{Distribution}

Tetramorium peringueyi is known to occur in South Africa (Western Cape, Northern Cape and Eastern Cape) and Namibia. This species has been recorded from Drakensberg Montane Grasslands, Kalahari Xeric Savanna, Nama Karoo and Namibian Savanna Woodlands.

\section{Remarks}

Tetramorium peringueyi has been found nesting in sandy soils and in deep dolerite reddish soils. The nests normally have more than one entrance. They occur in open areas at the basal parts of plants, often with a crater of soil around the entrance. This species feeds on seeds and stores them inside the nest; seed stores have been recorded within $8 \mathrm{~cm}$ of the soil surface. In one of the samples collected, the larvae and alates were found at about $22 \mathrm{~cm}$ down. Pitfall trapping, sugar baiting and hand collecting have been used to collect this species.

\section{Tetramorium pogonion Bolton, 1980}

Figs $3 \mathrm{~K}, 18,24$

Tetramorium pogonion Bolton, 1980: 249.

\section{Diagnosis}

Tetramorium pogonion is the only species in the T. solidum group with the head broader in front of the eyes than behind (Fig. 3K).

\section{Material examined}

\section{Holotype}

NAMIBIA: worker, 37 miles $(60 \mathrm{~km}) \mathrm{W}$ of Aus, $500 \mathrm{~m}$ a.s.l., 5 May 1958, E.S. Ross and R.E. Leech leg. (CASC: CASTYPE13390).

\section{Paratypes}

NAMIBIA: 8 pinned specimens ( 5 workers, $1 \AA$, 2 queens), same collection data as for holotype (CASC: CASENT0270793, CASENT0270794).

\section{Measurements (worker $\mathrm{N}=4$ )}

HL 0.924-0.954 (0.944); HW 0.875-0.895 (0.887); SL 0.688-0.767 (0.718); EL 0.266-0.285 (0.275); PH 0.452-0.492 (0.470); PW 0.580-0.610 (0.590); WL 0.964-0.983 (0.971); PSL 0.118-0.148 (0.135); PTH 0.275-0.295 (0.289); PTL 0.275-0.295 (0.288); PTW 0.275-0.295 (0.285); PPH 0.305-0.334 (0.325); PPL 0.256-0.275 (0.270); PPW 0.344-0.374 (0.356); OI 30-32 (31); CI 94-95 (94); SI 79-85 (81); DMI 59-63 (61); LMI 47-51 (48); PSLI 13-15 (14); PeNI 47-49 (48); LPeI 97-102 (100); DPeI 97-104 (99); PpNI 58-63 (60); LPpI 79-90 (83); DPpI 125-146 (132); PPI 120-131 (125).

\section{Distribution}

Only known from Namibia, where it was collected in the Namib Desert and Namib Savannah Woodlands.

\section{Tetramorium rothschildi (Forel, 1907)}

Figs 2C, 19, 24

Triglyphothrix rothschildi Forel, 1907: 134 (included in Bolton 1976: 334).

\section{Diagnosis}

Tetramorium rothschildi is the only species in the T. solidum group with branched hairs (Fig. 2C, 19). 

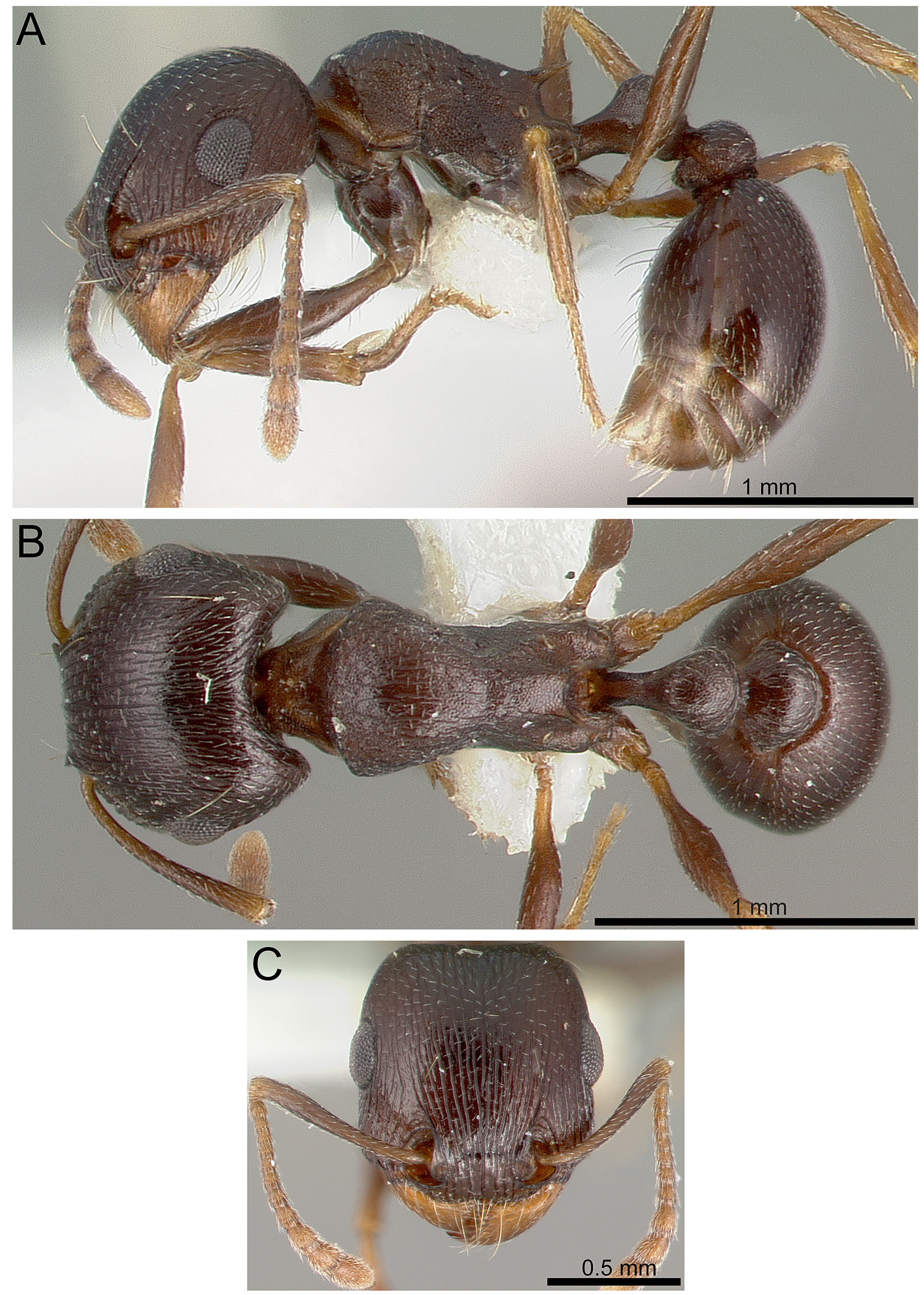

Fig. 18. Tetramorium pogonion Bolton, 1980 (CASTYPE13390 - Antweb, photographer unknown). A. Body in profile. B. Body in dorsal view. C. Head in full-face view. 


\section{Material examined}

Holotype

ETHIOPIA: pinned worker, Harar, 1 Mar. 1905, Maurice de Rothschild leg. (MNHN: CASENT0915429).

\section{Other material}

TANZANIA (27 pinned workers): Mkomazi Game Reserve, Kisima pitfall site, $4^{\circ} 01^{\prime} 30^{\prime \prime} \mathrm{S}, 38^{\circ} 02^{\prime} 27^{\prime \prime} \mathrm{E}$, lightly wooded on red laterite soil, dominant trees Acacia mellifera, A. reficiens, A. senegal and A. zanzibarica, 2-4 Jan. 1997, G. McGavin leg. (SAM-HYM-C011140); Mkomazi Game Reserve, Ibaya, $3^{\circ} 58^{\prime}$ S, 374ㅇ' E, 18 Nov. 1994, grassland, pitfall traps, A. Russell-Smith leg. (SAM-HYM-C009595); Mkomazi Game Reserve, on top of Kisima Mountain, $4^{\circ} 06^{\prime} \mathrm{S}, 38^{\circ} 05^{\prime} \mathrm{E}, 1$ Dec. 1995, nest entrance in the open (round with no crater of soil around), mountain top grassland with scattered trees and bushes, H.G. Robertson leg. (SAM-HYM-C008700); Ibaya Game Reserve, 1 Nov. 1995, H.G. Robertson leg. (CASENT0248479).

KENYA: foragers, Laikipia District, Mpala Research Centre, $0.29^{\circ} \mathrm{N}, 36.90^{\circ} \mathrm{E}, 1650 \mathrm{~m}$ a.s.1., 7 Oct. 1999, Acacia woodland, on ground, R.R. Snelling leg. (CASC: CASENT0217078); Narok, Rift Valley, Maasai Mara National Reserve, Mara River, riverbank close to Serena Lodge, $1.42478^{\circ} \mathrm{S}, 34.9099^{\circ} \mathrm{E}$, 1493 m a.s.l., hand collected on the ground, savannah, FHG00030, 1 Jul. 2007, F. Hita Garcia leg. (BMNH: CASENT0764432, CASENT0764433, CASENT0764435).

GHANA: Tumu, 25 Dec. 1969, P. Room leg. (BMNH: CASENT0764594, CASENT0790132).

\section{Measurements (worker $\mathrm{N}=5$ )}

HL 1.033-1.131 (1.068); HW 1.072-1.259 (1.121); SL 0.698-0.797 (0.745); EL 0.197-0.226 (0.212); PH 0.541-0.600 (0.570); PW 0.659-0.757 (0.708); WL 0.934-1.141 (1.060); PSL 0.216-0.285 (0.252); PTH 0.325-0.413 (0.378); PTL 0.315-0.374 (0.342); PTW 0.354-0.433 (0.384); PPH 0.354-0.413 (0.385); PPL 0.285-0.334 (0.299); PPW 0.393-0.492 (0.444); OI 18-21 (19); CI 102-111 (105); SI 63-70 (67); DMI 64-72 (67); LMI 48-58 (54); PSLI 21-26 (24); PeNI 53-57 (54); LPeI 85-97 (91); DPeI 107-117 (112); PpNI 56-66 (63); LPpI 73-81 (78); DPpI 133-172 (149); PPI 105-122 (116).

\section{Distribution}

This species is known from Ethiopia, Tanzania, Kenya and Ghana.

\section{Remarks}

Tetramorium rothschildi was first placed in the genus Triglyphothrix because of its branched pilosity (Bolton 1976). After Bolton (1985) revised the status of Triglyphothrix, he placed this species in the T. solidum group because of the deep indentation on the anterior clypeal margin. Despite Bolton's decision and our current treatment of this species as a member of the T. solidum group, we are not at all convinced that this species is a genuine member of the group. It is possible that $T$. rothschildi represents a convergent evolutionary lineage and the similarities in morphology are based on a similar granivore lifestyle. However, at present, it is not possible to address this question without a molecular phylogenetic framework. This species has been recorded from Ethiopia, Uganda, Kenya, Ghana and Tanzania. Tetramorium rothschildi has been found nesting in red laterite soils; nests sometimes have grass husks around the entrance. Pitfall traps and hand collecting methods have been used to collect this species. 

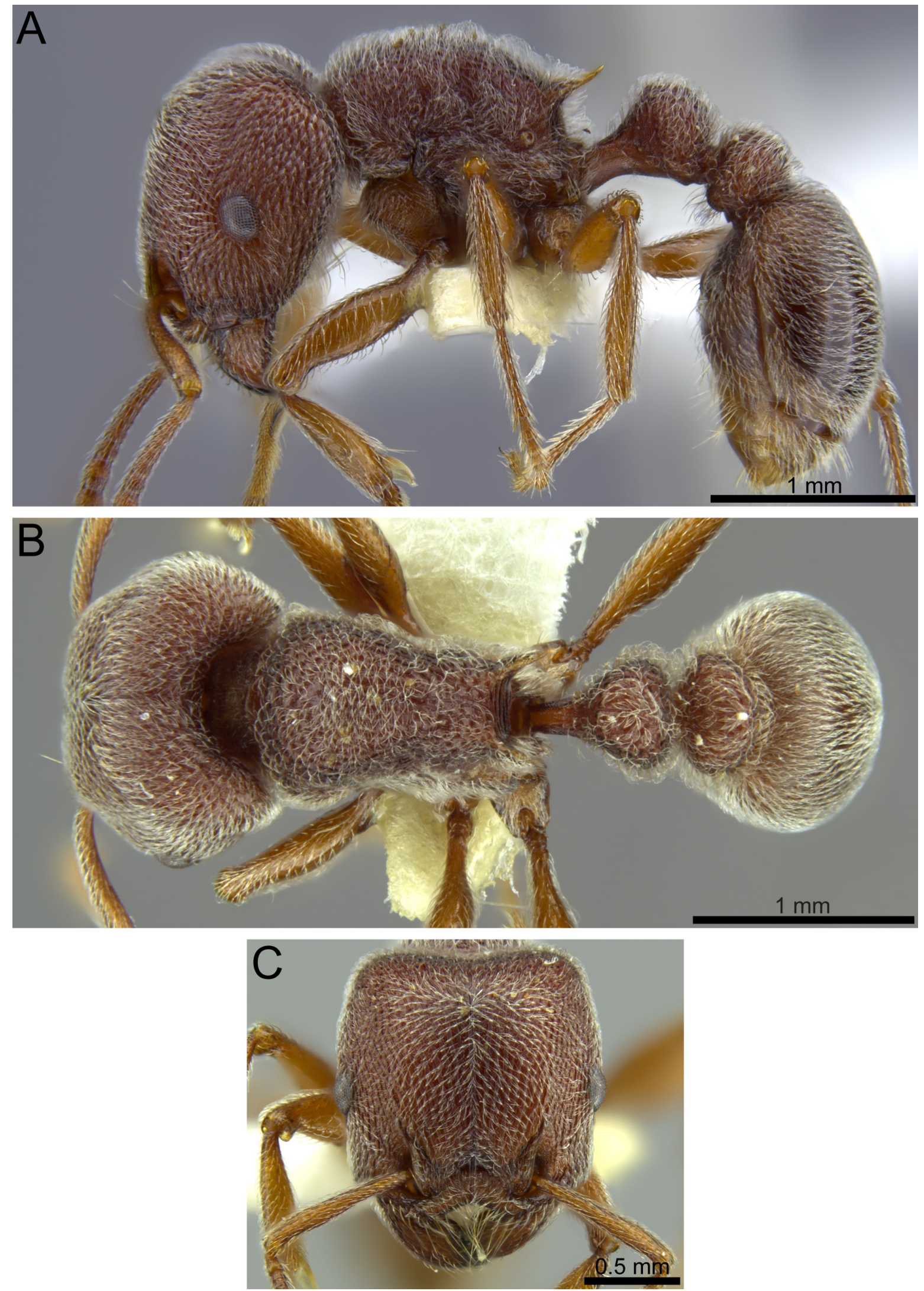

Fig. 19. Tetramorium rothschildi (Forel, 1907) (CASENT0764434). A. Body in profile. B. Body in dorsal view. C. Head in full-face view. 
Tetramorium rufescens Stitz, 1923

Figs 2H, 3I, M, P, 20, 24

Tetramorium solidum st. rufescens Stitz, 1923: 163.

\section{Diagnosis}

The following character combination distinguishes T. rufescens from T. glabratum and T. signatum: dorsum of mesosoma with dense reticulate punctate sculpture and propodeal spines long and narrow (PSLI 16-23).

\section{Material examined}

\section{Syntypes}

NAMIBIA: 3 pinned workers, Swakopmund, 12-19Apr. 1911, W. Michaelsen leg. (ZMHB: FOCOL2082 to FOCOL2084).

\section{Other material}

NAMIBIA (148 pinned specimens): Spitzkoppe, 21 ${ }^{\circ} 50^{\prime} \mathrm{S}, 1^{\circ} 5^{\circ} 11^{\prime} \mathrm{E}, 6-7$ Mar. 1995, pitfall traps, E.S. Ross and A.R. Stephen leg. (CASC: CASENT-0217976 (compared with type)); $61.2 \mathrm{~km} \mathrm{~S}$ of Gobabis on C20, at intersection of C20 and D1790, 22 ${ }^{\circ} 56.806^{\prime} \mathrm{S}, 18^{\circ} 44.681^{\prime} \mathrm{E}, 1353 \mathrm{~m}$ a.s.1., nesting in red sandy soil, 17 Apr. 2011, N. Mbanyana and H.G. Robertson leg. (SAM-HYM-C027008); Porcupine Camp Site, $2.8 \mathrm{~km}$ W of Kamanjab, 19³8.448' S, 1445.980' E, 10 Apr. 2011, nesting in loam soil, entrance in the open, N. Mbanyana and H.G. Robertson leg. (SAM-HYM-C026891); Spitzkopje, 50 mi. E of Hentiesbaai, 950 m a.s.1., 13 Oct. 1967, pitfall traps, H.G. Robertson leg. (SAM-HYM-C007990); Spitzkoppe, $21^{\circ} 50^{\prime} \mathrm{S}, 15^{\circ} 11^{\prime} \mathrm{E}, 6-7$ Mar. 1995, pitfall traps, H.G. Robertson leg. (SAM-HYM-C007993); Otjozondju, Otjiamongo, $21.60^{\circ} \mathrm{S}, 16.94^{\circ} \mathrm{E}, 1495 \mathrm{~m}$ a.s.1., 8 May 2007, C. Grohmann leg. (SAMHYM-C027188); Ongongo (= Warmquelle), $19^{\circ} 10^{\prime} \mathrm{S}, 13^{\circ} 49^{\prime} \mathrm{E}$, foraging on rocky ground, 10 Mar. 1995, H.G. Robertson leg. (SAM-HYM-C008141); Epupa Falls, $17^{\circ} 00^{\prime} \mathrm{S}, 1^{\circ}{ }^{\circ} 15^{\prime} \mathrm{E}$, open rocky savanna, H.G. Robertson leg. (SAM-HYM-C009147, SAM-HYM-C009089); Spitzkoppe, $21^{\circ} 50^{\prime}$ S, 15¹1' E, 6-7 Mar. 1995, pitfall traps, H.G. Robertson leg. (SAM-HYM-C007998); Gamsberg Pass, $23.16^{\circ} \mathrm{S}, 16.20^{\circ}$ E, 7 Sep. 1987, H.G. Robertson leg. (SAM-HYM-C000496); Naukluft PK, Mirabib, 12 Mar. 1988, collected from nest, H.G. Robertson leg. (SAM-HYM-C001039); Namib Nuakluft Park, Ganab Camp Site, 13 Mar. 1986, collected from nest, H.G. Robertson leg. (SAM-HYM-C001044); SE of Windhoek, M'Bela Farm, on sand, C. Dickman leg. (SAM-HYM-C006260, SAM-HYM-C006263, SAM-HYM-C006265); Hobatere, 15 Mar. 1995, open mopane savanna on granite derived gravelly soils, H.G. Robertson leg. (SAM-HYM-C009193); Hobatere (3 km from gate), Boomrivier, Luderitz District, $28^{\circ} 01^{\prime} \mathrm{S}, 1^{\circ} 04^{\prime} \mathrm{E}, 13-26$ Nov. 1992, pitfall traps, E. Marais leg. (SAM-HYM-C027181); Daberas, Diamond Area 1, $28^{\circ} 12^{\prime} \mathrm{S}, 1^{\circ} 49^{\prime}$ E, pitfall trap, 14-29 Sep. 1994, E. Marais leg. (SAM-HYM-C027184); miscellaneous foragers, Opuwo, $3 \mathrm{~km}$ from Opuwo Junction on C35, open savanna on red clay soils, pointed termite mounds, 14 Mar. 1995, H.G. Robertson leg. (SAM-HYM-C009186); Klein-Aus Vista, rocky north-facing slope with low shrubs and grass, $26^{\circ} 39.221^{\prime} \mathrm{S}, 16^{\circ} 14.532^{\prime} \mathrm{E}, 1325 \mathrm{~m}$ a.s.1., soils

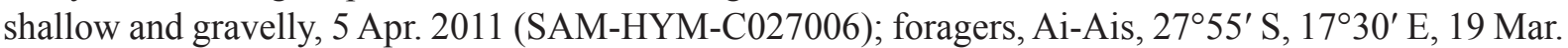
1995, on gravel/bare ground outside bungalow, H.G. Robertson leg. (SAM-HYM-C009267); Namib Desert, Skeleton Coast, 10 Aug. 1982, collected from a gravel plain, desert, A.C. Marsh leg. (CASC: CASENT0764595, CASENT0764596); Karibib, Erongo, Central Namib Desert 2010 site 33, 22.13598 ${ }^{\circ}$ S, $14.86326^{\circ}$ E, $596 \mathrm{~m}$ a.s.1., hand collected, desert, Central Namib vegetation, 28 Oct. 2010, P. Hawkes, J. Fisher, J. Irish and R. Scholtz leg. (CASC: CASENT0250971).

SOUTH AFRICA: Northern Cape: road from Klein Pella to Orange River, $28.98596^{\circ} \mathrm{S}, 18.99436^{\circ} \mathrm{E}$, $615 \mathrm{~m}$ a.s.1., 15 Dec. 2007, Eastern Gariep plain desert with deep soils and Euphorbia, found nesting at base of grass tuft, N. Mbanyana and H.G. Robertson leg. (SAM-HYM-C019958); Hopetown Municipal 

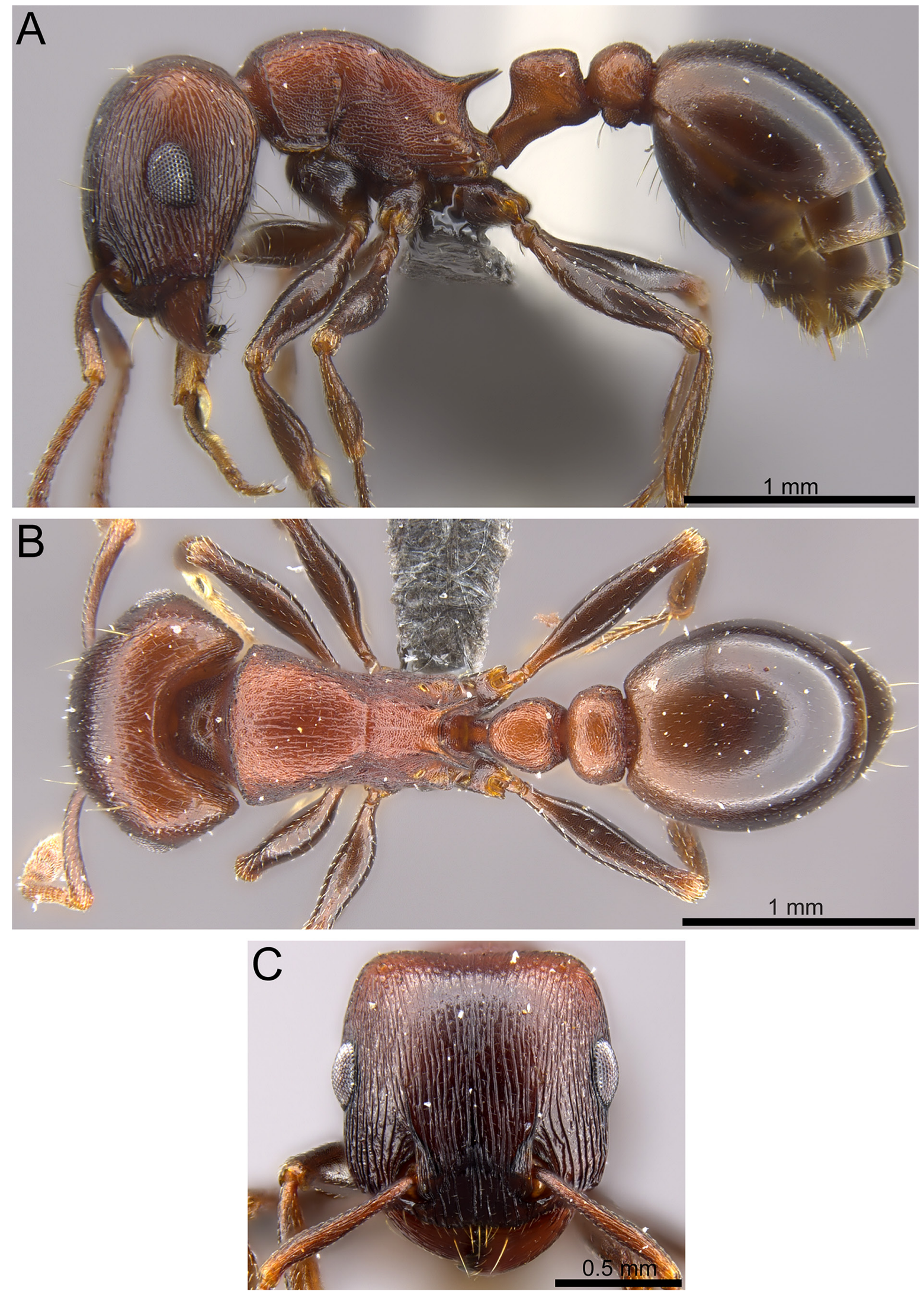

Fig. 20. Tetramorium rufescens Stitz, 1923 (CASENT0250852). A. Body in profile. B. Body in dorsal view. C. Head in full-face view. 
Farm, Hopetown District, 4 km E of Hopetown, 15 Feb. 1997, B. Chambers leg. (SAM-HYM-C011115); Brandvlei, 23 Nov. 1963 (SAM-HYM-C017177); Postmasburg, Oryx Game Farm site 5, pitfall trap, $28.44786^{\circ} \mathrm{S}, 22.13321^{\circ} \mathrm{E}, 1107$ m a.s.l., mixed savannah in Gordonia Duneveld, 26 Mar. 2011, D. Pietersen leg. (CASC: CASENT0250875); Postmasburg, SIO-site 4, $27.80767^{\circ} \mathrm{S}, 22.94291^{\circ} \mathrm{E}, 1170 \mathrm{~m}$ a.s.l., pitfall trap, ephemeral river bed and adjacent vegetation in Olifantshoek Plains Thornveld, 19 Feb. 2015, P. Hawkes and J. Fisher leg. (CASC: CASENT0250852). - Eastern Cape: Grahamstown, 19 Nov. 1965, A.J. Prins leg. (SAM-HYM-C019173).

\section{Measurements (worker $\mathrm{N}=13$ )}

HL 0.983-1.200 (1.065); HW 0.954-1.151 (1.021); SL 0.708-0.856 (0.772); EL 0.266-0.325 (0.291); PH 0.393-0.570 (0.460); PW 0.610-0.777 (0.678); WL 1.003-1.141 (1.101); PSL 0.167-0.236 (0.206); PTH 0.315-0.403 (0.348); PTL 0.275-0.325 (0.305); PTW 0.295-0.425 (0.343); PPH 0.315-0.418 (0.362); PPL 0.226-0.291 (0.259); PPW 0.369-0.521 (0.433); OI 27-30 (29); CI 91-100 (96); SI 73-81 (76); DMI 57-69 (62); LMI 36-50 (42); PSLI 16-23 (19); PeNI 46-61 (50); LPeI 78-100 (88) DPeI 97-127 (112); PpNI 59-75 (64); LPpI 59-77 (72); DPpI 154-188 (167); PPI 121-133 (127).

\section{Distribution}

Tetramorium rufescens is known from South Africa and Namibia.

\section{Remarks}

The description of this species matches that of Bolton (1980), except for colour. We observed some variation in the specimens examined, ranging from red to light brown, in those collected at certain localities in South Africa (Klein Pella) and Namibia (Kamanjab, Luderitz District, Daberas, Hobatere, Epupa Falls). This species has been recorded from the Drakensberg Montane Grasslands, Kalahari Xeric Savanna, Nama Karoo, Namib Desert, Namibian Savanna Woodlands and Succulent Karoo.

\section{Tetramorium setuliferum Emery, 1895}

Figs 2F, 3A, 21, 24

Tetramorium squamiferum Forel, 1894: 80 (attributed to Emery; nomen nudum, see Wheeler 1922: 903; included in Bolton 1980: 250).

Tetramorium setuliferum Emery, 1895: 36 (included in Bolton 1980: 250).

Tetramorium setuliferum var. cucalense Santschi, 1910: 356 (included in Bolton 1980: 250).

Tetramorium setuliferum var. triptolemus Arnold, 1917: 292 included in Bolton 1980: 250).

\section{Diagnosis}

Tetramorium setuliferum is morphologically similar to $T$. clunum. The two species are separated by the characters listed under T. clunum.

\section{Material examined}

Type material

SOUTH AFRICA: syntypes of Tetramorium setuliferum Emery, 1895: 2 pinned workers, Orange Free State, Bethlehem, Weitzecker leg. (MSNG: CASENT0904839).

ANGOLA: syntypes of Tetramorium setuliferum var. cucalense Santschi, 1910: 1 pinned worker, Cucala, Benguela, J. Cruchet leg. (RMCAENT000017786); 1 pinned worker, Cucala near Caconda, Benguela, 31 Dec. 1910, Santschi leg. (NHMB: CASENT0915077; MNHN: CASENT0915425). 
ZAMBIA: syntype of Tetramorium setuliferum var. triptolemus Arnold, 1917: 1 pinned worker, "N. Rhod." according to label, Lusakas, Oct. 1913, G. Arnold leg. (BMNH: CASENT0901177).

\section{Other material}

SOUTH AFRICA (241 pinned specimens): Northern Cape: Cullinan Farm, 26.33562 ${ }^{\circ} \mathrm{S}, 22.61217^{\circ} \mathrm{E}$, 962 m a.s.1., 19 Dec. 2007, nest with crater of soil around the entrance, N. Mbanyana and H.G. Robertson leg. (SAM-HYM-C019898); Cullinan Farm, 26.34087 S, 22.6083 E, 977 m a.s.1., 19 Dec. 2007, N. Mbanyana and H.G. Robertson leg. (SAM-HYM-C019870); Mokala National Park, 29.14467 S, 24.28437 ${ }^{\circ}$ E, 1185 m a.s.1., 12 Jan. 2009, N. Mbanyana and H.G. Robertson leg. (SAM-HYM-C023299); Mokala National Park, $29.06377^{\circ}$ S, $24.47202^{\circ}$ E, 1124 m a.s.l., 12 Jan. 2009, N. Mbanyana and H.G. Robertson leg. (SAM-HYM-C023300); Mokala National Park, 29.16644 S, 24.34299 E, $1262 \mathrm{~m}$ a.s.1., 12 Jan. 2009, N. Mbanyana and H.G. Robertson leg. (SAM-HYM-C023301). - North West:

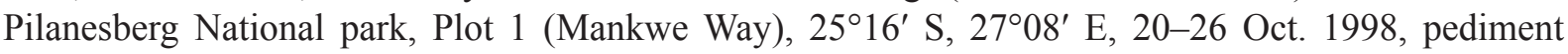
grassland, C.L. Parr leg. (SAM-HYM-C016874). - KwaZulu-Natal: Thurlow Game Park, Midmar, Howick, $29^{\circ} 32^{\prime} 20^{\prime \prime} \mathrm{S}, 30^{\circ} 10^{\prime} 0^{\prime \prime} \mathrm{E}$, nest in grass roots, rocky grassland, loam substrate, gentle hillside, 4 Jan. 2005, H. Adie leg. (SAM-HYM-C018292); Mkuze Game Reserve, Mantamu rest camp, 27.36 ${ }^{\circ} \mathrm{S}, 32.13^{\circ} \mathrm{E}, 8$ Dec. 1986, from a nest, H.G. Robertson leg. (SAM-HYM-C000256); foragers, Sodwana Bay, coastal evergreen forest, sand dunes, $27^{\circ} 33^{\prime} 00^{\prime \prime} \mathrm{S}, 32^{\circ} 40^{\prime} 00^{\prime \prime} \mathrm{E}, 15$ Feb.

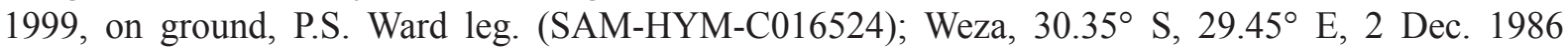

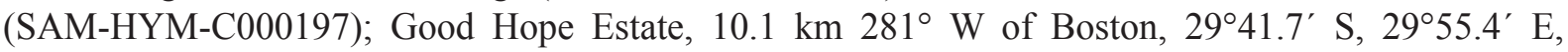
1500 m a.s.1., 25-30 Aug. 1998, B.L. Fisher leg. (CASC: CASENT0100777, CASENT0100778, CASENT0100780). - Gauteng: Primier Mine, Cullinan, 10 Feb. 2001, P. Hawkes leg. (SAMHYM-C016219); Wits University, near nursery, $26.11^{\circ} \mathrm{S}, 28.02^{\circ} \mathrm{E}, 17 \mathrm{Feb} .1988$, collected from nest, H.G. Robertson leg. (SAM-HYM-C000966); Jan Van Riebeek, Johannesburg, 26.095 ${ }^{\circ} \mathrm{S}, 28.00^{\circ} \mathrm{E}$, 24 Nov. 1987, collected from nest, H.G. Robertson leg. (SAM-HYM-C000761); foragers, Farmall,

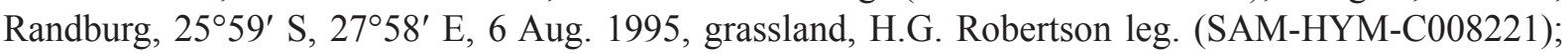

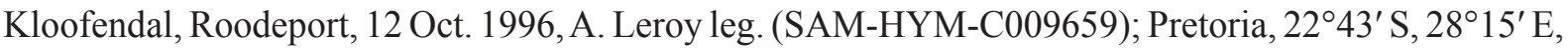
29 Apr. 1990, B.J. Kotzie leg. (SAM-HYM-C011557). - Limpopo: Soutpansberg 55, 232'3" S, $29^{\circ} 25^{\prime} 45^{\prime \prime}$ E, 12 Aug. 2007, A. Heiduk leg. (SAM-HYM-C019677); Soutpansberg 56, 231'55" S, 29²5'41" E, 19 Aug. 2007, A. Heiduk leg. (SAM-HYM-C019678), Landbou Proef Plaas, Messina, 28 Apr. 1969, A.J. Prins leg. (SAM-HYM-C015070); Voorspoed, Naboomspruit, 29 Apr. 1969, A.J. Prins leg. (SAM-HYM-C015077); Groblersdal, Mooiuitsig, 29 Apr. 1969, A.J. Prins leg. (SAM-

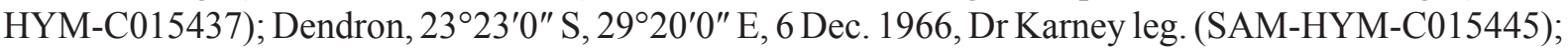
Kruger National Park, near Satara, Marenya plots, $24^{\circ} 32^{\prime}$ S, 31 ${ }^{\circ} 46^{\prime}$ E, 320 m a.s.1., Jan. 2002, Acacia nigrenscens savannah, pitfall trap, C.L. Parr leg. (SAM-HYM-C023460); Kruger National Park, near Satara, Satara plots, $24^{\circ} 24^{\prime}$ S , $31^{\circ} 45^{\prime}$ E, 300 m a.s.l., Jan. 2002, Acacia nigrenscens savannah, pitfall trap, C.L. Parr leg. (SAM-HYM-C023461); Kruger National Park, near Mopane, Dzombo plots, $23^{\circ} 26^{\prime}$ S, $31^{\circ} 22^{\prime}$ E, 360 m a.s.1., Jan. 2002, Acacia nigrenscens savannah, pitfall trap, C.L. Parr leg. (SAMHYM-C023462); Kruger National Park, near Satara, N'wanetsi plots, 2426' S, 31 ${ }^{\circ} 53^{\prime}$ E, 240 m a.s.l., Jan. 2002, Acacia nigrenscens savannah, pitfall trap, C.L. Parr leg. (SAM-HYM-C023463); Mpzema, $22.56^{\circ} \mathrm{S}, 30.11^{\circ}$ E, 20 Oct. 1987, collected from nest, H.G. Robertson leg. (SAM-HYM-C000645); Umbabat Rural Facility near Acornhoek, 26 Sep. 1990, M. Villet leg. (SAM-HYM-C002634); Letaba Estate, $23.51^{\circ} \mathrm{S}, 30.18^{\circ} \mathrm{E}, 9 \mathrm{Feb} .1988$, collected from nest, H.G. Robertson leg. (SAM-HYM-C000933); Dendron, 2323'0" S, 29²0'0" E, 9 Feb. 1966, Dr Karney leg. (SAM-HYM-C015446); 7 km W of Giyani, $7 \mathrm{~km}$ NW of Letaba River, $23.17^{\circ} \mathrm{S}, 30.37^{\circ} \mathrm{E}, 18$ Oct. 1987, collected from nest, H.G. Robertson leg. (SAM-HYM-C000624); Roschdraai Farm, NE of Vaalwater, $24.12^{\circ} \mathrm{S}, 28.17^{\circ} \mathrm{E}, 13 \mathrm{Jun} .1987$, collected from nest, H.G. Robertson leg. (SAM-HYM-C000429). - Mpumalanga: Vygenhoek, 25.03323 S, $30.16407^{\circ}$ E, $1401 \mathrm{~m}$ a.s.1., 15 Dec. 2007, P. Hawkes and J. Fisher leg. (SAM-HYM-C024385); Nelspruit, Dumas, 23 Apr. 1969, A.J. Prins leg. (SAM-HYM-C015312); Sabie Sand Game Reserve, $24^{\circ} 46^{\prime}$ S, 31 $1^{\circ} 22^{\prime}$ E, 23 Jun. 1992, J. Swart leg. (SAM-HYM-C006341). - Orange Free State: Edenville, 


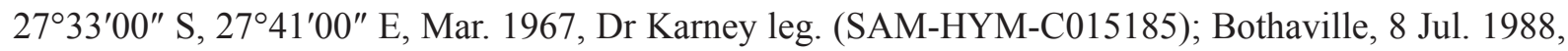
A.J. Prins and A. Roux leg. (SAM-HYM-C001757). - Eastern Cape: Stutterheim, 3 May 1993, W. Coetzer leg. (SAM-HYM-C006786).

NAMIBIA (60 pinned specimens): miscellaneous foragers, just outside Opuwo, open savanna on white clay soil, 14 Mar. 1995, H.G. Robertson leg. (SAM-HYM-C009176); foragers, Waterberg Rest Camp, bare ground outside bungalow, 16 Mar. 1995, H.G. Robertson leg. (SAM-HYM-C009241); Waterberg area, Klarwater Farm, on sand, C. Dickman leg. (SAM-HYM-C006268); Avis Dam, Windhoek, 22 ${ }^{\circ} 34.925^{\prime}$ S, $17^{\circ} 08.134^{\prime} \mathrm{E}$, nest in soil, entrance in open, 14 Apr. 2011 (SAM-HYM-C026798); Porcupine Camp, $8 \mathrm{~km} \mathrm{~W}$ of Kamanjab, $19^{\circ} 38.950^{\prime} \mathrm{S}, 1^{\circ} 45.952^{\prime} \mathrm{E}, 10$ Apr. 2011, nesting in deep fine red sandy soil, nest entrance with crater of soil around, N. Mbanyana and H.G. Robertson leg. (SAM-HYM-C027093); Porcupine Camp, $8 \mathrm{~km}$ W of Kamanjab, 19³8.969' S, 14²45.971' E, 10 Apr. 2011, nesting in sandy soil, nest entrance in the open with crater of soil around, N. Mbanyana and H.G. Robertson leg. (SAMHYM-C027094); Zelda Guest Farm site 1, 22 ${ }^{\circ} 17.311^{\prime}$ S, 1949.199' E, 16 Apr. 2011, nest in sandy soil, entrance in the open, with crater of soil around it, males collected from the nest, N. Mbanyana and H.G. Robertson leg. (SAM-HYM-C027096); Zelda Guest Farm site 4, 22 $16.596^{\prime}$ S, 1949.701' E, 16 Apr. 2011, nest in soft sandy soil, entrance at base of grass tuft, N. Mbanyana and H.G. Robertson leg. (SAMHYM-C027097); 61.2 km S of Gobabis, C20 site 3, 22 ${ }^{\circ} 56.806^{\prime}$ S, 1844.681' E, 17 Apr. 2011, nest in red sandy soil, N. Mbanyana and H.G. Robertson leg. (SAM-HYM-C027099).

BOTSWANA: Nata Saltpan, 2 km into saltpan, 1 Dec. 1986, R.J. Nefdt leg. (SAM-HYM-C000295); Madikwe Game Reserve, Tshwene Combretum apiculatum mountain field, 244ㄴ'43" S, 26 $17^{\prime} 14^{\prime \prime}$ E, Jan. 2001, N. Govender leg. (SAM-HYM-C016269).

ZIMBABWE: Rusape, $18.32^{\circ} \mathrm{S}, 32.08^{\circ} \mathrm{E}, 5$ Dec. 1987, collected from nest, H.G. Robertson leg. (SAM-HYM-C000817); Kyle View Chalets, $20.05^{\circ} \mathrm{S}, 31.01^{\circ}$ E, 30 Nov. 1987, collected from nest, H.G. Robertson leg. (SAM-HYM-C000770); Noga Island Okavango Delta, sand, 23 Sep. 1991, R. Newman leg. (SAM-HYM-C005634); Khami Ruins, 14 mi. W of Bulawayo, 22. Mar. 1958, $1275 \mathrm{~m}$ a.s.l., E.S. Ross and R.E. Leech leg. (CASC: CASENT0270795); Oshikongo, $3200 \mathrm{ft}$ (= $975 \mathrm{~m})$ a.s.1., 9 Mar. 1970, E.S. Ross leg. (CASC: CASENT0270796).

ZAMBIA: Gwabe Camp near Chirundu, 20 Dec. 1986, R.J. Nefdt leg. (SAM-HYM-C007280); Lusaka, Xanadu Farm, in soil about $10 \mathrm{~cm}$ deep, Miomba woodland, legume-like seeds in nest, 2 Jan 1987, R.J. Nefdt leg. (SAM-HYM-C000298); Choma, 16²47.72' S, 265․ $560^{\prime}$ E, 1330 m a.s.l., 3 Dec. 2005, Fisher et al. leg. (CASC: CASENT0066874).

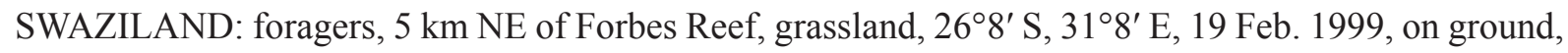
P.S. Ward leg. (SAM-HYM-C016538).

Measurements (worker $\mathrm{N}=13$ )

HL 0.964-1.210 (1.114); HW 0.969-1.259 (1.151); SL 0.698-0.846 (0.803); EL 0.220-0.275 (0.254); PH 0.433-0.561 (0.486); PW 0.610-0.799 (0.724); WL 0.983-1.210 (1.118); PSL 0.197-0.285 (0.289); PTH 0.266-0.403 (0.362); PTL 0.293-0.388 (0.337); PTW 0.329-0.433 (0.391); PPH 0.329-0.408 (0.364); PPL 0.197-0.310 (0.279); PPW 0.401-0.600 (0.540); OI 20-24 (22); CI 100-106 (103); SI 66-74 (70); DMI 62-70 (65); LMI 41-50 (44); PSLI 21-31 (26); PeNI 51-57 (54); LPeI 79-108 (93); DPeI 103-147 (117); PpNI 66-79 (75); LPpI 74-87 (77); DPpI 167-212 (194); PPI 122-143 (138).

\section{Distribution}

This is a widespread and common species in savanna and grassland regions of southern Africa, including South Africa (Western Cape, Northern Cape, Eastern Cape, KwaZulu-Natal, Mpumalanga, Limpopo, 

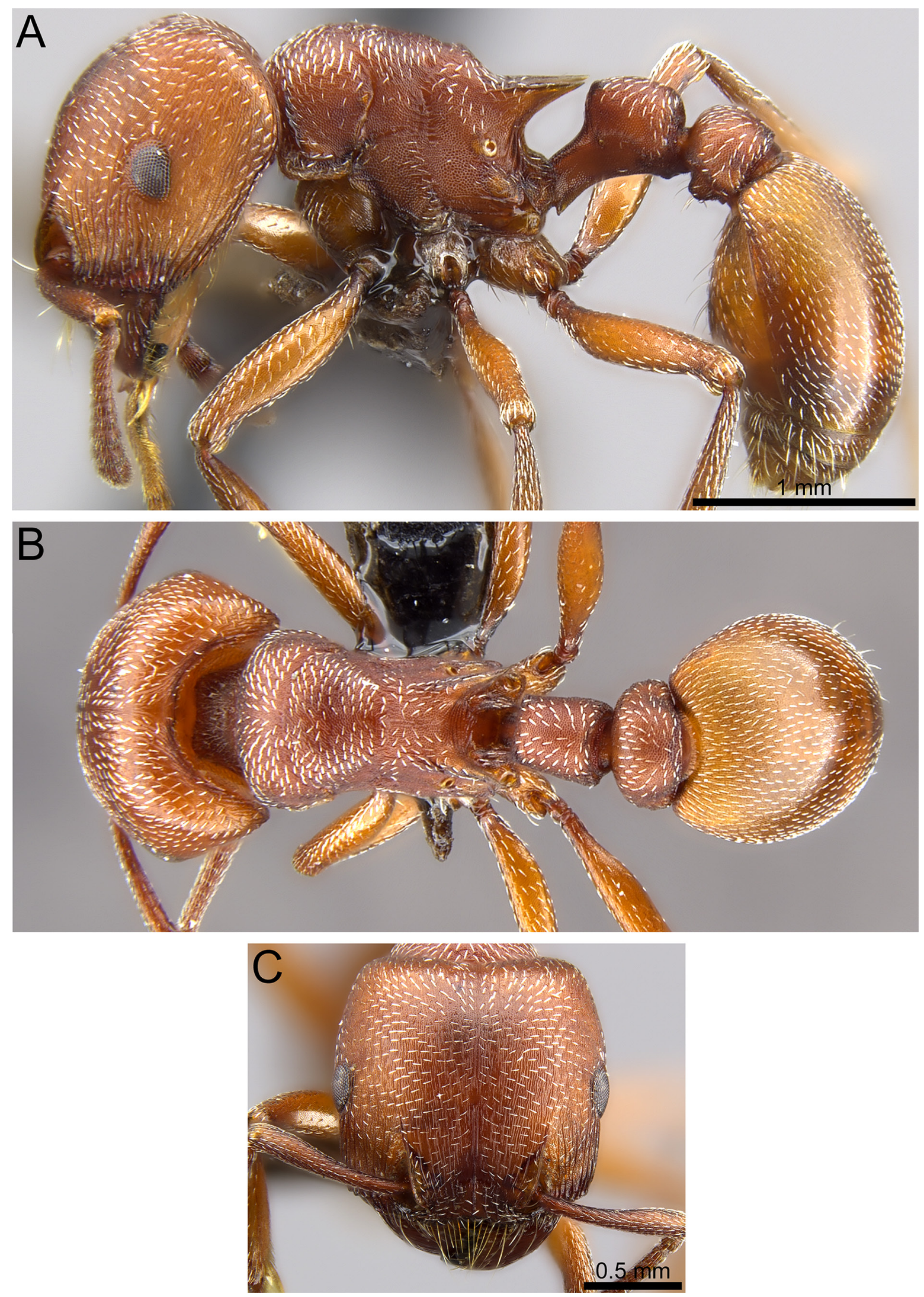

Fig. 21. Tetramorium setuliferum Emery, 1895 (MCZ_ENT00512567). A. Body in profile. B. Body in dorsal view. C. Head in full-face view. 
Gauteng, North West, Free State), Angola, Botswana, Lesotho, Malawi, Mozambique, Namibia, Tanzania, Zaire, Zambia and Zimbabwe. It has been recorded from the following ecoregions: Angolan Mopane Woodlands, Drakensberg Montane Grasslands, Highveld Grasslands, Kalahari Xeric Savanna, Kalahari Acacia-Baikiaea Woodlands, Maputaland-Pondoland Bushland and Thickets, Nama Karoo, Namibian Savanna Woodlands, Southern Africa Bushveld, Southern Africa Mangroves, Southern Miombo Woodlands, Succulent Karoo, Zambezian and Mopane Woodlands, Zambezian Flooded Grasslands.

\section{Remarks}

This species has been collected in forest clearings, in weedy areas, in savanna on white clay soil, dry forest savanna, Thornveld savanna, Kimberley Thornveld, Miombo woodland, riverine-grassveld, old tobacco fields, sandy soil areas dominated by shrubs, and in citrus orchards. Tetramorium setuliferum normally nests in sandy to loamy soils, with nest entrances found in open areas. Circles of grass seed husks, piles of small stones or scattered soil particles have been found around nest entrances. Seeds are regularly found in nests. Reproductive forms have been collected from nests between October and February. Collected using pitfall traps, tuna baits, and sugar baits.

\section{Tetramorium signatum Emery, 1895}

Figs 3E, 4A, 22, 24

Tetramorium solidum var. signatum Emery, 1895: 35 (included in Bolton 1980: 251). Tetramorium solidum subsp. lugrubre Forel, 1910: 425 (included in Bolton 1980: 251). Tetramorium solidum var. grootensis Forel, 1913: 118 (included in Bolton 1980: 251). Tetramorium solidum var. tuckeri Arnold, 1926: 259 (included in Bolton 1980: 251).

\section{Diagnosis}

Tetramorium signatum is similar to T. rufescens and T. pogonion. Tetramorium pogonion is relatively smaller compared to the other two species with relatively larger eyes $(\mathrm{OI}>30)$ and a different head shape (Fig. 3K). Tetramorium signatum and T. rufescens can be separated on basis of the sculpture pattern on the dorsum of mesosoma. In T. signatum, the dorsum of the mesosoma has distinct longitudinal or irregular rugulae (Fig. 4A), whereas in T. rufescens, the dorsum of the mesosoma has a dense reticulate punctation and sometimes with a few short faint longitudinal costulae (Fig. 4B).

\section{Material examined}

Type material

SOUTH AFRICA: syntype of Tetramorium solidum var. signatum Emery, 1895: 1 pinned worker, Western Cape, Matjiesfontein, E. Simon leg. (MSNG: CASENT0904841); syntypes of Tetramorium solidum var. grootensis Forel, 1913: 1 pinned queen, 1 pinned ${ }^{\lambda}$, Eastern Cape, Willowmore, H. Brauns leg. (BMNH: CASENT0901188; MHNG: CASENT0909156).

ANGOLA: syntype of Tetramorium solidum subsp. lugrubre Forel, 1910: 1 pinned worker, Mossamedes, de Picard leg. (MHNG: CASENT0909157).

NAMIBIA: syntypes of Tetramorium solidum var. tuckeri Arnold, 1926: 1 pinned queen, 1 pinned worker, Brehdon, 20 Dec. 1915, R.W.E. Tucker leg. (BMNH: CASENT0901189; SAMC: SAM-ENT-0011762).

\section{Other material}

SOUTH AFRICA (262 pinned specimens): Northern Cape: Dreghorn, $26.85755^{\circ} \mathrm{S}, 20.78949^{\circ} \mathrm{E}$, 862 m a.s.1., 17 Dec. 2007, N. Mbanyana and H.G. Robertson leg. (SAM-HYM-C019926); Dreghorn, $26.85755^{\circ}$ S, $20.78949^{\circ}$ E, 862 m a.s.l., 17 Dec. 2007, N. Mbanyana and H.G. Robertson leg. (SAMHYM-C019927); Cullinan Farm, 26.34087 S, 22.61083 E, 977 m a.s.1., 19 Dec. 2007, N. Mbanyana 
and H.G. Robertson leg. (SAM-HYM-C019928 to SAM-HYM-C019932); Cullinan Farm, 26.34087 S, 22.61083 E, 977 m a.s.1., 19 Dec. 2007, N. Mbanyana and H.G. Robertson leg. (SAM-HYM-C019933 to SAM-HYM-C019937); Cullinan Farm, 26.85770 S, 20.78656 E, 855 m a.s.1., 17 Dec. 2007, N. Mbanyana and H.G. Robertson leg. (SAM-HYM-C019938); between Askham and Vansylsrus, $27.03322^{\circ} \mathrm{S}, 21.09746^{\circ} \mathrm{E}, 872 \mathrm{~m}$ a.s.1., 18 Dec. 2007 , nest entrance with crater of soil around entrance, N. Mbanyana and H.G. Robertson leg. (SAM-HYM-C019939); Cullinan Farm, 26.33562 ${ }^{\circ}$ S, 22.61217 ${ }^{\circ}$ E, 962 m a.s.1., 17 Dec. 2007, N. Mbanyana and H.G. Robertson leg. (SAM-HYM-C019940); Cullinan Farm, $26.34087^{\circ}$ S, $22.61083^{\circ}$ E, 977 m a.s.l., 19 Dec. 2007, N. Mbanyana and H.G. Robertson leg. (SAM-HYM-C027128); Loeriesfontein (SAM-HYM-C019277); Loeriesfontein (SAMHYM-C019283); Rietfontein Oos (SAM-HYM-C019284); road between Karsten Farms and Goodhouse, Kokerboom site, Klein Pella, 29.06211 S, $18.97985^{\circ}$ E, 832 m a.s.l., 16 Dec. 2007, Gariep rocky desert with Kokerboom and Euphorbia, N. Mbanyana and H.G. Robertson leg. (SAM-HYM-C019946, SAMHYM-C019954); road between Karsten Farms and Goodhouse, Kokerboom site, Klein Pella, $29.03527^{\circ}$ S, $18.97662^{\circ}$ E, 678 m a.s.1., 16 Dec. 2007, east desert with large Eurphobia trees, N. Mbanyana and H.G. Robertson leg. (SAM-HYM-C019955); road between Karsten Farms and Goodhouse, Euphorbia site, Klein Pella, 29.03527 ${ }^{\circ}$ S, $18.97662^{\circ}$ E, 678 m a.s.1., 16 Dec. 2007, east Gariep desert with large Euphorbia, soil around the entrance, N. Mbanyana and H.G. Robertson leg. (SAM-HYM-C019956); road from Klein Pella to Orange River, 28.95083 $\mathrm{S}, 18.199153^{\circ} \mathrm{E}, 449 \mathrm{~m}$ a.s.l., Gariep plain desert, 16 Dec. 2007, sandy soil with gravel, shallow soil, found foraging on ground, N. Mbanyana and H.G. Robertson leg. (SAM-HYM-C019957); Goegab Nature Reserve, Jul. 1998, U. Kruger leg. (SAM-HYM-C013303); Brandvlei, 30³1' S, 20²9’ E, 28 May 1986, A.J. Prins leg. (SAM-HYM-C001716); Dreghorn near Chalets, 26.85770 ${ }^{\circ}$ S, 20.78656 ${ }^{\circ}$ E, 855 m a.s.1., 17 Dec. 2007 (SAM-HYM-C019904， SAM-HYM-C019905， SAM-HYM-C019907， SAM-HYM-C019921); Dreghorn, $26.85755^{\circ} \mathrm{S}, 20.78949^{\circ} \mathrm{E}, 862 \mathrm{~m}$ a.s.1., 17 Dec. 2007, N. Mbanyana and H.G. Robertson leg. (SAM-HYM-C019922, SAM-HYM-C019925); Hopetown, 4 km E of Hopetown, Hopetown Municipal Farm, 15 Feb. 1992, B. Chambers leg. (SAM-HYM-C010856); road between Karsten Farms and Goodhouse, $29.06211^{\circ} \mathrm{S}, 18.97985^{\circ} \mathrm{E}, 832 \mathrm{~m}$ a.s.1., 16 Dec. 2007, N. Mbanyana and H.G. Robertson leg. (SAM-HYM-C019868); Mokala National Park, Lilydale Lodge, $29.06377^{\circ} \mathrm{S}, 24.47202^{\circ} \mathrm{E}, 602 \mathrm{~m}$ a.s.1., 12 Jan. 2009, N. Mbanyana and H.G. Robertson leg. (SAM-HYM-C023331); Tankwa Karoo National Park, $32.17430^{\circ}$ S, $19.97382^{\circ}$ E, 602 m a.s.l., 7 Jan. 2009, N. Mbanyana and H.G. Robertson leg. (SAM-HYM-C023332, SAM-HYM-C023324); Mokala National Park, Lilydale Lodge, $29.06377^{\circ}$ S, $24.47202^{\circ}$ E, $602 \mathrm{~m}$ a.s.1., 12 Jan. 2009, N. Mbanyana and H.G. Robertson (SAMHYM-C023310); Mokala National Park, 29.14467 $\mathrm{S}, 24.28437^{\circ}$ E, 1185 m a.s.l., 12 Jan. 2009, N. Mbanyana and H.G. Robertson leg. (SAM-HYM-C023311); Kimberley (SAM-HYM-C004019); Melton Wold, $31.46626^{\circ}$ S, 22.72004 ${ }^{\circ}$ E, 1332 m a.s.l., 9 Jan. 2009, N. Mbanyana and H.G. Robertson leg. (SAM-HYM-C023315, SAM-HYM-C023316); Tankwa Karoo National Park, 32.17430 ${ }^{\circ}$ S, $19.97382^{\circ}$ E, 490 m a.s.1., 7 Jan. 2009, N. Mbanyana and H.G. Robertson leg. (SAM-HYM-C023317, SAM-HYM-C023318); Melton Wold, 31.46741 ${ }^{\circ}$ S, 22.721550 E, $1333 \mathrm{~m}$ a.s.1., 7 Jan. 2009, N. Mbanyana and H.G. Robertson leg. (SAM-HYM-C023320); Tankwa Karoo National Park, $32.17430^{\circ} \mathrm{S}, 19.97382^{\circ} \mathrm{E}, 602 \mathrm{~m}$ a.s.1., 7 Jan. 2009, N. Mbanyana and H.G. Robertson leg. (SAMHYM-C023322, SAM-HYM-C023325, SAM-HYM-C023327, SAM-HYM-C023328); Dreghorn near Chalets, $26.85770^{\circ} \mathrm{S}, 20.78656^{\circ} \mathrm{E}, 855 \mathrm{~m}$ a.s.1., 17 Dec. 2007, nest in soil underground, nest entrance at base of grass tuft, N. Mbanyana and H.G. Robertson leg. (SAM-HYM-C024391); Kortkop Farm, near Strydenburg, 30 $09^{\prime}$ S, $23^{\circ} 44^{\prime}$ E, 17 Jun. 1995, pitfall trap, Karoo vegetation, B. Chambers leg. (SAMHYM-C008768); Tankwa Karoo National Park, 32.21512 ${ }^{\circ}$ S, 20.07671 ${ }^{\circ}$ E, 522 m a.s.1., 7 Jan. 2009, N. Mbanyana and H.G. Robertson leg. (SAM-HYM-C023321); Tankwa Karoo National Park, $32.24758^{\circ} \mathrm{S}, 20.09660^{\circ} \mathrm{E}, 490 \mathrm{~m}$ a.s.1., 7 Jan. 2009, N. Mbanyana and H.G. Robertson leg. (SAMHYM-C023319); Tankwa Karoo National Park, 32.42325 S, 19.98843, 379 m a.s.1., 7 Jan. 2009, N. Mbanyana and H.G. Robertson leg. (SAM-HYM-C023326); Kalahari Gemsbok National Park, Gemsbokplain waterhole and dung, 2609.1' S, 20³1.8' E, 935 m a.s.1., 21 Nov. 1997, M. Uhlig leg. 
(SAM-HYM-C011358); Namakwaland, Gamsberg 2009 transect v4-s7-t1, 29.22153 S, $18.97957^{\circ} \mathrm{E}$, 959 m a.s.1., hand collected, 5 Sep. 2009, P. Hawkes and J. Fisher leg. (CASC: CASENT0250961). Western Cape: Ladismith (SAM-HYM-C019279); Onder-Downs (SAM-HYM-C019282); 33 km from

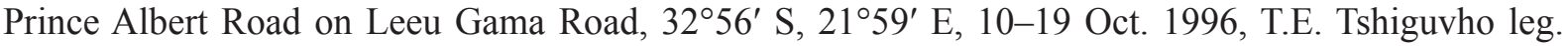
(SAM-HYM-C009330); 40 km from Seekoegat on Prince Albert Road, 3310' S, 22 ${ }^{\circ} 10^{\prime}$ E, 10-19 Oct. 1996, T.E. Tshiguvho leg. (SAM-HYM-C009331); 2 km from Prince Albert Road on Leeu Gamka road, $33^{\circ} 11^{\prime} \mathrm{S}, 2^{\circ} 02^{\prime}$ E, 10-19 Oct. 1996, T.E. Tshiguvho leg. (SAM-HYM-C009332); Josephskraal, $33.04182^{\circ}$ S, $20.72157^{\circ}$ E, 896 m a.s.l., 16 Apr. 2008, Koedoesberge-Moordenaars Karoo, nesting in soil under rock, N. Mbanyana and H.G. Robertson leg. (SAM-HYM-C020573); Abrahamskraal, $32.92874^{\circ} \mathrm{S}, 22.00435^{\circ} \mathrm{E}, 522 \mathrm{~m}$ a.s.l., 12 Apr. 2008, drainage line with deep soils soft at about $20 \mathrm{~cm}$ and after that harder and compacted, nesting in soil under rock, N. Mbanyana and H.G. Robertson leg. (SAM-HYM-C020506, SAM-HYM-C020510, SAM-HYM-C020513); Abrahamskraal, 32.93011 S, $22.00949^{\circ}$ E, $522 \mathrm{~m}$ a.s.l., 12 Apr. 2008, rocky ridges with sparsely distributed shrubs, shallow soil, N. Mbanyana and H.G. Robertson leg. (SAM-HYM-C020330, SAM-HYM-C020335, SAM-

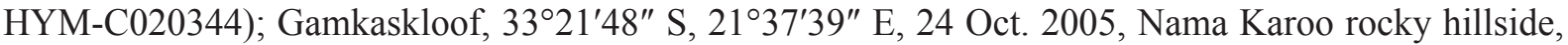
N. Mbanyana and H.G. Robertson leg. (SAM-HYM-C019028); Gamkaskloof, 33⒉ $1^{\prime 4} 8^{\prime \prime}$ S, $21^{\circ} 37^{\prime} 39^{\prime \prime}$ E, 25 Oct. 2005, Nama Karoo rocky hillside, N. Mbanyana and H.G. Robertson leg. (SAMHYM-C019033); Vêrgenoeg, 33.24421 ${ }^{\circ}$ S, 21.47939 ${ }^{\circ}$ E, 670 m a.s.1., 10 Apr. 2008, KoedoesbergeMoordenaars Karoo, N. Mbanyana and H.G. Robertson leg. (SAM-HYM-C020400); Vêrgenoeg, $33.24467^{\circ}$ S, $21.47597^{\circ}$ E, 670 m a.s.1., 10 Apr. 2008, Koedoesberge-Moordenaars Karoo, east-facing rocky slope, N. Mbanyana and H.G. Robertson leg. (SAM-HYM-C020431); Josephskraal, 33.04182 ${ }^{\circ}$ S, $20.72157^{\circ}$ E, 896 m a.s.1., 16 Apr. 2008, Koedoesberge-Moordenaars Karoo, found nesting in deep soil on elevated flood plain, N. Mbanyana and H.G. Robertson leg. (SAM-HYM-C020469, SAM-

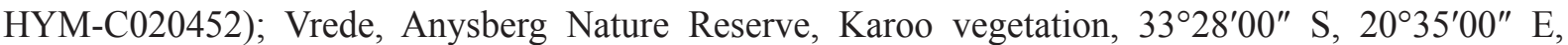
27 Feb. 1999, foraging in front of a bungalow, H.G. Robertson leg. (SAM-HYM-C013034); Vrede,

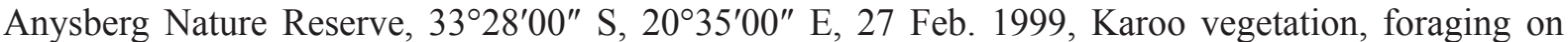
sandy soils near river (SAM-HYM-C013039); Prince Albert, Tierberg Research Station, $33.168833^{\circ} \mathrm{S}$, 22.270111 ${ }^{\circ}$ E, $740 \mathrm{~m}$ a.s.1., 14 Feb. 2006, succulent Karoo, pitfall trap, Iimbovane Outreach Project, B. Braschler leg. (SAM-HYM-C024974); Vêrgenoeg, 33.23126 S, 21.46445 E, 630 m a.s.1., 10 Apr. 2008, Koedoesberge-Moordenaars Karoo, Karoo plain with succulent components mainly mesems (Aizoaceae), nest with at least 15 entrances covering about half a meter square, N. Mbanyana and H.G. Robertson leg. (SAM-HYM-C020539, SAM-HYM-C020546); Josephskraal, 33.04287 S, $20.7193^{\circ} \mathrm{E}$, 900 m a.s.l., 16 Apr. 2008, Koedoesberge-Moordenaars Karoo, Karoo plain slightly N-facing, N. Mbanyana and H.G. Robertson leg. (SAM-HYM-C020436); Die Hell, Synamn Hut, 33 $21^{\prime} 49^{\prime \prime}$ S, $21^{\circ} 37^{\prime} 39^{\prime \prime}$ E, 25 Oct. 2005, A. MacArthur leg. (SAM-HYM-C019522); Namakwa Sands, 31 ${ }^{\circ} 16^{\prime} 14.1^{\prime \prime}$ S, 1756'23.7" E, 31 Mar.-4 Apr. 2003, natural vegetation, Strandveld, pitfall traps, N. Ndivhuwo leg. (SAM-HYM-C018093, SAM-HYM-C018097). - Eastern Cape: Willowmore, 1 Jan. 1914, Rhodesia Museum (SAM-HYM-C004017); Willowmore, Oct. 1912, Dr H. Brauns leg. (SAM-HYM-C004018);

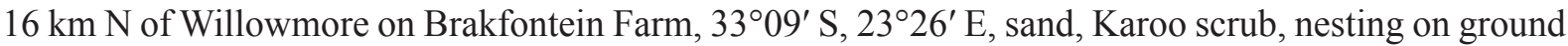
partly under rock, 5 Sep. 1988, H.G. Robertson leg. (SAM-HYM-C005328); Aberdeen, 27 May 1987, A.J.Prins andA. Roux leg. (SAM-HYM-C001686); Vanrhyns Pass, 24Aug. 1963 (SAM-HYM-C004122); Brandkop, 22 Apr. 1963 (SAM-HYM-C004124); Blomplaas, $60 \mathrm{~km}$ SE of Aberdeen, 32 $52^{\prime} \mathrm{S}, 23^{\circ} 40^{\prime}$ E, 5 Sep. 1988, bare ground on Karoo scrub, nesting underground, H.G. Robertson leg. (SAM-

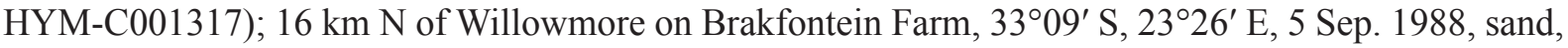
Karoo scrub, nest partly under rock, partly underground, H.G. Robertson leg. (SAM-HYM-C001311).

NAMIBIA: $61.2 \mathrm{~km}$ S of Gobabis on C20, at intersection of C20 and D1790, 234․ $44.908^{\prime} \mathrm{S}, 18^{\circ} 50.987^{\prime} \mathrm{E}$, $1246 \mathrm{~m}$ a.s.1., nesting in deep red-orange sandy soils, nest with a crater of soil around entrance, $17 \mathrm{Apr}$. 2011, N. Mbanyana and H.G. Robertson leg. (SAM-HYM-C027005); 31 km NW of Henties Bay on C35, $21^{\circ} 55.433^{\prime} \mathrm{S}, 1^{\circ} 25.164^{\prime} \mathrm{E}$, nesting in loose gravely soil, entrance in open, 9 Apr. 2011, N. Mbanyana 
and H.G. Robertson leg. (SAM-HYM-C027007); Klein-Aus-Vista, 26³9.221' S, 16 ${ }^{\circ} 14.532^{\prime}$ E, 1325 m a.s.1., rocky $\mathrm{N}$-facing slope with low shrubs and grass, soil shallow and gravelly, 5 Apr. 2011, N.Mbanyanaand H.G. Robertsonleg.(SAM-HYM-C027009); 157 km from Gobabis on C20, 23 $44.908^{\prime}$ S, $18^{\circ} 50.987^{\prime}$ E, 17 Apr. 2011, entrance with crater of soil around, N. Mbanyana and H.G. Robertson leg. (SAM-HYM-C027011); Klein-Aus Vista, 2639.198' S, 16²14.542' E, 1273 m a.s.l., 3 Apr. 2011, nest in rocky sand soil at base of dead grass tuft in middle of dry riverbed, entrance with crater of soil around it (SAM-HYM-C026892, SAM-HYM-C027012); Klein-Aus Vista, 26³9.143' S, 16²14.546' E, 1316 m a.s.1., 4 Apr.2011, nest in rocky sands, with about four entrances closer to each other with crater of soil around entrance (SAM-HYM-C027015); Marienfluss, Koakoveld, 17²3'38.4" S, 12²9'59.2" E, 15 Oct. 2008, M. Picker leg. (SAM-HYM-C023244); Kakamas, Orange River, National Museum of South Rhodesia leg. (SAM-HYM-C004019); Marienfluss, Koakoveld, 17²3'38.4" S, 12²9'59.2" E, 15 Oct. 2008, M. Picker leg. (SAM-HYM-C027002); Gamsberg, 29.22153ํ S, $18.97953^{\circ}$ E, 929 m a.s.l., 15 Dec. 2007, P. Hawkes and J. Fisher leg. (SAM-HYM-C024382); Diamond Area 1, 27 ${ }^{\circ} 17^{\prime}$ S, $15^{\circ} 58^{\prime}$ E, 2-3 Nov. 1986, pitfall traps, E. Griffin leg. (SAM-HYM-C027111); Keetmanshoop District, Khabus $146,26^{\circ} 18^{\prime} \mathrm{S}, 18^{\circ} 13^{\prime} \mathrm{E}$, on sandy plain next to dry riverbed, 14 Apr.-30 Jun. 1988, N. and G. Olivier leg. (SAM-HYM-C027177); Keetmanshoop District, Khabus 146, 26 $6^{\circ} 17^{\prime} \mathrm{S}, 18^{\circ} 14^{\prime} \mathrm{E}$, on dolerite hill, E slope, pitfall traps, 23 Jul.-1 Oct. 1988, N. and G. Olivier leg. (SAM-HYM-C027180); Diamond Area 1, $28^{\circ} 12^{\prime}$ S, 16 $6^{\circ} 49^{\prime}$ E, 14-29 Sep. 1994, pitfall traps, E. Marais leg. (SAM-HYM-C027182); Klein

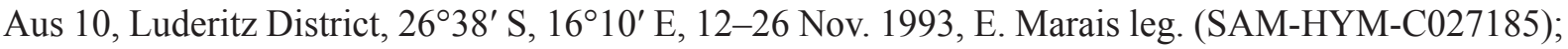
Keetmanshoop District, Khabus $146,26^{\circ} 18^{\prime} \mathrm{S}, 18^{\circ} 13^{\prime} \mathrm{E}$, on sandy plain next to riverbed, 14 Mar.14 Apr. 1988, N. and G. Olivier leg. (SAM-HYM-C027186, SAM-HYM-C027187); Diamond Area 1, $28^{\circ} 14^{\prime}$ S, 16³9' E, 25-29 Sep. 1994, E. Marais leg. (SAM-HYM-C027189); Sendelingsdrift, Diamond Area 1, 28 $07^{\prime}$ S, 16 $6^{\circ} 50^{\prime}$ E, 14-29 Sep. 1994, E. Marais leg. (SAM-HYM-C027190); Askham and Vansylsrus, $27.03322^{\circ} \mathrm{S}, 21.09746^{\circ} \mathrm{E}, 872 \mathrm{~m}$ a.s.1., nest with crater of soil around entrance, 18 Dec. 2007, N. Mbanyana and H.G. Robertson leg. (SAM-HYM-C024392); Uniab Delta, 20.11 ${ }^{\circ} \mathrm{S}, 13.12^{\circ} \mathrm{E}$, collected from nest, 9 Apr. 1987, J. Irish leg. (SAM-HYM-C001053); $40 \mathrm{~km} \mathrm{~W}$ of Aus Desert, 26 34.7' S, 1553.6' E, 25 Nov. 1997, M. and B. Uhlig leg. (SAM-HYM-C011357); 9 mi. NW of Grunau, 4 May 1958, E.S. Ross and R.E. Leech leg. (CASC: CASENT0280906).

\section{Measurements (worker $\mathrm{N}=47$ )}

HL 0.885-1.249 (1.092); HW 0.875-1.219 (1.053); SL 0.708-0.934 (0.808); EL 0.266-0.344 (0.308); PH 0.393-0.590 (0.488); PW 0.570-0.816 (0.695); WL 0.944-1.328 (1.139); PSL 0.079-0.246 (0.179); PTH 0.285-0.438 (0.348); PTL 0.246-0.384 (0.319); PTW 0.275-0.471 (0.356); PPH 0.295-0.482 (0.377); PPL 0.226-0.334 (0.279); PPW 0.315-0.610 (0.437); OI 25-33 (29); CI 90-105 (96); SI 71-82 (77); DMI 55-81 (61); LMI 35-57 (43); PSLI 7-21 (16); PeNI 45-58 (51); LPeI 80-108 (92); DPeI 93-124 (112); PpNI 51-75 (63); LPpI 62-97 (74); DPpI 128-200 (157); PPI 106-132 (123).

\section{Distribution}

Known from South Africa and Namibia.

\section{Remarks}

The material examined matched mostly Bolton's description, but a number of differences were noted. Interestingly, the colour variation in this species is explained by geographical distribution. It looks like there are two forms, the Karoo form and the Kalahari sand form. The specimens collected in the Karoo region mainly in South Africa are brown to black. The specimens collected from red sand dunes (Northern Cape, i.e., Dreghorn and Cullinan Farm, and parts of southern Namibia) are reddish. There is also variation in sculpture pattern. In black coloured specimens, the mesosoma has a strong irregular sculpture on the pronotum and short longitudinal striations on the mesonotum with a punctulate sculpture in between. The nodes have a punctulate sculpture overlain by irregular striations. The first gastral tergite 

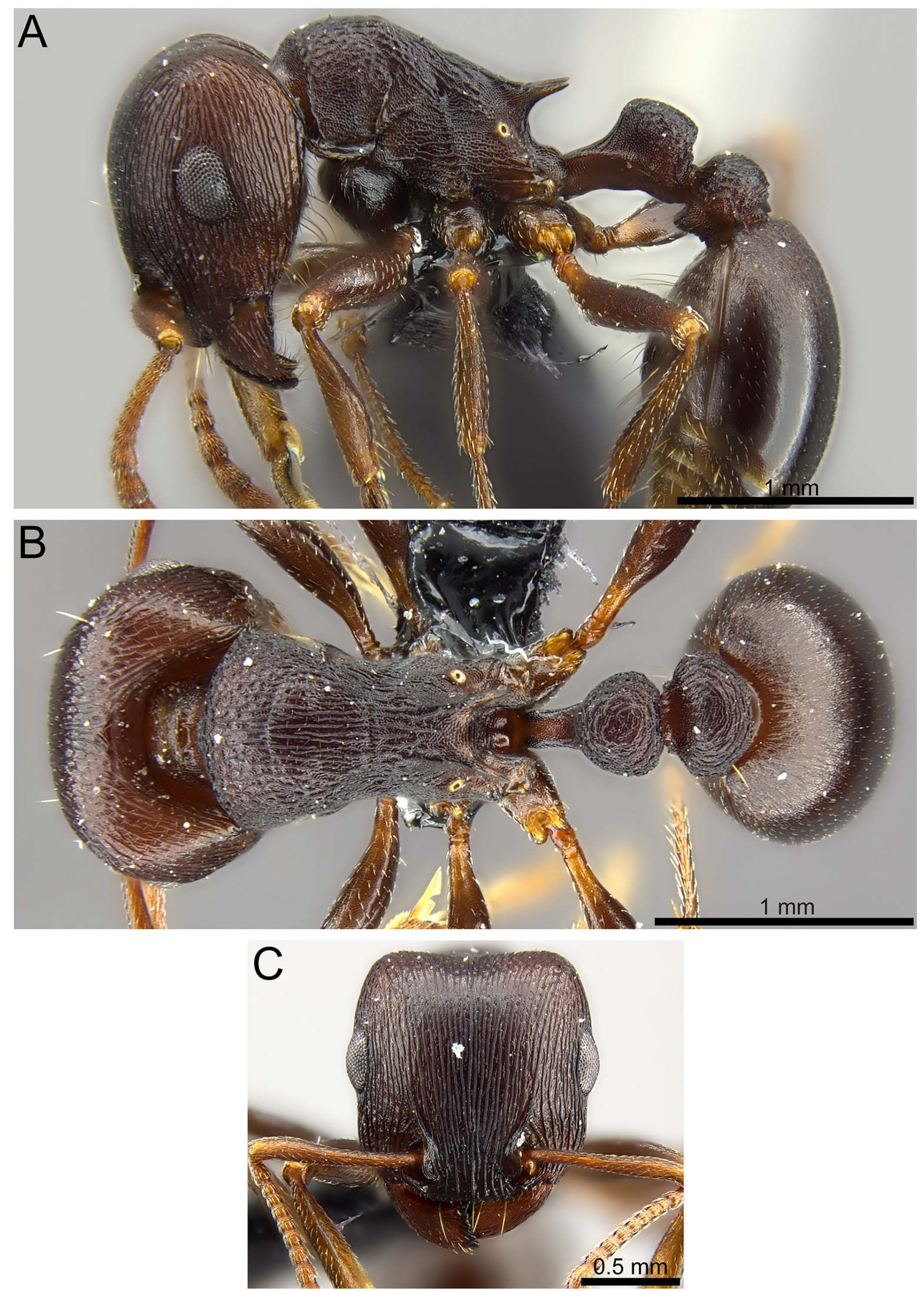

Fig. 22. Tetramorium signatum Emery, 1895 (SAM-HYM-C020573). A. Body in profile. B. Body in dorsal view. C. Head in full-face view. 
is punctulate or shagreened at the base. Most of the reddish specimens have a strong, irregular sculpture on the pronotum and short longitudinal striations on the mesonotum with a punctulate sculpture in between. In a few specimens, the nodes are predominantly smooth with only reticulate sculpture. The spine length varies in all forms from medium, which are broad at the base, to very short. Based on that high degree of morphological variation, there is a possibility that there is more than one species within both $T$. signatum and $T$. rufescens. Nevertheless, this can only be properly addressed within a molecular phylogenetic framework, which is outside the scope of this study. We are hopeful to resolve this question in a future study addressing the evolutionary and biogeographical history of this group. This species has been recorded from South Africa (Eastern Cape, Western Cape and Northern Cape) and Namibia. It has been recorded from the following ecoregions: Albany Thickets, Kalahari Xeric Savanna, Kaokoveld Desert, Knysna-Amatole Montane Forests, Montane Fynbos and Renosterveld, Nama Karoo (including Koedoesberge-Moordenaars Karoo), Namib Desert, Namibian Savanna Woodlands and Succulent Karoo. This species nests in sandy to loamy soils, entrances sometimes with crater of soil around them. Alates were collected from nests in December. Two nests were found with Thysanura inquilines. This species has been collected by digging up nests and also from pitfall traps, yellow pan traps, tuna baits, sugar baits and cookie baits.

Tetramorium solidum Emery, 1886

Figs 2I, 4K, 23-24

Tetramorium solidum Emery, 1886: 362 (included in Bolton 1980: 252).

\section{Diagnosis}

In the T. solidum-group, only $T$. solidum and $T$. aisha sp. nov. have sparse hairs that are restricted to the mesosoma and the petiole; other species in this group either have abundant hairs covering the whole body or lack erect hairs. Tetramorium solidum has very long and acute propodeal spines (PSLI 17-20) (Fig. 4K), whereas the propodeal spines in T. aisha sp. nov. are very short (PSLI 5-9) (Fig. 4L).

\section{Unexamined type material}

Syntypes

SOUTH AFRICA: pinned workers, Cape of Good Hope, L. Peringueyi leg. (MHNG: CASENT0904840; RMCA).

\section{Material examined}

\section{Other material}

SOUTH AFRICA (121 workers): Northern Cape: Tankwa Karoo National Park, $32.24758^{\circ}$ S, $20.09660^{\circ}$ E, 490 m a.s.1., 7 Jan. 2009, N. Mbanyana and H.G. Robertson leg. (SAM-HYM-C023312). - Western Cape: Anyskop Farm, $4 \mathrm{~km} 270^{\circ} \mathrm{W}$ of Langebaanweg, 32 $2^{\circ} 58.611^{\prime} \mathrm{S}, 18^{\circ} 06.976^{\prime} \mathrm{E}, 18-25$ Sep. 2002, yellow pan traps, Fynbos on limestone, S. van Noort leg. (SAM-HYM-C018836); West

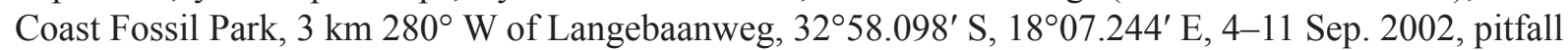
traps, rehabilitated mine dump, S. van Noort leg. (SAM-HYM-C018823); West Coast Fossil Park, $3 \mathrm{~km} 280^{\circ} \mathrm{W}$ of Langebaanweg, $32^{\circ} 58.020^{\prime} \mathrm{S}, 18^{\circ} 07.285^{\prime} \mathrm{E}, 4-11 \mathrm{Sep} .2002$, pitfall traps, rehabilitated mine dump (SAM-HYM-C018830); West Coast Fossil Park, $4 \mathrm{~km} 290^{\circ}$ E of Langebaanweg, $32^{\circ} 57.512^{\prime} \mathrm{S}$, $18^{\circ} 06.728^{\prime}$ E, 4-11 Sep. 2002, pitfall traps, rehabilitated mine dump, S. van Noort leg. (SAMHYM-C018824); Helshoogte Valley outside Stellenbosch, 335' S, $18^{\circ} 54^{\prime}$ E, 22-23 Mar. 1996, P.J. Pieterse leg. (SAM-HYM-C008817); Lorraine Farm, $32^{\circ} 04^{\prime} \mathrm{S}, 1^{\circ} 03^{\prime} \mathrm{E}$, five open nest entrances with crates of sand round them, 9 Sep. 1996 (SAM-HYM-C008986); Jacobsbaai, 3258' S, 1754' E, 16 Feb. 1966, A.J. Prins leg. (SAM-HYM-C007491); 6 mi. from Saldanha Bay to Jacobsbaai, Long 

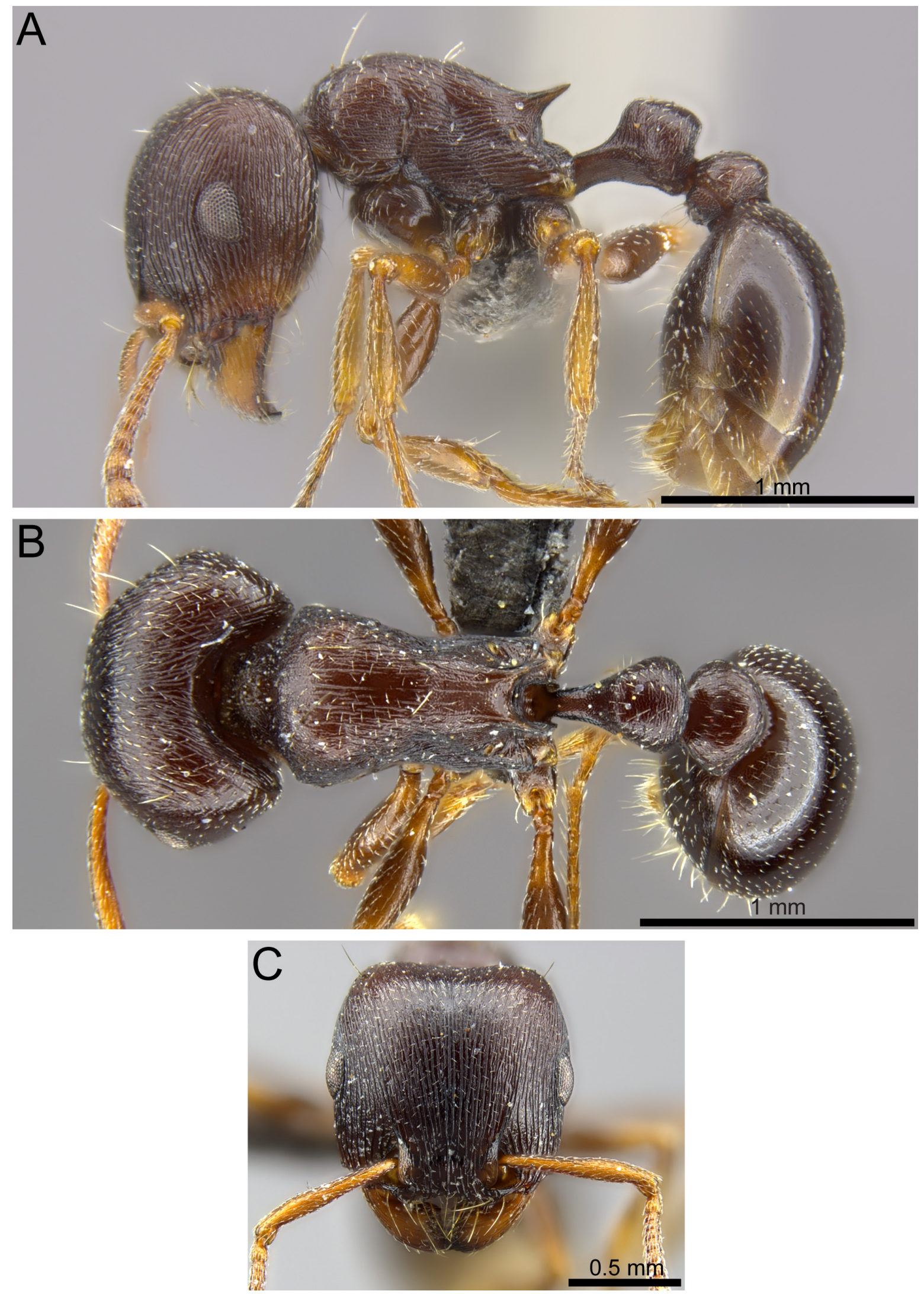

Fig. 23. Tetramorium solidum Emery, 1886 (CASENT0250960). A. Body in profile. B. Body in dorsal view. C. Head in full-face view. 
Point, 3259' S, 1753' E, 9 Jan. 1963, A.J. Prins leg. (SAM-HYM-C007496); Sevilla Rock Art Trail, $32.0797^{\circ} \mathrm{S}, 19.08828^{\circ}$ E, 329 m a.s.1., 10 Sep. 2009, P. Hawkes and J. Fisher leg. (SAM-HYM-C024393); jeep tract between Welbedacht and Sneeukop Hut Site 1, Cederberg Wilderness Area, Wupperthal, $32.45515^{\circ} \mathrm{S}, 19.235033^{\circ}$ E, $1187 \mathrm{~m}$ a.s.l., Fynbos pitfall trap, 5 Mar. 2003, A. Botes leg. (SAMHYM-C024975); Sneeukop, A. Andersen leg. (CASC: CASENT0248478); foragers, $5 \mathrm{~km} \mathrm{~S}$ of Lamberts Bay, $32.41603^{\circ} \mathrm{S}, 18.30696^{\circ} \mathrm{E}, 10 \mathrm{~m}$ a.s.l., West Coast Strandveld, on ground, 30 Sep. 2011, B.L. Fisher leg. (CASC: CASENT0264029, CASENT0264031); Clanwilliam, Sevilla Rock Art Trail, $32.07973^{\circ}$ S, 19.08828 E 329 m a.s.1., Cedarberg Sandstone Fynbos, hand collected, 8 Sep. 2009, P. Hawkes and J. Fisher leg. (CASC: CASENT0250960); Berg River, 4 mi. S of Piketberg, 150 m a.s.l., 30 Apr. 1958, E.S. Ross and R.E. Leech leg. (CASC: CASENT0217978, CASENT0270797 to CASENT0270799).

\section{Measurements (worker $\mathrm{N}=13$ )}

HL 0.905-1.076 (1.004); HW 0.905-1.151 (1.026); SL 0.669-0.831 (0.755); EL 0.207-0.275 (0.242); PH 0.452-0.580 (0.523); PW 0.575-0.698 (0.647); WL 0.964-1.153 (1.081); PSL 0.177-0.197 (0.188); PTH 0.295-0.374 (0.345); PTL 0.256-0.315 (0.290); PTW 0.305-0.396 (0.346); PPH 0.295-0.384 (0.363); PPL 0.246-0.325 (0.277); PPW 0.379-0.482 (0.432); OI 22-24 (24); CI 95-106 (102); SI 70-81 (74); DMI 56-61 (60); LMI 44-51 (48); PSLI 17-20 (19); PeNI 50-57 (53); LPeI 77-89 (84); DPeI 110-126 (119); PpNI 65-70 (67); LPpI 64-85 (76); DPpI 145-184 (157); PPI 119-134 (125).

\section{Distribution}

Only known from South Africa.

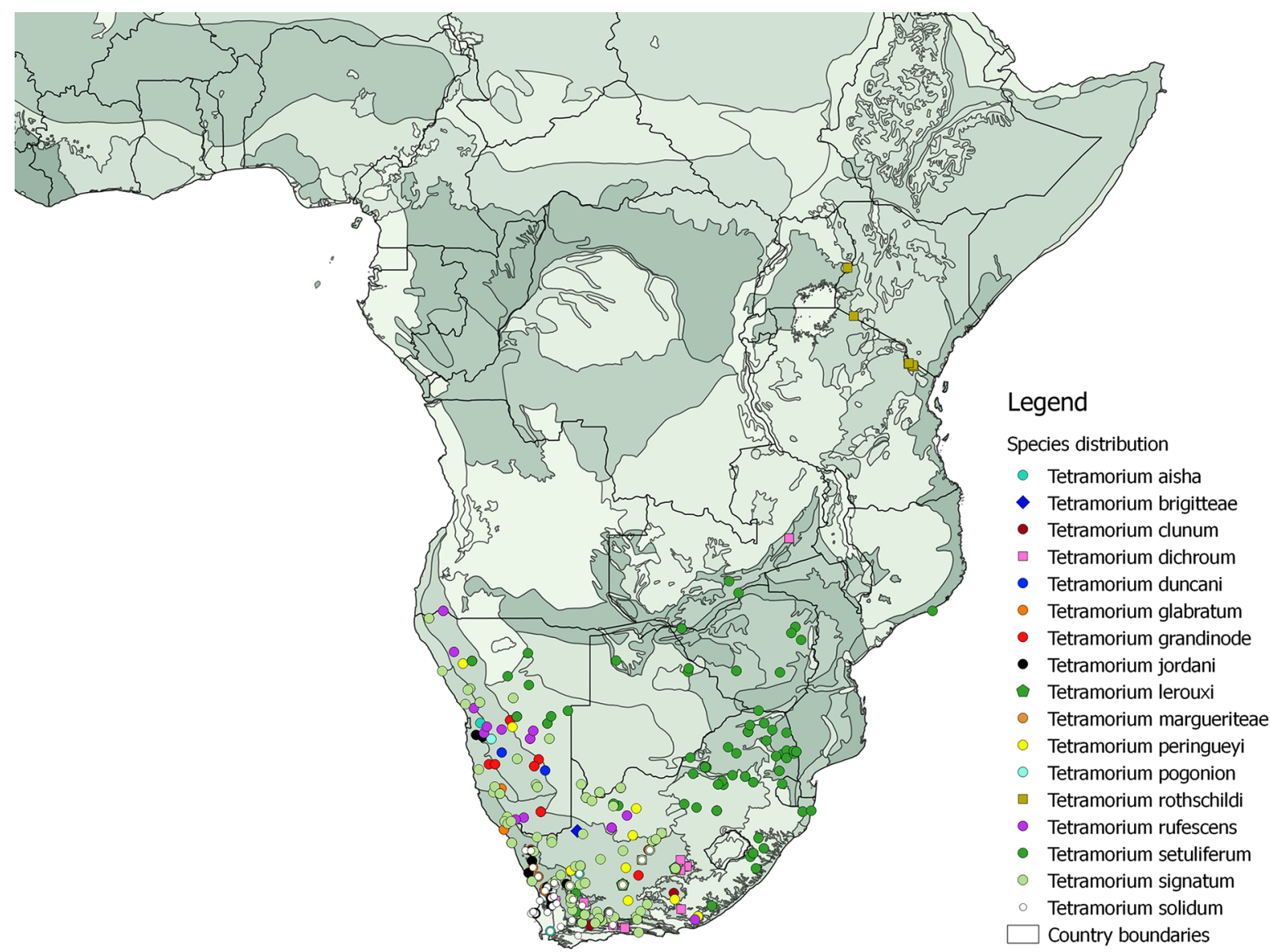

Fig. 24. Map showing the distribution of species in the Tetramorium solidum group. 


\section{Remarks}

Tetramorium solidum has been collected in Strandveld, Succulent Karoo, Fynbos and in transformed lands on tillite shales. This species has been recorded only in the Montane Fynbos and Renosterveld, Nama Karoo and Succulent Karoo; found nesting in clays soils, with craters of soil around nest entrances. Queens of this species were collected in April and males were collected in September from the nests. Seed stores have been found in nests. This species has been collected either by digging up nests or from pitfall traps and yellow pan traps.

\section{Discussion}

The highest diversity of species in the Tetramorium solidum group is concentrated in the Nama Karoo with 14 species recorded from this region (Figs 24-25). Nine species were recorded from the Succulent Karoo region, which is considered to be a major biodiversity hotspot (Myers et al. 2000). Members of T. solidum group appear to be arid-adapted and their distribution closely reflects current rainfall patterns in Africa. Most of the species in this group occur in the southwestern parts of the Afrotropical region (Fig. 25), where there is less rainfall, avoiding the moist grassland, savannah, woodland, and forest vegetation types in the east. The western region of southern Africa experiences an annual rainfall of about $100 \mathrm{~mm}$ to nearly $500 \mathrm{~mm}$ per annum (Venter et al. 1986). In addition, at least eight species were recorded from Kalahari Xeric Savanna and seven from the extreme dry regions of Namibia. Soil might

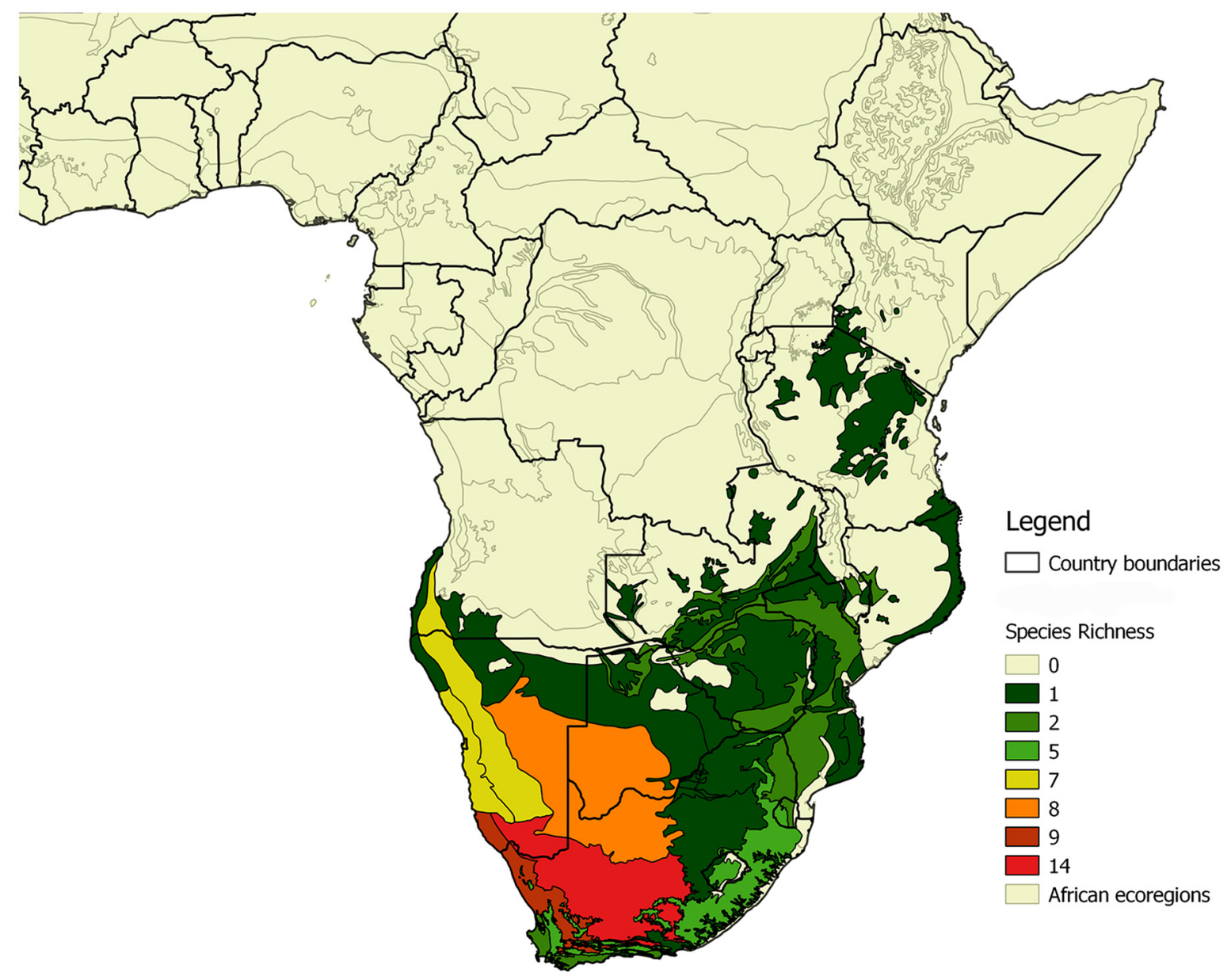

Fig. 25. Map showing the diversity of the T. solidum group across the different ecoregions of southern Africa. Numbers in the legend indicate number of species. 
also be influencing the distribution of these species. Tetramorium jordani is restricted to loose sandy areas and $T$. solidum extends more into the clay soils. Tetramorium rothschildi is the only species in the T. solidum group with branched hairs and the only species that has an equatorial distribution. We are not convinced that $T$. rothschildi is a genuine member of the group and hope that a currently ongoing molecular phylogenetic analysis will resolve the true relationship of $T$. rothschildi.

Defining species in the T. solidum group based on morphology alone is very challenging due to the intraspecific variation in most species. High levels of intraspecific variation in T. signatum and T. rufescens may indicate the presence of several cryptic species. The issue of cryptic species is prevalent in many taxa (e.g., Bickford et al. 2007; Molino et al. 2011; Crespo \& Lumbsch 2010) including ants (Seifert 2009; Schlick-Steiner et al. 2006).

\section{Acknowledgements}

We are grateful to Dr Brigitte Braschler (DST-NRF Centre of Excellence for Invasion Biology (CIB)), Peter Hawkes (AfriBug), Dr Brian Fisher (California Academy of Sciences) and Suzanne Ryder (Natural History Museum) for the loan of specimens, Tracy Audisio from the Okinawa Institute of Science and Technology for creating the line drawings used in this study, and Albe Bosman from the Iziko Museums of South Africa for assisting with the species distribution maps. We would also like to thank the National Research Foundation (GUN 61499, GUN 79969) and the Iziko Museums of South Africa for funding this project. Jaco Le Roux acknowledges funding received from Stellenbosch University's Subcommittee B and the Centre for Invasion Biology at Stellenbosch University.

\section{References}

Arnold G. 1917. A monograph of the Formicidae of South Africa. Part III. Myrmicinae. Annals of the South African Museum 14: 271-402. https://biodiversitylibrary.org/page/39035954

Arnold G. 1926. A monograph of the Formicidae of South Africa. Appendix. Annals of the South African Museum 23: 191-295. https://biodiversitylibrary.org/page/42375467

Bickford D., Lohman D.J., Sodhi N.S., Ng P.K.L., Meier R., Winker K., Ingram K.K. \& Das I. 2007. Cryptic species as a window on diversity and conservation. TRENDS in Ecology and Evolution 22 (3): 148-155. https://doi.org/10.1016/j.tree.2006.11.004

Bolton B. 1976. The ant tribe Tetramoriini (Hymenoptera: Formicidae). Constituent genera, review of smaller genera and revision of Triglyphothrix Forel. Bulletin of the British Museum (Natural History) Entomology 34: 281-379. https://doi.org/10.5281/zenodo.26843

Bolton B. 1980. The ant tribe Tetramoriini (Hymenoptera: Formicidae). The genus Tetramorium Mayr in the Ethiopian zoogeographical region. Bulletin of the British Museum (Natural History) Entomology 40: 193-384. https://doi.org/10.5281/zenodo.26845

Bolton B. 1985. The ant genus Triglyphothrix Forel a synonym of Tetramorium Mayr. (Hymenoptera: Formicidae). Journal of Natural History 19: 243-248.

Bolton B. 2017. An Online Catalogue of the Ants of the World. Available from http://www.antcat.org [accessed 17 Apr. 2017].

Crespo A. \& Lumbsch H.T. 2010. Cryptic species in lichen-forming fungi. IMA Fungus 1 (2): 167-170. http://dx.doi.org/10.5598/imafungus.2010.01.02.09

Emery C. 1886. Alcune formiche africane. Bollettino della Societa Entomologica Italiana 18: 355-366. https://doi.org/10.5281/zenodo.25418 
Emery C. 1895. Voyage de M.E. Simon dans l'Afrique australe (janvier-avril 1893). 3e mémoire. Formicides. Annales de la Société entomologique de France 64: 15-56.

Forel A. 1894. Abessinische und andere afrikanische Ameisen, gesammelt von Herrn Ingenieur Alfred Ilg, von Herrn Dr Liengme, von Herrn Pfarrer Missionar P. Berthoud, Herrn Dr Arth. Müller, etc. Mitteilungen der schweizerischen entomologischen Gesellschaft 9: 64-100.

Forel A. 1907. Fourmis d'Ethiopie récoltées par M. le baron Maurice de Rothschild en 1905. Revue d'Entomologie (Caen) 26: 129-144.

Forel A. 1910. Note sur quelques fourmis d'Afrique. Annales de la Société entomologique de Belgique 54: 421-458.

Forel A. 1913. Ameisen aus Rhodesia, Kapland usw. (Hym.) gesammelt von Herrn G. Arnold, Dr. H. Brauns und Anderen. Deutsche entomologische Zeitschrift 1913 (Suppl.): 203-225.

Forel A. 1914. Formicides d'Afrique et d'Amérique nouveaux ou peu connus. Bulletin de la Société Vaudoise des Sciences naturelles 50: 211-288.

Hita Garcia F. \& Fisher B.L. 2013. The Tetramorium tortuosum species group (Hymenoptera, Formicidae, Myrmicinae) revisited - taxonomic revision of the Afrotropical T. capillosum species complex. Zookeys 299: 77-99. https://doi.org/10.3897/zookeys.299.5063

Hita Garcia F. \& Fisher B.L. 2015. Taxonomy of the hyper-diverse ant genus Tetramorium Mayr in the Malagasy region (Hymenoptera, Formicidae, Myrmicinae) - first record of the T. setigerum species group and additions to the Malagasy species groups with an updated illustrated identification key. ZooKeys 512: 121-153. https://doi.org/10.3897/zookeys.512.9860

Hita Garcia F., Fischer G., Kück P., Thormann B. \& Peters M.K. 2010a. Tetramorium boehmei sp. n. - a new ant (Hymenoptera: Formicidae) species from the Kakamega Forest, Western Kenya. Bonn Zoological Bulletin 57: 359-366.

Hita Garcia F., Fischer G. \& Peters M.K. 2010b. Taxonomy of the Tetramorium weitzeckeri species group (Hymenoptera: Formicidae) in the Afrotropical zoogeographical region. Zootaxa 2704:1-90.

Hita Garcia F., Fischer G. \& Peters M.K. 2010c. Tetramorium snellingi sp.n. - a new leaf-litter ant species (Hymenoptera: Formicidae) from a Western Kenyan rainforest. Myrmecological News 13: 141-146.

Molina M.C., Del-Prado R., Divakar P.K., Sánchez-Mata D. \& Crespo A. 2011. Another example of cryptic diversity in lichen-forming fungi: the new species Parmelia mayi (Ascomycota: Parmeliaceae). Organisms Diversity \& Evolution 11 (5): 331-342. https://doi.org/10.1007/s13127-011-0060-4

Mucina L. \& Rutherford M.C. (eds) 2006. The Vegetation of South African, Lesotho and Swaziland. Strelitzia 19. South African National Biodiversity Institute, Pretoria.

Myers N., Mittemeier R.A., Mittemeier C.G., da Fonseca G.A.B. \& Kent J. 2000. Biodiversity hotspots for conservation priorities. Nature 403: 853-858. https://doi.org/10.1038/35002501

Netshilaphala N.M., Milton S.J. \& Robertson H.G. 2005. Response of an ant assemblage to mining on the arid Namaqualand coast, South Africa. African Entomology 13: 162-167.

Parr C.L., Bond W.J. \& Robertson H.G. 2002. A preliminary study of the effect of fire on ants (Formicidae) in a South African savanna. African Entomology 10: 101-111.

Prins A.J. 1973. African Formicidae (Hymenoptera) in the South African Museum. Description of four new species and notes on Tetramorium Mayr. Annals of the South African Museum 62: 1-40.

Robertson H.G. 2000. Afrotropical ants (Hymenoptera: Formicidae): taxonomic progress and estimation of species richness. Journal of Hymenoptera Research 9: 71-84. 
Santschi F. 1910. Formicides nouveaux ou peu connus du Congo français. Annales de la Société entomologique de France 78: 349-400.

Santschi F. 1913. Glanures de fourmis africaines. Annales de la Société entomologique de Belgique 57: $302-314$.

Santschi F. 1932. Formicides sud-africains. Livre du Centenaire: 381-392. Société entomologique de France, R. Jeannel, Paris. https://doi.org/10.5281/zenodo.14208

Santschi F. 1937. Glanure de fourmis éthiopiennes. Bulletin et Annales de la Société entomologique de Belgique 77: 47-66.

Schlick-Steiner B.C., Steiner F.M., Moder K., Seifert B., Sanetra M., Dyreson E., Stauffer C. \& Christian E. 2006. A multidisciplinary approach reveals cryptic diversity in Western Palearctic Tetramorium ants (Hymenoptera: Formicidae). Molecular Phylogenetics and Evolution 40: 259-273. https://doi.org/10.1016/j.ympev.2006.03.005

Seifert B. 2009. Cryptic species in ants (Hymenoptera: Formicidae) revisited: we need a change in the alpha-taxonomic approach. Myrmecological News 12: 149-166.

Stitz H. 1923. Hymenoptera, VII. Formicidae. Beiträge zur Kenntnis der Land-und Süsswasserfauna Deutsch-Südwestafrikas 2: 143-167.

Venter J.M., Mocke C. \& de Jager J.M. 1986. Climate. In: Cowling R.M., Roux P.W. \& Pieterse A.J.H. (eds) The Karoo Biome: a Preliminary Synthesis. Part 1. Physical Environment: 39-52. South African National Scientific Programmes Report 124. National Research Foundation, Pretoria, South Africa.

Wheeler W.M. 1922. Ants of the American Museum Congo expedition. Bulletin of the American Museum of Natural History 45: 711-1004.

Manuscript received: 7 February 2017

Manuscript accepted: 7 August 2017

Published on: 7 August 2018

Topic editors: Gavin Broad, Rudy Jocqué

Section editor: Kurt Jordaens

Desk editor: Danny Eibye-Jacobsen, Jeroen Venderickx

Printed versions of all papers are also deposited in the libraries of the institutes that are members of the EJT consortium: Muséum national d'Histoire naturelle, Paris, France; Botanic Garden Meise, Belgium; Royal Museum for Central Africa, Tervuren, Belgium; Natural History Museum, London, United Kingdom; Royal Belgian Institute of Natural Sciences, Brussels, Belgium; Natural History Museum of Denmark, Copenhagen, Denmark; Naturalis Biodiversity Center, Leiden, the Netherlands; Museo Nacional de Ciencias Naturales-CSIC, Madrid, Spain; Real Jardín Botánico de Madrid CSIC, Spain; Zoological Research Museum Alexander Koenig, Bonn, Germany. 